\title{
Digitally Connected: Global Perspectives on Youth and Digital Media
}

\section{Citation}

Urs Gasser \& Sandra Cortesi, eds., Digitally Connected: Global Perspectives on Youth and Digital Media, (Berkman Center Research Publication No. 2015-6, Mar. 26, 2015).

\section{Permanent link}

http://nrs.harvard.edu/urn-3:HUL.InstRepos:16145970

\section{Terms of Use}

This article was downloaded from Harvard University's DASH repository, and is made available under the terms and conditions applicable to Open Access Policy Articles, as set forth at http:// nrs.harvard.edu/urn-3:HUL.InstRepos:dash.current.terms-of-use\#OAP

\section{Share Your Story}

The Harvard community has made this article openly available.

Please share how this access benefits you. Submit a story.

\section{Accessibility}


Research Publication No. 2015-6

April 1, 2015

Digitally Connected:

Global Perspectives on Youth and Digital Media

Lead editors:

Sandra Cortesi

Urs Gasser

With essays by:

Gameli Adzaho

Bruce Baikie

Jacqueline Baljeu

Matthew Battles

Jacqueline Beauchere

Heather Booth

Elsa Brown

Jane Burns

Patrick Burton

Jasmina Byrne

Maximillion Colombo

Joe Douillette

Jorge Flores Fernandez

Zinelabidine Ghebouli

Juan Cruz Gonzalez-Allonca

Eric Gordon
Sarah Groustra

Max Hertz

Rey Junco

Yasir Khan

Nicholas Kimeu

Dorothea Kleine

Djordje Krivokapic

Viola Kup

Elif Kuzeci

María Paula Latorre Guzmán

David Li

Minu Limbu

Sonia Livingstone

Andres Lombana-Bermudez

Cynthia Massiel

Claire McCarthy
Maletsabisa Molapo

Maria Liliana Mor

Sarah Newman

Eldad Nutakor

Christopher Onoka

Chido Onumah

Ezequiel Passeron

Katarzyna Pawelczyk

Ricarose Roque

Kanyankore Marcel Rudasingwa

Nishant Shah

Luca Simeone

Andrew Siwakwi

Amanda Third

Camila Urbina Escobar

Grace Wang

The Social Science Research Network Electronic Paper Collection:

Available at SSRN: http://ssrn.com/abstract=2585686

\footnotetext{
23 Everett Street - Second Floor - Cambridge, Massachusetts 02138

$+1617.495 .7547 \cdot+1617.495 .7641$ (fax) • http://cyber.law.harvard.edu •

cyber@1aw.harvard.edu
} 


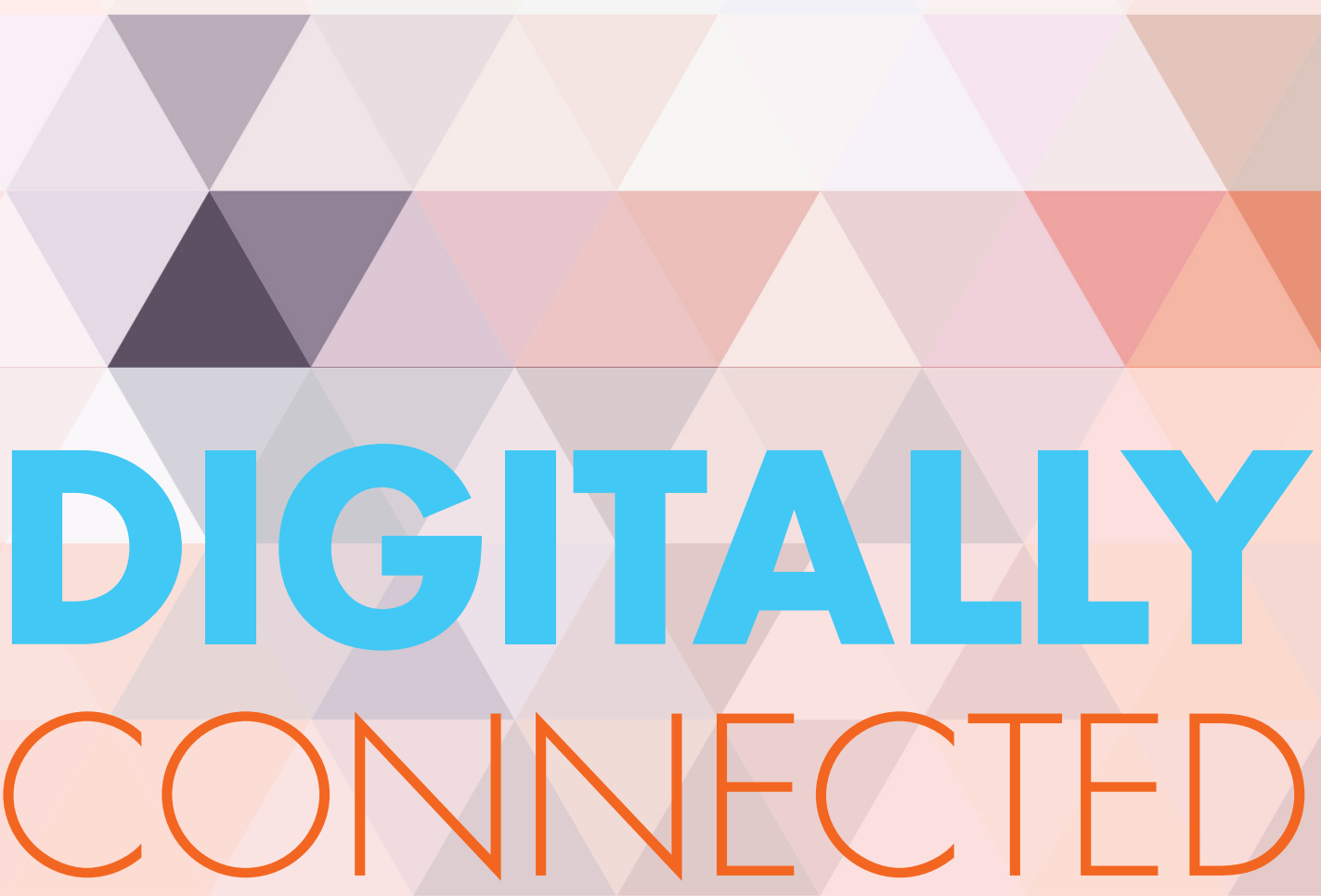

\section{Global Perspectives on Youth and Digital Media}

Lead editors: Sandra Cortesi \& Urs Gasser

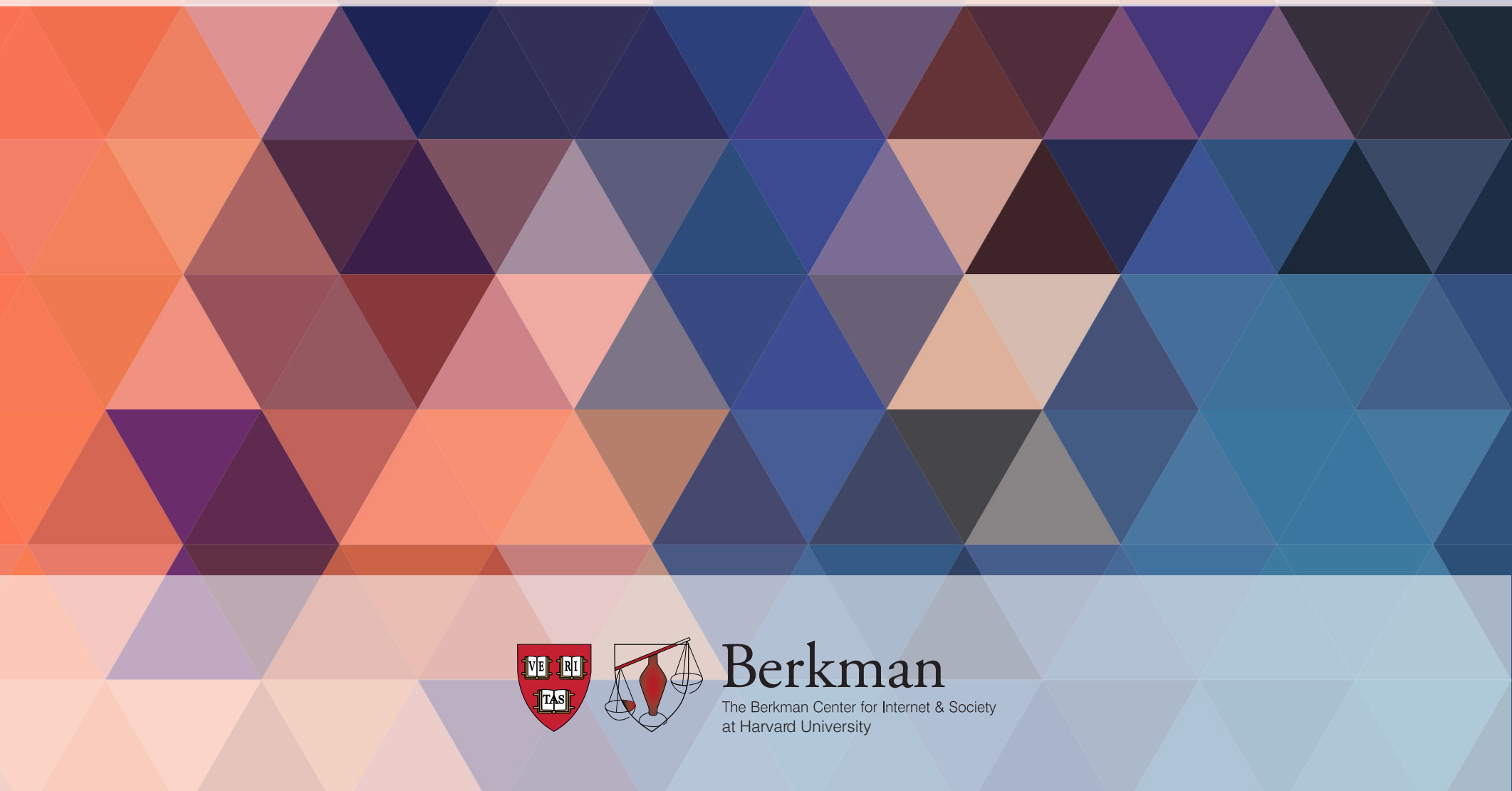




\section{COLLABORATORS}

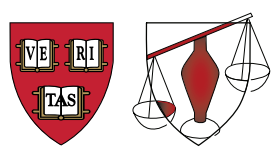

Berkman

The Berkman Center for Internet \& Society

at Harvard University

Since its founding in 1997, the Berkman Center has been at the forefront of the field of Internet and Society, pursuing a unique mix of interdisciplinary scholarship and engagement with legal and policy issues. We are home to a diverse group of scholars, policy experts, and advocates focused on the identification of emerging problems related to digitally-networked society and the search for solutions. We are committed to tackling the most important challenges of the digital age, to think big, to act with ambition and humility, to maintain academic rigor while keeping a focus on tangible real-world impact, and to serve the public interest. At its foundation, the Berkman Center informs and engages in the public interest through four core activities: conducting research, building tools and platforms, education, and creating and cultivating networks. \{cyber.law.harvard.edu\}

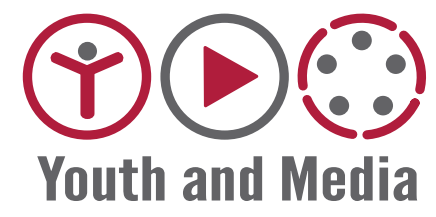

Youth and Media encompasses an array of research, advocacy, and development initiatives around youth and digital technology. Located at the Berkman Center for Internet \& Society, Youth and Media draws on the knowledge of and experience with various interdisciplinary backgrounds, including psychology, ethnography, sociology, education, media theory, and the law. Through these combined approaches, Youth and Media centers the voices and experiences of youth to research and cultivate the creative, educational, and revolutionary possibilities of youth activity in digital space while addressing the genuine concerns that come with living life online. \{youthandmedia.org\}

\section{DIGITALLY CONNECTED}

Digitally Connected is a collaborative initiative between UNICEF and the Berkman Center building upon a multi-year partnership for analysing digital and social media growth and trends among children and youth globally. Digitally Connected is a network consisting of academics, practitioners, young people, activists, philanthropists, government officials, and representatives of technology companies from around the world. Together, they are addressing the challenges and opportunities children and youth encounter in the digital environment. \{digitallyconnected.org\}

\section{unicef}

UNICEF promotes the rights and wellbeing of every child, in everything we do. Together with our partners, we work in 190 countries and territories to translate that commitment into practical action, focusing special effort on reaching the most vulnerable and excluded children, to the benefit of all children, everywhere. \{unicef.org\}

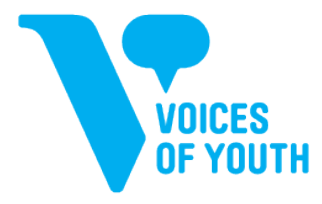

Voices of Youth is UNICEF's global digital engagement portal for children and young people. Recognizing and building on the opportunities for advancing children's rights in a digital era, Voices of Youth is a space where the voices of children and young people on issues that matter to them can be heard, and where learning, sharing, inspiration and cross-cultural exchange is actively encouraged. \{voicesofyouth.org\} 


\section{ABOUT THIS BOOK}

Reflecting on the 25th anniversaries of the invention of the World Wide Web by Sir Tim Berners-Lee and the adoption of the Convention on Rights of the Child by the US General Assembly, the Berkman Center for Internet \& Society at Harvard University and UNICEF co-hosted in April 2014 - in collaboration with PEW Internet, EU Kids Online, the Internet Society (ISOC), Family Online Safety Institute (FOSI), and YouthPolicy.org - a first of its kind international symposium on children, youth, and digital media to map and explore the global state of relevant research and practice, share and discuss insights and ideas from the developing and industrialized world, and encourage collaboration between participants across regions and continents.

With a particular focus on voices and issues from the Global South, the symposium addressed topics such as inequitable access, risks to safety and privacy, skills and digital literacy, spaces for participation, and civic engagement and innovation. The event also marked the launch of Digitally Connected - an initiative that brings together academics, practitioners, young people, activists, philanthropists, government officials, and representatives of technology companies from around the world who, together, are addressing the challenges and opportunities children and youth encounter in the digital environment. More information about the network (as well as the launch symposium) is available at http://www. digitallyconnected.org/about/.

This book is one contribution by this growing, global network of collaborators and consists of two parts. The first part brings together a series of reflection pieces in the form of short essays written by friends and colleagues who attended the Digitally Connected symposium at Harvard University. The second part consists of a collection of stories, art, and digital media by youth about their experiences online. These creative pieces were submitted through an open call, which consisted of 10 prompts youth could reflect upon. The call can be found here: http://www.digitallyconnected.org/youth-art/.

The contributions in this book reflect the diversity of ideas and perspectives that form the core and spirit of Digitally Connected. Some of the reflection pieces are closely connected to issues discussed at the symposium, others reflect more generally on personal observations and/or opinions, or highlight and discuss insights and learnings from specific studies or concrete projects. By making these reflection pieces and the youth work available to the expanding Digitally Connected network as well as the public at large, we hope to continue and further stimulate the global conversation about both the challenges and opportunities children and youth encounter in the digital environment. We hope you will join us in this conversation and collaborate with us to build a better world for - and together with - our children and young people. 


\section{ACKNOWLEDGEMENTS}

This book is the result of a sustained and concerted effort of an extraordinary network of people from around the globe. First and foremost, we wish to thank our collaborators at UNICEF, in particular Gerrit Beger, Jasmina Byrne, and Kate Pawelczyk. Further, we wish to express our deep gratitude to all authors and contributors, who graciously shared their time and expertise and made this project possible.

Special thanks are also due to Amar Ashar and the Berkman core team for ongoing support of Digitally Connected, Dana Walters for spearheading the collection of all contributions as well as the editing process, and to Elsa Brown for her amazing drawings. Thanks also to the Youth and Media Summer Interns 2014 - especially Gabriela Dumancela and Varoun Gulati - as well as all other Youth and Media team members, who have supported the evolution and production of this book and provided research and editorial support. We are also grateful to Emtype for the wonderful design of this book.

Finally, we would like to acknowledge a generous, unrestricted gift from Google, which has made this publication possible.

Urs Gasser \& Sandra Cortesi

On behalf of Digitally Connected
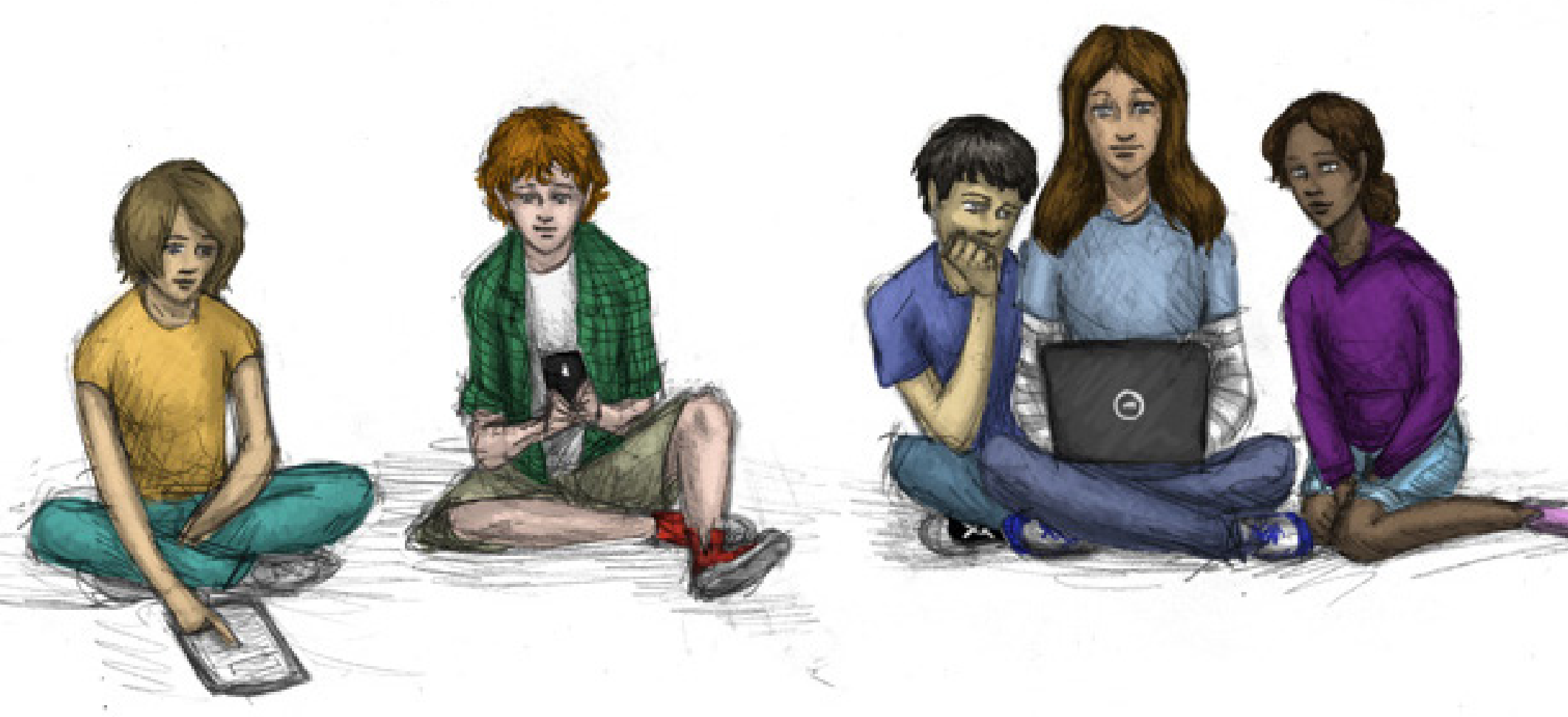


\section{A LOOK AT THE BROADER DISCUSSION}

Networked Margins: Revisiting Inequality

and Intersection

Nishant Shah

Ownership: The Key for ICT Accessibility and

Inclusion for Vulnerable Communities

Maria Liliana Mor

Libraries Driving Access to Information and Digital Literacy for Children and Youth: Going 'Beyond Access' to Promote Ownership and Agency of ICT Tools for Development

Camila Urbina

Why a Nuanced Approach to Social and

Digital Media Use by Children and Young People is Important - Learnings from Kenya Kate Pawelczyk

\section{SAFETY AND WELLBEING}

Sexting: Teens, Sex, Smartphones and the

Rise of Sextortion and Gender Based

Digital Violence

Jorge Flores Fernández

Challenges of Parental Responsibility in

a Global Perspective

Sonia Livingstone \& Jasmina Byrne

Safety Experts Call for Research on True Harms

30

of 'the Darker Web'

Jacqueline Beauchere

Health and the Digital Space

Claire McCarthy
IDENTITY, PRIVACY, AND REPUTATION

Who Should Take Care of Identity, Privacy and 35 Reputation?

Djordje Krivokapi

1:1 Education, Children, and (Lack of) Privacy: 40 The Story of the Fatih Project in Turkey

Elif Kuzeci

\section{SKILLS, LITERACIES, AND CULTURES OF LEARNING}

What Are Digital Literacies and

Why Do They Matter?

Rey Junco

On the Digital Path: New Experiences,

Challenges, and Opportunities to Learn

and Practice

Gameli Adzaho

Building a Global Alliance for

Partnerships on Youth and Digital Literacy

Chido Onumah

Local Games, Local Content, Local

Applications - On Mobile: ICTs for Informal Learning in Rural Africa

Maletsabisa Molapo

\section{CREATIVITY}

Connecting Creativity and Coding:

Creativity in the Context of Skills, Literacy, and Learning

Ricarose Roque

Mapping Danger, Making Connections

Matthew Battles, Sarah Newman,

\& Luca Simeone

New Media, Sharing and the Potential

Joe Dovillette 


\section{INNOVATION AND \\ ENTREPRENEURSHIP}

Small Big Things. The Challenges of Being

Creative in a Slum

Viola Kup \& Nicholas Kimeu

Software, Hardware, and Farming:

A Personal Journey with Open Innovation

David Li

Innovation and Entrepreneurship

Minu Limbu \&

Kanyankore Marcel Rudasingwa

5 Ways to Help ICT Projects Succeed for Youth

Bruce Baikie

\section{PARTICIPATION AND CIVIC ENGAGEMENT}

Participation and Engagement:

Defining Programs and Values

Eric Gordon

Re-Thinking Youth Participation and Civic Engagement in the Digital Age

Andres Lombana-Bermudez

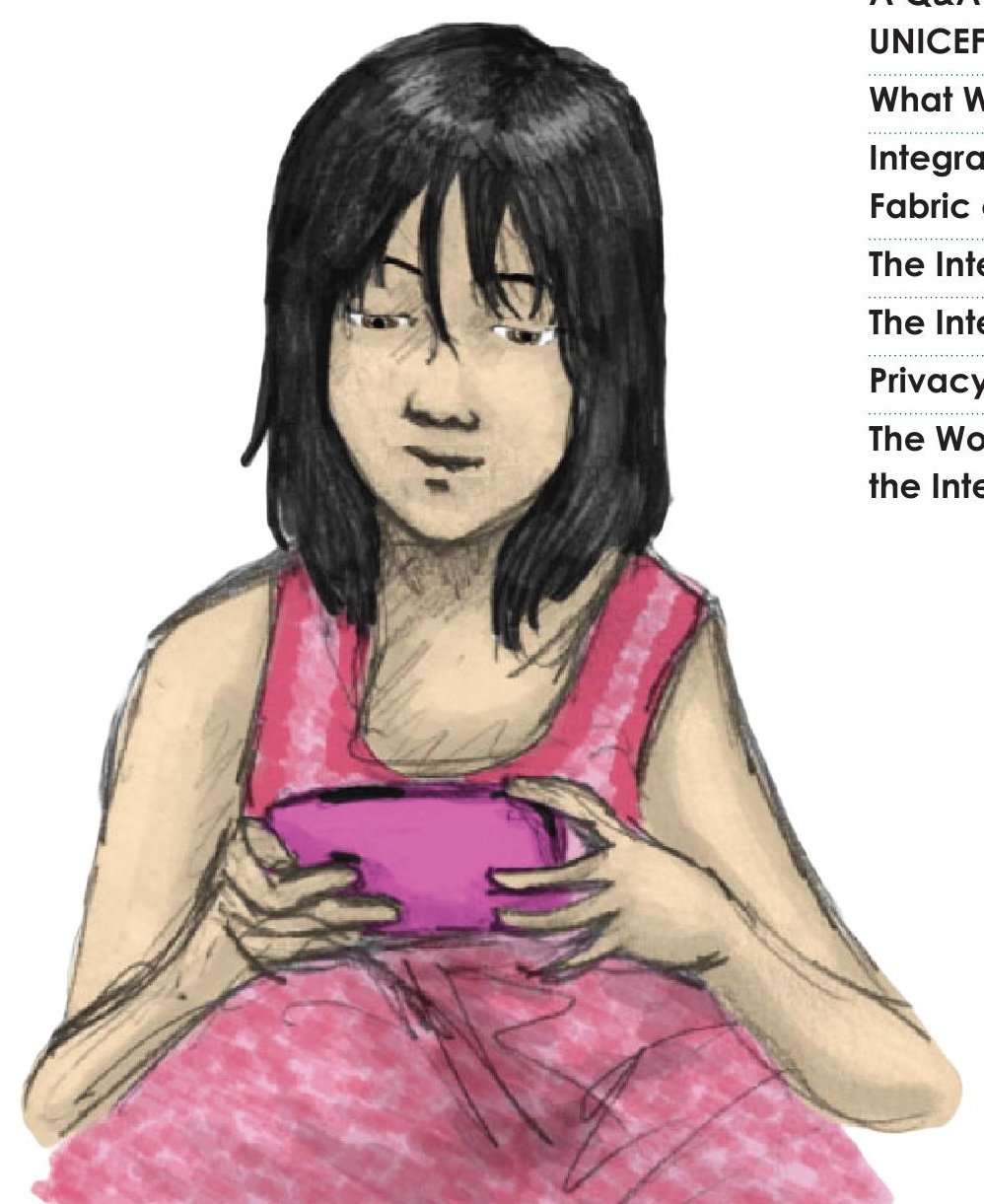

\section{YOUTH PARTICIPATION AND POLICY}

Children, ICT and Development: Innovation

for Equity on the Basis of Participatory Practice

Dorothea Kleine

Risky Business? Emerging Policy and Young

People's Agency in Online Safety: From

Risk to Harm in the South African Context

Patrick Burton

Research and Generation of Public Policies:

100

Future Challenges

Juan Cruz Gonzalez Allonca

E-Inclusion Is Social Inclusion

Ezequiel Passeron

It's a Youth Quake! Mobilising Youth

Participation for Research, Policy and Practice

Jane Burns \& Amanda Third

Youth and Digital Media Research

Policy-Making Interface: Mapping Key

Design Challenges

Urs Gasser

\section{YOUTH SUBMISSIONS}

A Q\&A With the Members of the

NICEF Board (Netherlands)

ntegrating the Internet into the

abric of our World 
CHAPTER 1

A Look at the Broader Discussion 


\title{
Networked Margins: Revisiting Inequality and Intersection
}

\author{
Nishant Shah \\ The Centre for Internet \& Society, Bangalore \\ The Centre for Digital Cultures, Leuphana University, Lueneburg
}

The network has become a de-facto explanatory framework of our times. We are able to think of networks as both historically informed and forming the future. Different movements, flows, conjunctions, and intersections of history, from Colonial ventures to navigation adventures, from the spread of contagion to the virality of knowledge, are all now imagined, mapped, visualized, and understood through the network paradigm. The network is all encompassing and constantly moving, always shifting, plug-play-and-assimilate aesthetic, the network is also seen as a natural way of thinking about the world.

As the computational network becomes the predominant architecture through which we understand the world of models, visuals, traffics, flows, and connectors, it slowly changes and questions the ways in which other forms of understanding social relations and transactions are perceived. This is perhaps most visible in the ways in which networks define margins. One of the ways in which the digital network is designed, understood, deployed, and analysed is through the idea of an "edge." An edge, as network theorist Duncan Watts (1997) points out, is a line through which traffic moves from one node to another within a network. The edge, then, is not an outer limit, but a route that marks the transfer of data from one point to another. Moreover, the nodes are also not predefined permanent points but rather points in a network that gain intensity (and hence value and valence) because of the frequency with which data travels and intersects at that particular point. This quantum nature of a probability based network captures the essence of the Internet. The Internet is a potentially infinite network, not only because it has the capacity to constantly interact with other networks and assimilate them in its weblike structure, but because it is being constantly brought into being by the development of edges. This notion of the edge, not as a point of containment, but as a porous, in-the-making, shifting, and tenuous border gives us a new way of thinking about the margins. Margins, in our social sciences and humanities research and practice have been spaces of intrigue. In the history of the text, where authority often resides, margins are spaces for scholia - the unauthorised world of the text - that contests, questions and re-interprets the texts in different ways. In our politics around identity and community rights, the margins are often the locations that critique the center by offering alternative visions. For development interventions aimed at establishing equal access to resources, margins are the focus of attention and considered spaces which need to be rehabilitated into larger social patterns.

The "networked margin" is the blending together of the edge and the margin that shifts and recognizes that as we identify certain processes, communities, and people as nodes in our networks, we create new forms of exclusion and discrimination which need to be accounted for. The networked margin, formed through repetition of network traffics and human habits, offers a new intersection that maps different vectors of social and economic flow, political journeys, and cultural practices. These vectors can help critically reflect on the questions of inequality and intersection that are often flattened in the debates around "Technologies for Change." I offer the networked margin as a way of mapping and analyzing the different and ever-shifting zones of inequality, rather than locating it in geographical binaries like "developed vs. developing world" or the "Global North and the Global South." There are three challenges that shape continuum of negotiation and struggle that need to inform our policy, politics, and practice at the intersections of Internet and society: 


\section{The Predatory Nature of Unevenness}

Let me begin by talking about a visual map that has gone viral. It is a graphic that compares 12 different countries in the world to see the length of maternity leave provided to working women in those countries. It is a political statement that shows that there is a lot of unevenness in the conditions of work and living for women in some of the most affluent countries in the world. It is a map designed to pass a strong political commentary on the fact that the United States, as one of the most affluent countries in the world, provides almost no maternity leave to its female workforce. The map makes its point rather eloquently and is a great example of how open data analytics can help produce points of comparison and global discourse around social and political processes that we might otherwise have taken for granted.

Once the euphoria of this political critique has subsided, however, you realize that the points of comparison for the US are countries that are presumed to be similar to the US. The map claims that it is a survey of 'industrial countries' but what it is essentially suggesting is that there is a particular kind of Global North that falls in a similar class and consequently can offer points of comparison. These comparisons also suggests that outside of the small elite clique of countries, we don't really need to look at questions of human and women's rights in other countries. It repeats an idea that there is one part of the world that is a savior and the other that needs to be saved. Or that there is wealth in one part of the world and poverty in the other. The binary persists in different articulations like Global North versus Global South, First World versus Third World, Developed World versus Under-Developed World, and so on. This kind of essentialism is rampant when it comes to talking about ICTs and inequalities, without looking at granularity of reality and the sketchiness of everyday practice.

Arjun Appadurai (1996), the political scientist and theorist of media and modernity, suggests that we need to think of modernity as a predatory creature. It preys, unevenly, and thus creates patterns of incoherence that defy political strategies and tactics. The networked margin is a realization that it is not only the centers that network. The margins of things that are excluded, of people who are discriminated against, of communities that are left out, can form a powerful network. It is a network of things that are left out of mainstream networks, but it is a network nonetheless. I am suggesting that we need to think of different axes of unevenness rather than geographical divisions that divide the world in such unmessy zones.

\section{Willing Suspension of Knowing}

Gwyneth Paltrow, who is a strong candidate in becoming the reigning monarch of the social web, recently made news with her declaration of "conscious uncoupling." I want to counter her with the idea of "internal unknowing." There is a presumption that we, within India for instance, know what is happening in the country. It is true that, from visceral, lived, quotidian experiences, we might sometimes have hunches, ideas, and theories that might have a different grounding that is not just academic or theoretical in nature. However, the need to open our ICT policy knowledge to the dynamics of the social, political, and cultural is important. Let me draw from a story that binds together unevenness and internal unknowing. A bunch of graduate students went to a small rural village in Gujarat called Banni. Banni is small and it is one of the last villages on the India-Pakistan borders. It is far away from most city centers and the closest hospital is about 200 kilometers away.

It remains in a strange limbo where it is simultaneously hugely surveyed and controlled, yet curiously secluded and self-contained. When they went there they were astonished not only at the proliferation of smart phones and data usage, but also at the ease and fluency its rather undereducated, less literate, and socio-economically disadvantaged users had. When they encountered subject after subject showing us the extraordinary ways in which they were adapting the smart phone to their everyday uses, one of the students exclaimed, "I am just amazed that you have all this technology and that you use them." He had clearly, like many of us, presumed that this village in the farthest realms of nowhere would be somewhere in the uneven limbo of connectivity, where we would find our primitive and not ICT subjects.

The man who was wielding his smart phone, which was Chinese-made and had Chinese characters 
on the key, which he had remapped to fit his own purposes, looked at our group and said,

"'But this phone was made for me. You live in big cities. If there is an emergency, you step out and get help. For us, connectivity is a life line. It is something that helps us connect, call for help and hopefully get it in time. For you it is a value-add. For me it is survival. I don't know why you are surprised that we have all these technologies. Surely, they were made for us... you just have higher access to it, and can afford it more than we do."

This is a great moment of unlearning for us internally. To presume what technologies are made for and how they need to be regulated and monitored, but also how they need to be understood and analyzed in terms of human technology interaction. This moment of internal unknowing is good for all of us - even those of us who are familiar with these narratives but often fall into the trap of taking the dominant and the popular narratives for granted or as the natural state of things. The networked margins embody this notion of unknowing because they remain constantly in motion and fluctuating, where even the nodes are not pre-determined but actually created only through the flow of traffic.

\section{Distinguishing Between Having Access and Being Accessible}

The last point I want to make is directly about children and the notion of access that directly responds to the Digitally Connected symposium. There is a conflation of "having access to" with "living in the presence of" when it comes to ICTs. So when we think about children, we think of them only as users and as if their engagement with the digital is functional - just as a tool. We need to stop thinking of children or young people as users and start realizing the formative role that the digital aesthetic, poetics, logics, and architecture play in shaping how they see themselves as well as the world around them. It is time to stop thinking of only those children who are online as the ones who are digitally connected.

The digital at the level of gadget, the technological or the platform, is just one level. Digital also works at the level of imagination and aspiration. It works at the level of policy and infrastructure. In some of the work that we have been doing, we have been working with young kids who are severely socioeconomically disadvantaged and do not have access, despite their existence in pockets of urban poverty, to computers, smart phones, or Internet connectivity.

And yet, in conversations with them, we see the digital emerging as a strong motif — they often see the acquiring of the digital as a form of social and economic mobility and are catalyzed by its presence to bring about transformations in their lives. They have mystical notions of the digital which often persuade them to perform huge acts of sacrificing their rights in the quest for digital dreams. They are often dislocated and forcefully migrated to build digital cities where they are either employed as labor or are removed as a sight for sore eyes. It is necessary to shape our policy research where the digital is seen both as a habit and a habitus - something that we use, but also a space that we inhabit or occupy. It may open up to other intersections of social negotiation, like class, gender, sexuality, and race, without reducing research to business speak of demography, access, penetration, and impact.

The "networked margin," as it embodies these three principles, is a way by which to understand the intertwining of the technological and the social something that is often called Digital Humanities. The Digital Humanities help us question our own critical constructions of marginality, while also offering new models to understand the ways in which we locate questions of inequality, inequity, and interventions as distributed in different parts of the world rather than locating them in pre-conceived geographies and societies.

\section{References / Resources / Links}

Appadurai, A. (1996). Modernity at large: Cultural dimensions of globalisation. Minneapolis: University of Minnesota Press.

Chun, W. (2006). Control and freedom: Power and paranoia in the age of fiber optics. Cambridge: MIT Press.

Digital Media and Learning (DML) Hub. Retrieved from www.dmlcentral.net

Watts, D. (1997). The structure and dynamics of small world systems. Retrieved from http://search.proquest.com/docview/304342043 


\title{
Ownership: The Key for ICT Accessibility and Inclusion for Vulnerable Communities
}

\author{
Maria Liliana Mor \\ The Trust for the Americas
}

When thinking about the uses of ICT in the community, we always refer to knowing the community's needs, knowledge, and expectations, in order to determine in what way ICT can contribute to the development of people. However, when talking about youth with disabilities, the issue becomes more complex for ICT access centers and their support organizations, trainers and facilitators. This is important in order for ICT use and ownership to be fully inclusive, appropriate, and accessible for this population. Having the skills to teach in an ICT access center is very different from having the skills to tackle a learning process and reach an understanding of disability that fosters a holistic inclusion for youth with disabilities, from a human rights perspective. While there are many advances in this field, there is still much to do; a lot more awareness needs to be done in terms of physical, technological, and academic inclusion, as well as public policy advocacy. Unfortunately, there are more myths than realities, more fears than capabilities, and a great ignorance, especially when these ICT access centers are located in remote areas, where the needs and problems of people with disabilities are less visible.

We are in a new phase of social transformation, thanks to the use and ownership of technology. It's time for ICT access centers to be perceived as socially inclusive and accessible centers, which create spaces for knowledge sharing among vulnerable groups. Many organizations are already doing it, or are beginning to. Thus it is important to share experiences and knowledge so that other centers, which have not yet had the opportunity to open their doors to this population, can overcome their fears and learn new and innovative tools for the development of people with disabilities. Latin American organizations that run technology training centers have asked many questions on this subject and have been in situations where the needs and interests of youth with disabilities made them eliminate physical, social, and cultural barriers and face the fear of the unknown. This experience helped them start a process that, even though it is in continuous improvement, has allowed them to experiment, build, and provide social and economic development opportunity for youth with different types of disabilities.

This article brings together significant practices and lessons learned that we hope will serve to support those who lead and work at ICT access centers and who are interested in supporting the full development of young people with disabilities. The aim of this brief article is to showcase the experienced of technology centers in Latin America that work with this vulnerable group, who have been traditionally excluded from the social, economic, cultural, and academic spheres, and to systematize the experiences that ICT access centers operators have had by including this population as a priority group that can be trained and has the ability to acquire tools to fully enjoy their rights on an equal footing as the rest of the population. We encourage more organizations to join and dare to innovate in these areas:

\section{Learning}

\section{Every disability is different.}

It is good to find an organization, entity, or expert in the subject in order to guide the training process that will be implemented in the ICT access center. Ideally, this expert is a person with disability, or from an organization of people with disabilities from the community, so they can contribute their knowledge and personal experience in order to learn more about each disability. For each disability, methodologies and different training topics must be developed according to their conditions and skills.

\section{Reasonable adjustments.}

If you've made the decision to open the doors of the ICT access center, you should think about inclusion 
and accessibility. This is why it is good to have in mind signage for the blind and deaf, locating some equipment to the proper height, and looking for spaces where people with physical disabilities can move without difficulty. These settings are economical, and in order to achieve them, you must be resourceful and creative and take into account the participation of people with disabilities in these processes to ensure reasonable accommodation of accessible, inclusive, and universal spaces.

\section{Available software and hardware.}

It is important to be aware of open-source applications that can be installed in computers, as well as searching for organizations, universities, and entities dedicated to the research and production of open-source software and inviting them to support the disabled population served by the ICT access center. These tools facilitate the process and make a difference in the participants' social and economic development. Although there is still a high cost for the adaptive technologies, it is more common to use open-source software so youth with disabilities can access the hardware and software used in ICT access centers.

\section{Quality, not quantity.}

When talking about training at the ICT access center, it is about taking full advantage of the capacity it has in terms of equipment and provision. However, when it is about youth with cognitive, hearing, or visual disabilities, or people with multiple disabilities, it is best to have small groups (6-10 people) so you can dedicate sufficient time and attention and create a custom process in training, job placement, and adapting the workplace.

\section{Find partners.}

It is essential to know the public sector's disabilityrelated projects and policies. Besides this, it's important to know the projects and programs of the organizations that are dedicated to working with people with disabilities, as well as the work done by organizations that include people with disabilities within their team. This can be fostered as a training, ownership, and life skills process for people with disabilities. It is also key to look for volunteers or mentors willing to give their knowledge to people with disabilities and identify private sector organizations that provide training opportunities and labor inclusion as part of their corporate social responsibility. Online donation platforms are a good strategy for seeking financial resources to enable the development of their own projects.

\section{Understanding is better among pairs.}

Identify youth with disabilities who have some knowledge on the use of ICT and provide them with complementary methodologies so they develop the process. This is a technique that has had good results in ICT access centers, particularly in the case of youth who are hearing impaired, because a person who knows sign language is required. These opportunities are rich and rewarding for those who are given this possibility, as well as for their peers who now have an example to follow.

\section{Provide opportunities for the caregivers.}

This process should be viewed in a comprehensive way. Even though it is true that people with disabilities look for spaces with little dependence and greater freedom, you must provide an alternative space for their families and caregivers to be trained as well. This guarantees that caregivers can guide the ICT activities at home or can strengthen the interpersonal relationships. It is useless to provide tools to people with disabilities if their nearest supports are not aware and not fully involved in these processes.

\section{Create opportunities for development.}

In many places in Latin America, especially in rural areas, the use of adapted technologies is a novelty. When they identify the existence of technological tools that facilitate personal and professional development of the everyday life, great enthusiasm rises (ownership flourishes). The intention to seek educational opportunities, labor, and good use of free time increases as well. For many people with cognitive disabilities who have adopted ICT technologies, to be able to express themselves through a drawing, identify colors, and recognize shapes is part of a major breakthrough that had previously failed with everyday items. In addition to creating the training processes at the ICT access center, it is good to generate awareness with other people in the community, providing opportunities for integration, socialization, and respect of differences. 


\section{Low educational level.}

The existence of other barriers must be taken into account - in this case of structural matter particularly those that are generally prevalent among people with disabilities. The low or nonexistent chance of going to school and completing their basic studies generates illiteracy that leads us to think about a more extensive training process which integrates functional and technological literacy.

\section{Challenges}

\section{Training and awareness for the employers.}

These processes are necessary in order to eliminate myths and provide tools to generate inclusive recruitment processes and achieve effective hiring of youth with disabilities according to their skills and not because of pity or to enforce the quotas stipulated in the law. ICT access centers still lack knowledge on the subject of access, use, and ownership of ICT and disability, which is why the tools in this area must be provided, so they can be converted into spaces where you can train for job readiness and life skills for youth with disabilities.

\section{Design and implement strategies to expand the training offered in ICT access centers.}

This can be achieved by aligning them to be tailored to the needs of the labor market. Diagnoses and mappings have been performed worldwide to identify the job profiles that employers need. These strategies and the use of ICT to generate online short courses can facilitate the integration of youth with disabilities. Example subjects are: Accounting and Finance, Microfinance, Micro-entrepreneurship, Product Marketing, Languages (English), Tourism, Tele-work and Adapted Technology, among others, are of great interest to employers in Latin America.

\section{Technology Availability.}

Technology Availability is an important issue to analyze for those ICT access centers where there is no availability due to high costs or lack of technology infrastructure. Nonetheless, in other cases there is a big difference between availability of this technology for training and availability at the workplace. Software and inexpensive hardware are available at ICT access centers but not necessarily in workplaces because companies usually do not provide this type of accessible aid. We must find guides and low-cost accessible technologies so that employers don't see in the lack of these technologies an excuse to exclude youth with disabilities from economic opportunities and professional development.

\section{Continuation or termination of formal education.}

It is important to report and track young people that, thanks to their participation in ICT access centers, have decided to begin, or have completed, their formal education. In this way, we can show the impact on the population with disabilities and thus seek allies to promote the validation of these processes. This is particularly relevant when we consider that in some cases, ICT skills are being used as a substitute for formal education.

\section{Official certifying documents.}

Official certifying documents should be relevant to the local requirements of the labor market and valued by employers. The work done at the ICT access center should enable young participants to receive an award or certificate to support their aspirations for a job.

\section{Lack of low-cost adapted technologies in certain regions.}

There is a lack of low-cost adapted technologies in certain regions and, moreover, the software is not always available in the local language. This increases the need for training and searching for adapted technologies, both for trainers and beneficiaries.

\section{Adaptation of training models or modules.}

In ICT access centers, network training materials that have been used with different populations and organizations that offer courses are structured by modules to develop different skills and abilities in the students. It is important to use this information that is already validated and all the methodological aspects that ensure the success of the process. It is also important to make adjustments to these materials and identify the changes that need to be done in order to put them into practice with youth with disabilities. 


\section{Libraries Driving Access to Information and Digital Literacy for Children and Youth: Going 'Beyond Access' to Promote Ownership and Agency of ICT Tools for Development}

\section{Camila Urbina \\ Beyond Access}

Within the first few hours of the symposium, it was clear to me that ICT-for-development must go beyond providing infrastructure and connectivity for children and youth. This idea was the primary concern of researchers, practitioners, and entrepreneurs alike. Being part of Beyond Access - an initiative committed to the idea that modern public libraries help drive economic and social development, supported by the Bill \& Melinda Gates Foundation - I have noticed that one of the key aspects of successful ICT-for-development (ICT4D) projects for children and youth is that they ensure young minds are trained and empowered to use the technology to change their lives.

Some, if not most, of the ICT4D programs in the last decade have focused on bringing infrastructure and connectivity to remote communities lacking access. Hordes of computers and tablets were placed in the little hands of eager children and teens around the developing world, cementing ICT as a legitimate social investment. ICT also happened to look great on project websites and donor reports, but that was rather ineffective in bringing true socioeconomic development to the youth that needed it the most. With dismay, we often find years later, when visiting some of the communities that received such donations, that the same computers and tablets are in a corner gathering dust. Why? Because people had neither the resources nor the knowledge to use them, and the first group of young people trained by those projects was grown up and long-gone, or interested in activities that represented viable economic opportunities for them and their families.

The challenge presented to us now, one that was highlighted during the symposium, is to find a way to generate cyclical ownership in the communities. Hopefully, this can involve local, trusted institutions, the support of wider, long-lasting national programs, and allies from the private sector. This means not only shipping boxes full of equipment, but also giving these communities the opportunity to be part of sustainable projects for access to information and digital literacy. This can allow generation after generation to take advantage of the resources and knowledge to improve their economic opportunities.

This is even more important when it comes to children and youth; with young minds the equipment is only the beginning of providing impactful ICT access. We assume they instinctively use technology when it is provided to them. However, even if they are quicker and more likely to use technology as we saw Isaac Mao's lightning talk about future brains and technology - it is never enough just to provide computers, mobile devices, and the Internet. They need support, advice, and orientation so technology can empower them to be changemakers in their own communities.

ICT development projects must empower young people to develop the skills not only to use digital tools, but also to use them in a way that complements their growth and socioeconomic development while fostering global citizenship. It is imperative that the projects we create, endorse, and fund, encompass not only access, but the empowerment of young minds. Through technology, they can increase their opportunities for a better quality of life. ICT will provide youth with the tools and space to cultivate their interests, talents, and abilities, especially for those that lack this opportunity in a formal educational setting.

This is where libraries and the work of Beyond Access come into play. Public libraries are trusted and often community-based institutions. They are 
sustainable, publicly funded, professionally staffed, and conveniently located in many vulnerable and remote communities already. There are more than 230,000 public libraries - $73 \%$ of the world's total - in developing and transitioning countries. And whether they are in big cities or in remote communities, libraries can provide the perfect space to host digital literacy training and empowerment projects for children and youth.

At the same time, they guarantee public access to computers and Internet access in a sustainable and replicable manner for future generations.

Aside from their potential to aid future projects across the world, libraries are already hosts for innovative activities that harness the power of technology to transform the future opportunities of children and youth. In other words, they are already providing a viable solution to the challenge of sustainable agency and ownership in ICT, providing young minds with the creative and flexible support they need to better access and use technology to explore their talents and abilities.

Libraries are already advancing youth development around the world by doing more than just enabling access to information. They provide ideal environments in which to access ICT tools, otherwise unavailable at home or school. More importantly, they are playing a fundamental role in bringing innovative opportunities for education, capacity building, and digital literacy.

A library in Ukraine, for example, provides teenage girls from remote villages access to Skype and online forums about reproductive health, reproductive rights, and counseling services. Another library launched a service that uses Skype to provide counseling on teenage pregnancy prevention in cooperation with local social workers and medical specialists, a service that these girls wouldn't have access to otherwise. Similarly, a public library in Romania created a fitness and nutrition program for children and teens to participate in fitness classes using a Wii console and by organizing consultations with nutritionists in the capital city, Bucharest, using Skype.
In Uganda, the National Library trains young people in basic computer literacy to improve employability, in addition to teaching them how to access information about job opportunities. Another library hosts a program to help pregnant teenagers learn to use technology to access information that will help them improve their health and livelihood, specifically using mobile phones. The Kitengesa Community Library, for example, trains students at a nearby school for the deaf on how to use Skype to communicate with others around the world.

In Kenya, the National Library Service has a tablet computer education program which teaches children from schools in Kibera, the largest slum in East Africa, how to use computers and access educational material online to improve in key subjects like English, mathematics, and science. Another library provides technology training for teachers from remote schools. Using the public library's smartphones, laptops, and video conferencing tools, schools that are hundreds of kilometers apart are able to engage in interschool debates, quizzes, and spelling competitions.

In Medellín, Colombia, the innovative libraries around the city hosted a robotics program to teach children and youth across the city to design, build, and program robots to participate in a local competition. Another library in a remote zone of the city created a mapping project with balloons and digital cameras so children and young people in the community could create a map for their otherwise invisible neighborhood and never get lost again.

Libraries are often overlooked and thought of as obsolete places; therefore the symposium was an excellent opportunity to share this new vision of the modern library with the diverse group of researchers, practitioners, leaders, and innovators. Most people would not necessarily think about libraries as allies that can help implement digital literacy, public access, and agency projects, but the symposium was the perfect forum to change their minds.

While going beyond providing access and ensuring youth are empowered to use technology to change their reality is a challenge, as a young person, the greatest challenge I have faced is being part of projects, initiatives, and programs that are beautifully 
written and conceived of but do not generate true community impact. As a result, they rarely made me feel like any of my concerns mattered to the people organizing the projects. It is disheartening that some youth projects and initiatives tend to be fleeting and "empty," creating an entire framework and events to collect and reproduce the voices and opinions of young people. But these events and projects stop at listening and reporting and often do not create true opportunities to improve our communities and strengthen our abilities. As a lawyer and activist, the greatest challenge for me has always been presenting access to the Internet and information as a human right. One of the biggest obstacles to creating sustainable projects is convincing local and sometimes national governments how important it is to promote and strengthen public access to information through technology.

Analyzing the content of the symposium, some of the most interesting new concepts came from the panel on children's rights in the digital age. These concepts consisted of geographic inequality with a focus on digital unevenness within territories, and how being online sometimes blurs the limitations of cultural difference.

I was especially moved by the simplicity of the insightful questions posed by Isaac Mao on how technology shapes the brain and how it can lead to an economic and social advantage for marginalized children and teens if introduced into their education. I was also intrigued by the challenges presented by teachers and education professionals during the first roundtable. They introduced me to the difficulty of having teachers that are not technologically-savvy and suffer from a lack of training in ICT. Furthermore, they made me aware of the fact that the generational gap is an important factor that widens the digital divide.

The Digitally Connected symposium was the ideal setting not only to form an international, intergenerational, and cross-sectorial community of professionals, leaders, and innovators, but also a place to find where we stand, what questions need to be answered, and what initiatives and ideas are empowering young people across the globe to leverage their projects. With the power of technology, they can forge alliances and discover paths for cooperation. The symposium gave me the chance to feel empowered and connect personally to the beating heart of the inclusion efforts of the digital age.

\section{References / Resources / Links}

Access to Information Central to Post-2015 Development: The Post-2015 Development Agenda seeks to provide proposals for the Sustainable Development Goals (SDGs), a new set of goals that will succeed the Millennium Development Goals (MDGs) in 2015. Some of the proposed goals address economic inequality, unemployment, and health. But discussion on one vital issue has been missing: access to information. http://beyondaccess.net/ resources/access-to-information-post-2015/

Connecting People for Development: Why public access ICTs matter: This report summarizes the study's key findings, situating public access in the context of national development, discussing some disputed issues, and providing recommendations for policymakers, public access practitioners and researchers. The results show that a central impact of public access is the promotion of digital inclusion through technology access, information access, and development of ICT skills. http://tascha. uw.edu/publications/connecting-people-for-development

Empowering Women and Girls Through ICT at Libraries: This brief examines the role (potential and actual) that libraries play in promoting gender equity, with a specific focus on access to technology. Examples from Uganda, Honduras, and Ukraine show that libraries are a safe, stable space for women and girls to work, learn, socialize, and gain digital skills. http://beyondaccess.net/ resources/empowering-women-and-girls-through-ict-at-libraries/

Internet Access and Public Libraries: An Investment in Digital Inclusion and Twenty-First Century Skills: This brief underscores how libraries are preferred venues for public access to the Internet. Governments should incorporate public libraries into national ICT and broadband initiatives, and public library staff should receive training in new technologies so that they can better serve community members and contribute to accelerating development. http://beyondaccess.net/resources/internetaccess-and-public-libraries-an-investment-in-digital-inclusionand-twenty-first-century-skills/ 


\section{Why a Nuanced Approach to Social and Digital Media Use by Children and Young People is Important - Learnings from Kenya}

Kate Pawelczyk

Division of Communication, UNICEF New York

Discussing mobile phone, Internet, and social media usage by children and young people in developing countries elicits different responses from people.

Some are quick to acknowledge the massive growth that has occurred in many countries in recent years; others acknowledge growth and opportunities but focus on the major gaps in access; and then there are some who immediately lament the growing access, warning of the proliferation of cyberbullying, sexual grooming, and pornography that it brings.

In early 2013, as part of the Voices of Youth Citizens initiative, UNICEF undertook a study entitled "A (Private) Public Space: Examining the Use \& Impact of Digital \& Social Media Among Adolescents in Kenya", focusing on the usage of digital tools and social media among children and young people in the country. Kenya - in comparison to some of the other countries where we've undertaken the initiative - has a relatively ample amount of information and data on the use of, access to, and habits surrounding digital media, but there are large gaps when it comes to children, and in particular, children below the age of 15, children living outside of urban centers, or children from families affected by poverty.

While we did not have the resources to embark on a large-scale research effort, together with the research company Intermedia, we sought to undertake a study which would capture the motivations driving the use of social and digital media among young Kenyans; to uncover how they negotiate different digital scenarios; and to include those children whose experiences are typically left out. This was done all with the intention of providing direction for future research and interventions related to children and their use of digital tools.
In the end, a total of 130 children aged 12-to17 participated through 20 digital clinics held in three locations in Kenya - Nairobi, Kissi, and Kitui - representing the urban, peri-urban, and rural contexts respectively. Each "digital clinic" had six male or female participants participating in a 90-minute focus group discussion. Additionally, as part of the process, 152 children' completed a 30-minute questionnaire prior to the focus groups. A qualifying criterion for the study was that participants were already users of digital tools and had daily access to their own or a shared mobile phone, and had used the Internet at least once in the three months preceding the study.

While participants did not always make the distinction between mobile and computer Internet use, an overwhelming sentiment shared by the majority was that their mobile phones and social media use gave them the opportunity to construct their own private worlds; to explore their identities free from the interference of family members; to strengthen existing social connections; and to establish new ones. In addition to looking at usage patterns and online habits, the study also sought to understand how risks associated with online useincluding cyberbullying, suggestive self-exposure, exposure to harmful content, scams, and grooming for sexual exploitation-were perceived by the participants and how they negotiated these risks.

The study identified three categories of users: the dabblers, the proficient, and the savvy set. The dabblers, typically younger and female, were those with more limited access to digital tools who are just starting to navigate the online world. They either do not have their own social media profiles, or if they do, they tend not to have online-only friends. The proficients constituted the larger proportion of the study participants - they tend to have shared 
or personal access to a mobile phone and the Internet; they have a social media profile; and they are likely to have online-only friends. The savvy set also emerged as the most advanced users, but they were also more likely to display risky behavior - echoing the finding from the comprehensive EU Kids Online study that opportunity and risk tend to go hand-in-hand (Livingstone et al., 2011). In our study, the savvy set tended to be older and male.

\section{A Few Findings from the Study Worth Highlighting}

\section{The digital literacy gap between children and their parents/caregivers often leads to concealment of activities.}

Most of the participants reported that they had learned how to use specific digital tools through older siblings, cousins, or family members - very few had been introduced by parents or teachers. With the exception of some of the more affluent urban participants, participants felt that their parents' digital literacy was low. Many reported that their parents or caregivers were not supportive of their use of social media and perceived it as a distraction from school work, or as a negative influence. The typical reaction of parents was to restrict rather than to engage or empower, and in response participants reported being covert-using shared devices when alone, going online late at night, using pseudonyms in their social media profiles, or having alternative accounts with falsified details.

\section{This gap also means that the potential of social media, and digital media more broadly, for empowerment or to support education, is largely unrecognised.}

While participants reported searching for a wide variety of information online, it was clear from the discussions that the digital world is also seen as a useful tool for information related to schoolwork or well-being. In spite of this, digital media was not integrated into the learning and educational experience of most of the participants - digital/ICT learning is largely confined to separate computer or IT classes, and most schools ban the use of mobile phones.

\section{Participants appeared to have only an abstract awareness of risk.}

Many were aware of the risks typically associated with the online world but ultimately did not believe that a dangerous encounter could befall them. Many had been warned by their parents of the dangers of the online world, but these warnings were seldom accompanied by practical, empowering information. Another common reaction was that being connected and having fun ultimately outweighed the risk of online harassment or unpleasant experiences. When asked to rate various risky behaviors on a scale of 1 to 10 (10 being the riskiest) participants regularly assigned a 5 .

Knowledge of or interest in changing privacy settings was low, although most reported knowing how to block unwanted interactions. Some of the participants, in particular those from the savvy set, felt that having low privacy settings was necessary for having the kind of online experience they desire. While most were not familiar — unsurprisingly — with the term "cyberbullying," many reported receiving hateful messages or encountering rumors which left them feeling hurt and/or embarrassed.

The study also found that there was a gap in knowledge about online safety between those coming from more digitally-savvy homes attending well-resourced schools and those who have access but come from resource-poorer and less digitallyoriented homes and schools. This type of digital literacy gap needs to be addressed if children and young people are to have an equal opportunity to participate in the increasingly digitally-orientated domestic and global economies.

\section{Interactions with online-only friends can be risky but might also be a source of support.}

Befriending people online who are not known offline is part of the appeal of social media - and having a high number of friends on social media is desirable. This behavior was common among the proficient and the savvy set, however, some of the young dabblers reported explicitly that they avoid friendship requests online from those who they do not know. In spite of the commonly held fears around online-only friendships, a number of the study participants reported how these friendships have been a source of support to them during difficult 
times. One participant shared an example of how an online-only friend from India had helped provided emotional support when she was feeling down.

The concerns about online friendships, however, are not completely unfounded, especially when the motivating factor behind them is a romantic relationship. Female study participants from more impoverished backgrounds (remote areas like Kitui or urban locations like Kawangware) reported engaging in sexual relationships online - at times with older men. Girls aged 15-17 who had dropped out of school were motivated to use social media to make connections that could lead to what they saw as a better life, pointing to the importance of examining online vulnerability within the wider context of a child's life.

Responses from participants were candid, and the focus group discussions often painted a more complex picture of reality than the questionnaires, especially when it came to discussing access to pornographic content or who was responsible for funding the mobile usage of the participants. While not nationally representative, the findings of the study are important because they capture nuances of digital habits and behavior and provide an important guide for the design of longer and more comprehensive research instruments. It is our hope that the study findings will inspire further research in Kenya; research that approaches digital media use holistically and which seeks to support interventions for equitable and safe digital access for all children and young people in the country.

\section{In Text}

1 The number of questionnaire respondents exceeds focus group discussion participants as not all those who completed the questionnaire went on to participate in the focus groups.

\section{References / Resources / Links}

Livingstone, S., Haddon, L., Görzig, A., \& Ólafsson, K. (2011). EU kids online: final report. EU Kids Online, London School of Economics \& Political Science, London, UK. Retrieved from http://eprints.Ise. ac.uk/39351/1/EU_kids_online_final_report_\%5BLSERO\%5D.pdf

Palfrey, J., Gasser, U., Maclay, C., \& Beger, G. (2011). Digital natives and the three divides to bridge. In The State of the World's Children 2011, Chapter 1: The emerging generation, pp. 14-15. UNICEF. Retrieved from http://www.unicef.org/sowc2011/pdfs/ SOWC-2011-Main-Report_EN_02092011.pdf

Samuels, C., Brown, Q., Leoschut, L., Jantjies, J., \& Burton, P. (2013). Connected dot com. Young People's Navigation of Online Risks. Cape Town, South Africa. Retrieved from http://www.unicef.org/ southafrica/SAF_resources_connecteddotcom.pdf

UNICEF (2013). A (private) public space: Examining the use and impact of digital and social media among adolescents in Kenya. Nairobi: UNICEF. Retrieved from http://www.intermedia.org/

wp-content/uploads/2013/09/A-Private-Public_Voices-of-YouthKenya-study.pdf

UNICEF (2011). Global safety Online: Global challenges and strategies. Florence: UNICEF. Retrieved from http://www.unicef-irc. org/publications/pdf/ict_eng.pdf 
CHAPTER 2

Safety and

Wellbeing the

Broader Discussion 


\section{Sexting: Teens, Sex, Smartphones and the Rise of Sextortion and Gender Based Digital Violence}

\section{Jorge Flores Fernández \\ Pantallas Amigas}

While reviewing my notes for this contribution I realized that it has already been five years since I published my first article about sexting (Flores, 2009). This phenomenon, which is almost a trend at the moment, had called the attention of PantallasAmigas several months earlier, in December 2008, as a practice that began to become a concern (most often the consequences - not the act itself) in the US and UK. Our experience and the characteristics of the phenomenon made us think that it would go global, like so many other things, so we decided at that very moment to try to provide information and prevention resources by creating the www.sexting.es microsite. Unfortunately, five years later, sexting has become, together with cyberbullying, one of the main concerns regarding children and teenagers on Internet.

\section{But ... What is Sexting?}

The term "sexting" was created by combining the words "sex" and "texting" and was initially used to describe the practice whereby "hot" or "spicy" sexually suggestive text messages were sent via cell. ${ }^{1}$ Today, sexting includes not only words, but also pictures and videos sent via smartphones that are often highly erotic and sometimes even pornographic in nature. The sender usually produces these images and videos by photographing or filming their own body. The recipient is often a current or prospective romantic or sexual partner. However, new opportunities provided by technology and broader uses of the term have expanded what is considered sexting. Such practices include cybersex sessions over webcam. Because of the expanding definitions, some people might even confuse the sending and sharing of commercial pornography for sexting.
According to different studies ${ }^{2}$ the prevalence of sexting among adolescents is high. There is a broad spectrum of reasons and contexts to practice sexting, to the extent that a certain degree of normalization of this practice seems to be taking place. For both adolescents and adults, sexting can serve as an expression of sexual identity ${ }^{3}{ }^{4}$, and for most people it is perceived to be a safe and private practice.

\section{What Problems Can Sexting Cause?}

Showing one's own body voluntarily to someone who wants to see it is not a problem in itself, regardless of any subjective ethical or moral considerations. But we cannot forget that when images and videos have sexually explicit or pornographic content, this content may result in legal problems. If the person featured in the content is a below the age of sexual consent - usually between 13 and 16 years, depending on local law - many countries will consider it an act of production, possession and/or distribution of child pornography. In some situations, minors have been charged for creating child pornography of their own bodies, although the trend, at least in the United States, seems changing so as not to prosecute adolescents for this practice. ${ }^{5}$ The fact that the children involved in the image or video might not be prosecuted doesn't mean that those who see, share (a simple retweet on Twitter or "Like" in Facebook is considered to be sharing), or keep the picture on their devices are free to go: an adult engaging in these behaviors could be charged with possession, distribution and receipt of child pornography.

Depending on the country and laws, if a minor receives sexual content from an adult, the adult can be charged with the crime of corruption of minors. The Spanish Criminal Code, for instance, criminalizes this behavior in its article $186^{6}$ if the intent was sexual provocation. 
Finally, making private and sensitive images available to third parties without permission of the person in them may constitute a crime against the subject's right to dignity, honor, reputation or privacy. ${ }^{7}$ In these instances, there is a clear irreparable moral damage and a violation of the privacy of the victim.

\section{Other Associated Risks: Cyberbullying, Grooming, and Sextortion}

Sexting may also put those who practice it at risk of suffering other delicate situations. If the compromising image is in the public domain, it can trigger unjustified harassment or mocking of the person in the image. This collective and public humiliation of the victim creates new stresses around previous actions that, at this point, the victim might want to forget or move past.

In a technologically and socially perfect world, teens and adults could sext with people that will never betray them using apps that protect their privacy, but in our imperfect world there will always be ways to get those intimate photos, a lesson learned the hard way by many celebrities when thousands of their private pictures and videos were leaked online in August 2014, as hackers stole the copies that their iPhones sent to the cloud without their knowledge.

Cyberbullying is the use of Internet, smartphones and/or social media to mock exert peer pressure deliberately and repeatedly. ${ }^{8}$ When combined with sexting, cyberbullying revolves around the public sharing of an intimate image leaked by accident, through a betrayal, by mistake, or by simple ignorance. Even though these type of incidents are rare, as only $2 \%$ of sexters had their photo shared with someone they didn't want to see it', when it does happen, the consequences can be severe. For example, Jesse Logan who, at the age of 17 , sent a nude picture to her boyfriend, committed suicide two years later due to the prolonged abuse to which she was subjected after the image was made public. ${ }^{10}$ She died as a consequence of cyberbullying and, indirectly, sexting.

Sextortion is another problem that can show up whenever intimate images are at stake. The mechanism is simple: someone, known or not, threatens to release the delicate image publically, or to certain other people, if the victim does not comply with the demands of the "sextortionist". According to Interpol, given the nature of the crime and to avoid potential embarrassment, many victims do not come forward, so it is difficult to provide figures. ${ }^{11}$

It is therefore a case of extortion or blackmail, and is a crime most often affecting adolescents and young women who practice "cybersex" (showing their private parts through a web camera). Young boys are less affected by sextortion, although they can also be blackmailed in this way. Girls on the other hand, are being asked at younger ages to perform sexual acts for boys, in some cases in front of friends and classmates, which can facilitate the recording of such acts and their future use for extortion.

Sextortion is becoming a way of exerting violence against women, as they are pressured by their partners to sext more and more explicit content, which in turn is used to threaten women into engaging in the behavior more if they do not wish the sexts to be made public. As a control mechanism, as opposed to physical violence, sextortion within couples is discrete, and often imperceptible to third parties.

Sextortion can have many purposes, but two stand out:

1) Subdue the will of the victim, with one of three potential goals in mind:

- Coerce sexual concessions, as in the case of online child grooming.

- Keep a relationship going after a fight or breakup.

- Obtain personal and/or professional secrets.

\section{Causes and Catalysts}

We have to ask ourselves, why do adolescents "sext"? There are a few possible answers:

1) They do not expect or consider that these images can be seen by other people

- When performed within the framework of an affective relationship, they rely heavily on the discretion of the other partner, but they lack 
life experience to know that not everyone has the same concept of privacy or trust, or that things in life change and that many love affairs end in hatred. There are even cases of "revenge porn", that is, the vengeful posting of sexual images of former partners.

- They believe that an image on a cell phone is safe and are not able to anticipate or imagine the various ways that this picture may leave the device: a robbery, a mistake, a joke, a misplaced or lost phone.

2) They ignore or underestimate the likelihood and consequences of an image ending up in the wrong hands or becoming public.

- The lack of perception of risk is a characteristic of adolescence. When we talk about Internet use, where everything is about what's going on in the present and happens in real time, the ability to project medium-term consequences is challenging.

3) They find reinforcement for this practice in current social models and pressures.

- Some individuals allege that the increasing hyper-sexualization of women in childhood can have a negative impact for equality between men and women, and can result in some sexual behaviors starting earlier. Moreover, popular culture influences and social models are far from modest on many occasions.

- The exposure of what is personal and private on the Internet causes situations of compulsive exposure of private life, what it's known as a culture of "extimity". The concepts of privacy and intimacy are being redefined by new generations who have been socializing on the Internet since childhood.

- The Internet, and even more so social networks, stimulates teen competitiveness in several aspects, such as who has more friends, or more comments on their pictures. Every time they receive a positive comment, "like", or retweet in a social network, this will result in a hit of dopamine, a chemical neurotransmitter associated with the motivation and reward response in the human brain. If they get hooked on this "drug", the pressure to be popular, influential and original in their online socialization, added to the fact that building empathy online is still difficult, could lead to bad behavior. $^{12}$

- The abundance of amateur pornographic content on the Internet can contribute to the standardization of practices like sexting, which news reports indicate is also practiced by celebrities, famous athletes, and influential politicians.

4) They feel the call of adolescence: hormones, fun, flirting with others, and the desire to transgress restrictive social models.

- The practice of sexting helps serve adolescents' sexual awakening. High hormone levels and an impulsive transgressive spirit are the bullets for a "loaded gun" that the smartphones represent: fire the shot, and there's no way to stop it.

5) They see sexting as a normal part of human sexual identity expression. ${ }^{13}$

In addition to these factors, we can identify three other major catalysts for sexting tied to technological advancements:

- Higher performance: better devices and higher broadband speeds.

- Cost reduction: instant messaging programs, such as the popular WhatsApp or WeChat allow sending pictures via Internet without the cost of an MMS.

- New tools: emergence of applications such as SnapChat, which allows users to send photos that can be seen for just a few seconds.

\section{Prevention of Sexting and its Potential Consequences}

Prevention work starts with being aware of the issue, the possible risks and harms, as well as the responsibilities and consequences. All of these measures involve the protagonists themselves. Teenagers are practically unstoppable if they want to practice sexting as they have all the necessary tools: their body and a smartphone.

Can sexting risks and harms be reduced? I believe, there is no such thing as safe sexting unless the person on the image cannot be identified in any way. Remaining anonymous is not as easy as it seems: one should avoid including the face, 
particular characteristics of the body (such as skin spots, piercings or tattoos), clothing, ornaments or any surroundings that will help identify the individual pictured. Also, one must be careful with geolocation data included in some pictures, as it is sometimes inadvertently sent together with the photograph. One must keep in mind that the very existence of the image in a given cell phone, or the fact of having sent it from a known phone, can connect the anonymous person in the photograph to the owner of the device.

Apart from what kind of image has been taken, it is important to consider how, when, and to whom it is sent. The receiving party always has to be a person of high trust who must be notified in advance, lest they open the message at the wrong time. Also, the recipient should be warned that in any case he or she should not show the picture to anyone else, nor mention that such an image exists. Generally speaking, boys should be taught more empathy skills, since they are often the ones who have images sent to them and then commit unauthorized re-sharing without fully realizing the harm they might cause or the betrayal they are committing. Of course, the sender has to be very careful while selecting the recipient of the message, as the finger can tap the wrong part of the screen easily, sending the image to the next contact in the address book.

\section{In Text}

1 For more information about sexting and its definition: Sacco, D., Argudin, R., Maguire, J., \& Tallon, K. (2010). Sexting: Youth practices and legal implications. Retrieved from http://cyber.law. harvard.edu/sites/cyber.law.harvard.edu/files/Sacco_Argudin_ Maguire_Tallon_Sexting_Jun2010.pdf

2 Cox Communications Teen Online \& Wireless Safety Survey, in Partnership with the National Center for Missing \& Exploited Children (NCMEC) and John Walsh. Teen Online \& Wireless Safety Survey. Retrieved from http://www.cox.com/wcm/en/aboutus/ datasheet/takecharge/2009-teen-survey.pdf

Lenhart, A. (2009). Teens and Sexting. Pew Internet \& American Life Project. Retrieved from http://www.pewinternet.org/files/2014/02/ PIP_Couples_and_Technology-FIN_021114.pdf

Lenhart, A., \& Duggan, M. (2014). Couples, the Internet, and Social Media. Pew Internet \& American Life Project. Retrieved from http://www.pewinternet.org/files/old-media//Files/Reports/2009/ PIP_Teens_and_Sexting.pdf

3 Allyson, L., Steiner, J. L., \& Cyders, M. A. (2013). Understanding differences in sexting behaviors across gender, relationship status, and sexual identity, and the role of expectancies in sexting. Cyberpsychology, Behavior, and Social Networking, 16, 568-574. doi:10.1089/cyber.2012.0545.
4 Lenhart, A., \& Duggan, M. (2014). Couples, the Internet, and Social Media. Pew Internet \& American Life Project. Retrieved from http://www.pewinternet.org/files/old-media//Files/Reports/2009/ PIP_Teens_and_Sexting.pdf

5 Hinduja, S., \& Patchin, J. W. (2014). State sexting laws: A brief review of state sexting laws and policies. Retrieved from http://www.cyberbullying.us/state_sexting_laws.pdf

6 Noticias Juridicas. Retrieved from http://noticias.juridicas.com/ base_datos/Penal/lo10-1995.12t8.html

7 See for example: Winsconsin (USA) has "Crimes Against Reputation, Privacy and Civil Liberties" (https://docs.legis. wisconsin.gov/statutes/statutes/942.pdf) where they include defamation or invasion of privacy. Crimes against honor where introduced during Napoleon but are still mixed with other crimes such as injury, defamation, or right to intimacy/privacy http:// dialnet.unirioja.es/descarga/articulo/46497.pdf

8 More information about cyberbullying: Levy, N., Cortesi, S., Gasser, U., Crowley, E., Beaton, M., Casey, J. A., \& Nolan, C. (2012). Bullying in a Networked Era: A Literature Review. Berkman Center Research Publication No. 2012-17. Retrieved from http://ssrn.com/ abstract $=\mathbf{2 1 4 6 8 7 7}$

9 Cox Communications Teen Online \& Wireless Safety Survey, in Partnership with the National Center for Missing \& Exploited Children (NCMEC) and John Walsh. Teen Online \& Wireless Safety Survey. Retrieved from http://www.cox.com/wcm/en/aboutus/ datasheet/takecharge/2009-teen-survey.pdf

10 Jessica Logan Suicide: Parents Of Dead Teen Sue School, Friends Over Sexting Harassment. Huffingtonpost (2009, December 7). Retrieved from http://www.huffingtonpost.com/2009/12/07/ jessica-logan-suicide-par_n_382825.html

11 Interpol. Questions and Answers. Retrieved from http://www. interpol.int/Media/Files/News-Media-releases/2014/Sextortion\%E2\%80\%93-Questions-and-Answers

12 Lenhart, A., Madden, M., Smith, A., Purcell, K., Zickuhr, K., \& Rainie, L. (2011). Teens, kindness, and cruelty on social network sites. Pew Internet and American Life Project. Retrieved from http://www.pewinternet.org/files/old-media/Files/Reports/2011/ PIP_Teens_Kindness_Cruelty_SNS_Report_Nov_2011_FINAL_110711. pdf

13 Junco, R. (2014, May 22). What's the big deal about sexting? CNN. Retrieved from http://www.cnn.com/2014/05/21/opinion/ junco-sexting-teenagers

\section{References / Resources / Links}

Flores, A. (2009). Sexting: adolescentes, sexo y teléfonos móviles. PantallasAmigas: Blog. Retrieved from http://www. pantallasamigas.net/proteccion-infancia-consejos-articulos/ sexting-adolescentes-sexo-y-telefonos-moviles.shtm

Lenhart, A., \& Duggan, M. (2014). Couples, the Internet, and Social Media. Pew Internet \& American Life Project. Retrieved from http://www.pewinternet.org/files/old-media//Files/Reports/2009/ PIP_Teens_and_Sexting.pdf 


\title{
Challenges of Parental Responsibility in a Global Perspective
}

\author{
Sonia Livingstone \\ London School of Economics \\ EU Kids Online
}

Jasmina Byrne

UNICEF Office of Research

Who is responsible for managing children's online opportunities and risks? In the Global North, the most common answer is parents, especially when it comes to keeping children safe. Teachers are expected to ensure that children have the digital literacies needed to benefit from the expanding media and information opportunities. A host of other stakeholders - from NGOs, child welfare bodies and governments, to industry players across the value chain - also bear some responsibility, both directly insofar as they engage with children and indirectly because they can support parents and teachers.

This paper began as a dialogue in which Sonia Livingstone drew on the evidence base of the EU Kids Online network to review how parents are approaching this responsibility. However, as the number of children gaining Internet access increases worldwide, it is timely to question the extent to which this evidence can be generalized. Are there any particular challenges to parenting in the Global South? These questions led Jasmina Byrne to reflect on UNICEF's experience in diverse cultural contexts. Our aim is to challenge the assumption — often heard in debates about children's rights, Internet governance, and multi-stakeholder responsibilities - that parents are ready and available to facilitate children's rights to protection, provision, and participation in the digital age.

\section{In the Global North}

In the early days of Internet access in Europe and North America, many children became confident and competent Internet users before their parents and teachers. This resulted in considerable generation gaps-parents underestimated their children's use and the risk of harm they encountered online. As a consequence, few parents supported their children's Internet use beyond the fact of providing access. By the same token, few children turned to their parents for support when they encountered a problem on the Internet. A culture rapidly developed in which, to generalize, many parents felt disempowered-ignorant of their children's experiences online, susceptible to media panics about Internet predators or pornography, and therefore restrictive in managing their children's Internet access.

Research shows that restrictive parental mediation works to keep children safer online, but it limits the quality of their overall experience, restricting their online opportunities and the development of digital skills and resilience to harm (including cyberbullying, pornography, and "stranger danger") (Duerager and Livingstone, 2012). To sum up, what we learned in the Global North suggests the value of an open dialogue between parent and child so that each comes to understand and respond to the online experiences, competencies, and concerns of the other.

However, research also reveals some problems under this framework. For instance, poorer and lesseducated parents tend to prefer restrictive over "active" mediation, including talking to children about the Internet, sitting with them while they use the Internet, or sharing online activities. Even though active mediation works better than restrictions at reducing children's exposure to online risks without diminishing online opportunities, it also increases the likelihood that younger children (9-12 years) are upset when encountering risks. In effect, relative disadvantages in home life offline may be extended online (just as children more vulnerable to risk of harm offline also tend to be more vulnerable online). 
However, as parents become more experienced Internet users, matters may improve: research finds a correlation between parental knowledge of the Internet and how competently children use the Internet, as well as whether children turn to parents if something is problematic (Livingstone, et al, 2012). Nonetheless, around one in eight parents does not provide supportive or safety mediation. Additionally, around half of parents whose child has encountered an online risk is unaware of this-and this in countries where two-thirds of children say their parents know a fair amount about what they do online.

\section{In the Global South}

It seems likely that the above problems are exacerbated in the Global South, as many children in developing countries are brought up by a single parent (18-43 percent in Sub-Saharan Africa, 18-27 percent in Central and South America, and 9-12 percent in South Asia). The number of children without any parental care is also high in sub-Saharan Africa, ranging from 11-20 percent across countries (Child Trends, 2014). Since in the least-developed countries school attendance is low, pupil-to-teacher ratios are high, and the overcrowded classrooms and untrained teachers are common (World Bank, 2012), it seems fair to conclude that in many countries, children lack a supportive and/or informed adult in their lives.

Two-thirds of the world's almost three-billion Internet users are from the developing world, the numbers are growing rapidly, and many users are young (ITU, 2014). Not only are young people often the early adopters of the Internet but they go online without adult support (and the ratio of young-to-all Internet users is twice as high in lower-income as in developed countries) (ITU, 2013). This generational knowledge gap is even more pronounced in poorer and rural areas. UNICEF research points up some further significant trends.

For instance, UNICEF's (2013a) study in Zambia found that while only 23 percent of children go online at home and 16 percent at school, 78 percent access the Internet through a mobile device. In this context, it is hardly surprising that fewer than 20 percent learned how to use the Internet from their teachers, although 60 percent said they were helped by parents to find information online for school. UNICEF's study in Kenya pinpoints the impact of youth using the Internet in little-supervised cybercafes, something common in many other countries (UNICEF 2013b). This reflects the limited access at home and school, and also teenagers' desire for privacy. Kenyan children said that when their parents do not understand the digital world, they are more fearful about its negative impact, and try to restrict their children's usage; thus children seek access in cybercafes. Also, few of them said they would turn to parents for help with an online problem.

\section{What is Being Done, What Can Be Done?}

In Europe, Insafe, www.saferlnternet.org, is the awareness-raising network for national centers that coordinates the annual Safer Internet Day, and provides parental guidance regarding the latest popular site or newest online fashion among children. The ITU's Guidelines for Parents, Guardians and Educators on Child Online Protection are available in six world languages (www.itu.int/ pub/S-GEN-COP.EDUC-2012), although they are not regularly updated. Furthermore there are numerous multi-stakeholder initiatives that draw together the combined expertise of educators, parenting groups, child welfare bodies, industry, and law enforcement.

Coordinated, accessible, parent-focused efforts in the Global South are few and far between. Although there are many parenting education programs in this region, very few address children's online experiences. Integrating online issues into existing programs may be a way to reach more parents and address their needs holistically. One good example of support to parents and teachers in preventing digital violence in school, developed in Serbia, views such violence in the context of the deeper social causes of peer violence. Additionally, it offers strategies that include systematic, preventative measures and close collaboration with teachers and parents (Popadic and Kuzmanovic, 2013).

Another resource - useful in promoting children's access and use of online resources, innovation, and participation in the absence of a reliable parent figure - could be peer mentoring. This support becomes particularly important when it comes to 
marginalized groups of children, e.g. children with disabilities or adolescent girls in societies where gender inequality undermines girls' opportunities to benefit from ICT use. For instance, in Iraq provision of online resources allowed adolescent girls to access information, also linking them to peer-to-peer support networks where they could discuss issues usually considered private or taboo in their society (UNICEF 2013c).

Although in many countries there are signs that local networks of young entrepreneurs and innovators, NGOs, and youth groups can bring ICT learning into their communities and neighborhoods, extending initiatives similar to the ones previously mentioned faces many challenges. These impediments are derived from the low levels of awareness, undeveloped infrastructure and lack of local capacity. (UNICEF, 2014). Additionally, the widespread use of cybercafes (e.g. in Brazil, 43 percent of children use the Internet through socalled LAN houses) (Barbosa et al., 2013) and their potential as centers of play, learning and creativity is as yet untapped.

\section{Conclusion}

In the Global North, multi-stakeholder discussions often express the hope or expectation that parents will take primary responsibility for child safety online. Parental mediation can be tailored according to the age, maturity, or cultural/psychological circumstances of each child. It doesn't limit other adults' freedoms online and it is cheap - parents are already on hand, willing to play their role. But, they also expect that their child's school will offer them advice and safety education, and that the government will "police" the Internet so that parental lapses in effort or effectiveness don't have disastrous consequences.

Under the framework of parental mediation, the problems are obvious. First, parents are often the last people children wish to tell about their relational, emotional, or sexual concerns. Second, the Internet is hugely complicated, fast-changing, and varied, making it difficult for any adult, let alone a busy parent, to grasp what children need to know. Third, some parents do not take on this responsibility, and they are "hard to reach" by awareness campaigns.
Fourth, small minorities of parents are truly neglectful of or abusive to their children, making it hardly appropriate to rely on them to ensure their child's safety. However, for those seeking to prevent or manage the risks of harm to children, it is important to empower all parents and also to provide a safety net for circumstances of childhood vulnerability.

Some trends in the Global North have implications for experience in the Global South. For instance, the growing understanding and willingness of parents to engage with their children's Internet use as they catch up with their early adopter children. By the same token, some trends in the Global South have implications for experience in the Global North. From this perspective, we can point the trend towards "mobile first," replacing first use via desktop or laptop computer, which is now also spreading in the Global North, reducing parents' ability to monitor their child's Internet use (Madden, 2013). Other trends invite us to look anew at the Global North - there, too, exist children escaping parental oversight by going online in cybercafes and children who lack reliable parenting or adult figures in their lives. Moreover, as the Internet becomes more important on a daily basis, even in the Global North there are signs that parents are becoming more anxious, more restrictive, and more intrusive into their children's privacy online. Paradoxically, too, the more society calls on parents and care-givers to monitor, supervise, and support children's online activities, the more children will seek to evade or subvert these efforts (which is not to say children reject all parental support, far from it) (Duerager and Livingstone, 2012).

Evidence from developing countries suggests five dimensions of parenting that matter for child and adolescent well-being: connection, behavior control, respect for individuality, modelling of appropriate behavior, and provision and protection (WHO 2007). These ideas have resonance for families everywhere, for most parents struggle with the tension between protecting their children and giving them the freedom to explore, learn, and grow independently. In addition, most parents can be encouraged to draw on what they know about their child and the wider society, as often this knowledge is also applicable in the digital domain. Therefore, in considering the stakeholders supporting parents, there are questions about 
balance. For instance, should they encourage parents to exercise their parenting role in general, (including good communication and engagement with their children) or teaching them specific digital and safety skills? Should they try to minimize the risks by restricting online services available to children or helping them build resilience and strengthening children's protective networks? In making these decisions, especially in the Global South, it is problematic that few evaluations about the impact of specific interventions in relation to parenting support have been conducted, to serve as a reference.

In seeking answers to these dilemmas, we would refer to the 25-year-old UN Convention on the Rights of the Child. This clearly specifies that parents have the primary responsibility for childrearing, but it also places obligations on states and communities to support parents in these endeavors. It seems that the old saying "it takes a village to raise a child" still applies in a digital world.

\section{References / Resources / Links}

Barbosa, A., O'Neill, B., Ponte, C., Simões, J.A., \& Jereissati, T. (2013). Risks and safety on the Internet: Comparing Brazilian and European children. LSE, London: EU Kids Online. Retrieved from http://eprints.Ise.ac.uk/54801/http://eprints.Ise.ac.uk/54801/

Child Trends (2014). World Family Map: mapping Family Trends and Wellbeing Outcomes. Retrieved from http://www.itu.int en/ITU-D/ Statistics/Documents/facts/ICTFactsFigures2014-e.pdf

Duerager, A., \& Livingstone, S (2012). How can parents support children's Internet safety? LSE, London: EU Kids Online. Retrieved from http://eprints.Ise.ac.uk/42872/

ITU (2013). Measuring the Information Society 2013: Measuring the World's Digital Natives. Geneva: International Telecommunications Union. Retrieved from http://www.itu.int/en/ITU-D/Statistics/ Documents/publications/mis2013/MIS2013_without_Annex_4.pdf

ITU (2014). ICT Facts and Figures. Geneva: Information Telecommunication Union. Retrieved from http://www.itu.int/en/ ITU-D/Statistics/Pages/facts/default.aspx

Livingstone, S., \& Bulger, M. (2013). A Global Agenda for Children's Rights in the Digital Age: Recommendations for Developing UNICEF's Research Strategy. Florence: UNICEF Office of Research. Retrieved from http://www.unicef-irc.org/publications/702

Livingstone, S., Haddon, L., \& Görzig, A. (Eds.) (2012). Children, Risk and Safety Online: Research and policy challenges in comparative perspective. Bristol: The Policy Press. Retrieved from http://eprints.Ise.ac.uk/44761/1/EUKidsOnlinebookExecSummary. pdf
Madden, M., Lenhart, A., Duggan, M., Cortesi, S., \& Gasser, U. (2013). Teens and technology 2013. Washington D.C.: Pew Research Center's Internet \& American Life Project. Retrieved from http://www.pewInternet.org/files/old-media/Files/Reports/2013/ PIP_TeensandTechnology2013.pdf

Popadic, D., \& Kuzmanovic, D. (2013). Utilisation of Digital Technologies, Risks and Incidence of Digital Violence among Students in Serbia. Belgrade: UNICEF Serbia. Retrieved from http://www.unicef.org/serbia/Digital_Violence_Summary_2013.pdf

UNICEF (2013a). Understanding Digital Access \& Use by Adolescents in Zambia: Findings from an exploratory study. New York: UNICEF. (not published)

UNICEF (2013b). A (Private) Public Space: Examining the Use and Impact of Digital and Social Media Among Adolescents in Kenya. Nairobi: UNICEF. Retrieved from http://www.intermedia.org/ wp-content/uploads/2013/09/A-Private-Public_Voices-of-YouthKenya-study.pdf

UNICEF (2013c). Integrating Information and Communication Technologies into Communication for Development Strategies to Support and Empower Marginalized Adolescent Girls. New York: UNICEF. Retrieved from http://www.unicef.org/cbsc/files/ ICTPaper_Web.pdf

UNICEF (2014). Children, ICT and Development: Capturing the potential, meeting the challenges, Innocenti Insight, Florence. Florence: UNICEF Office of Research. Retrieved from http://www. unicef-irc.org/publications/pdf/unicef_royalholloway_ict4dreport_ final.pdf

World Bank (2013) Pupil-teacher ratio, primary. Retrieved from http://data.worldbank.org/indicator/SE.PRM.ENRL.TC.ZS 


\title{
Safety Experts Call for Research on True Harms of "the Darker Web"
}

\author{
Jacqueline Beauchere \\ Microsoft
}

Online risk does not equate to offline (or online) harm. This compelling theme emerged quite prominently for me at the recent Digitally Connected symposium, co-hosted by Harvard University's Berkman Center for Internet \& Society and UNICEF. In fact, a number of online safety and other experts acknowledged "risk as opportunity" — the notion that introducing some degree of calculated online risk will likely be beneficial to young people, resulting in increased resilience, confidence, and a sense of empowerment and fulfillment.

Accordingly, research and resources need to be directed to better understand the true harms that may stem from young peoples' online activities. And, any follow-on public-policy efforts need to be based on an accurate portrayal of those risks most likely to cause harm.

To date, related research has focused largely on kids' online activities and the risks they face. Microsoft and others look at risks as stemming from some combination of "The Four Cs" - content, contact, conduct, and commerce (Livingstone, et al., 2010). While innocuous in and of themselves, it's the illegal content, inappropriate or unwanted contact, and illegitimate commerce that should cause concern. In fact, our very definition of online safety centers on the notion of risk management. We define online safety as enabling individuals and families to maximize their desirable online experiences, while minimizing those associated with The Four Cs. As with other online and offline activities, we encourage risk identification, evaluation, and mitigation.

Experts attending the symposium agreed there is certainly value in risk-based work; it has largely set the stage for what we know about current Internet habits and practices among youth. For example, to better understand the global pervasiveness of online bullying, in 2012, Microsoft's Online Safety Team conducted research in 25 countries (Microsoft, 2012). We asked young people ages 8-17 about some of the more negative behaviors they encounter online. Similar to other data compiled about online bullying, our research showed the vast majority of kids are doing the right thing in the digital space; they're behaving civilly and appropriately. In short:

- Twenty-four percent, on average, said they had bullied someone else online at one time or another, indicating that more than three-quarters (76 percent) had not.

- Still, the most compelling findings were tied to reactions to information about behaviors, as opposed to any exhibited behaviors themselves. Specifically, more than half (57 percent) of young people around the world, on average, said they were aware of online bullying.

- Moreover, 54 percent said they were worried that they would be bullied online.

Indeed, media's spotlight on the most severe and tragic cases of young peoples' online activities and behaviors has sparked concern and stirred emotion. In addition, it has prompted largely reflexive responses, particularly in the public-policy arena. Going forward, even under the most heartbreaking of circumstances, "facts must displace emotion," and - many experts at the symposium agreed robust evidence must supplant reactionary policies.

Another research nugget emerged from the symposium: for the most part, data that has been collected thus far - particularly via more extensive academic endeavors - has assembled a wealth of information about "The Global North" (Livingstone, S. \& Bulger, M., 2013). The conference seemed keen to determine if similar research approaches would apply equally to "The Global South." That theme and question spurred considerable reaction from attendees from The Global South. Many did not want 
the geography to be viewed as "different" and, instead preferred to characterize the international research-base as one.

To gather opinions about more impactful research, I hosted a "Food for Thought" session at the symposium, where I shared with attendees our plans for fresh research and an examination of some more "darker side of the Web" issues. I look at the range of issues that children face online in terms of a spectrum. I call it "from selfies to CSAM" - at one end, those sometimes risky images that kids take of themselves to, at the other extreme, the most horrific form of content circulating on the Web today: child sexual abuse material (CSAM). Teasing, taunting, bullying, over-use, over-exposure, reputation management, and other issues fall somewhere in between. More on this new research in the coming months, but know that we're thinking carefully about trends suggesting actual or probable harm, and what we might do to raise awareness and inform parents and others about such issues.

Other themes surfaced at the symposium, as well. Namely, the power of resilience and the need to build children up so that they can more readily address those instances when perhaps something they encounter online upsets them or makes them uncomfortable. The ongoing challenge of adapting to mobile technology was another recurring refrain. In fact, many said current strategies intent on blocking or restricting young peoples' access to certain online content or activities may be for naught, as kids now easily move between home, school, sporting events, and social functions with the Internet in their pockets, purses, and backpacks.

Participants were also intent on having stakeholders from various disciplines collaborate more closely and combine resources and assets where appropriate. I, for one, have always been a fan of collaborating whenever possible to achieve maximum impact and reach. Just such a program took place in Paris in late-May. Some 40 representatives from 13 countries/ regions convened to discuss information-, researchand resource-sharing, as well as collaboration and amplification - all with an eye toward harmonizing around a simple set of online safety messages for both young people and adults. This truly global and worthwhile effort is being led by National Cyber Security Alliance and APWG.

The 2014 Digitally Connected symposium, held at Harvard Law School, brought together 150 academics, practitioners, government officials, representatives from technology companies, and others from around the world to begin to chart a path "towards a global community of knowledge and practice around children, youth, and digital media." Over the three days, the group shared research, insights and experience on topics ranging from privacy, identity and reputation among young people, to risky behaviors, online safety, health, well-being, innovation and more. At this event, I met many new colleagues with whom I hope to explore further the intriguing theme of "risk as opportunity."

\section{References / Resources / Links}

Livingstone, S., \& Bulger, M. (2013). A Global Agenda for Children's Rights in the Digital Age: Recommendations for Developing UNICEF's Research Strategy. Retrieved from http://www.unicef-irc. org/publications/pdf/lse\%20olol\%20final3.pdf

Livingstone, S., Haddon, L., Görzig, A., \& Ólafsson, K. (2010). Risks and safety for children on the Internet: the UK report. Politics, 6(2010), 1. Retrieved from http://www. researchgate.net/publication/50902989_Risks_and_safety_on_ the_internet_the_perspective_of_European_children._Full_findings/ file/9fcfd5058770fd13fb.pdf

Microsoft. Online safety research. Retrieved from http://www. microsoft.com/security/resources/research.aspx\#onlinebullying 


\section{Health and the Digital Space}

\author{
Claire McCarthy \\ Boston Children's Hospital \\ Berkman Center for Internet \& Society
}

In many countries and communities around the world, it can be very hard to see a doctor. These countries, including Nigeria, Rwanda, Ghana, India, Myanmar, Indonesia, and Guatemala, have fewer-often far fewer-than one doctor for every thousand people (World Bank). Even in countries that have many more doctors than this, rarely are those doctors available to everyone who needs one.

Think about what this ratio means for the youth growing up in these countries and communities. It's difficult enough for youth with chronic medical problems that have easy access to doctors to get the care that they need and meet other individuals struggling with the same problems. Getting confidential care, such as reproductive health care, without friends of family being aware of it is extremely difficult-and going to the doctor when you are healthy simply to get information or advice becomes hard to justify.

But the Internet can help.

Already, people are turning to the Internet for health information. According to a 2013 survey, three quarters of US adults who use the Internet look for health information online and one in three have gone online in an attempt to figure out what medical condition they or others might be experiencing (Fox \& Duggan, 2013). Using resources available online, one can find information about many health problems and treatments without ever having to see a doctor. For some it is about convenience, but for others online information is the only option available. This is true for many youth living in medically underserved areas.

But it's not just about accessing information. While nothing completely replaces direct doctor-patient encounters, especially if an examination or a procedure is needed, a remarkable amount of medical care can happen virtually. Whether through high-tech telemedicine or a simple text message reminder to take a medication, the digital space has tremendous potential to expand the reach and scope of medical care efficiently and effectively.

The digital space also offers something traditional medical care does not: the possibility of peer-to-peer health care - connection, education and support between people who share similar experiences. In areas with limited practitioners, peer-to-peer support can make all the difference.

Youth are in an extraordinary and important time of life when it comes to health and well-being. As a pediatrician, I find my patients to be remarkably full of pertinent and important questions about their bodies and health. It is so important that youth be able to find accurate and helpful answers to those questions because the decisions they make and the care they get now can significantly impact their future health and productivity. The mental healthcare they get is just as vital. Even in countries with ample physical health resources, mental health resources are often limited-and there is generally a stigma attached to accessing them.

Today's youth are growing up in an increasingly digital culture. The Internet, along with the concepts of search and of sharing, is familiar to them. This makes the use of the digital space for youth health a particularly appropriate, and exciting, avenue to pursue.

Of course, there are challenges.

\section{Digital Literacy and Information Quality}

Although youth have grown up with the Internet, that doesn't necessarily mean that they know how to search it efficiently-or evaluate the information they find and its sources. When it comes to health, both physical and mental, it's crucial that people find, read, and follow information that is accurate, 
reliable, and relevant. If the digital space is to help improve youth health, youth must know how to search and evaluate online information.

\section{Technology Limitations}

As much as we take Internet access for granted, it's not always available. We need to be creative in how we use other technologies, such as SMS, and we need to think about how we can increase Internet access. Building infrastructure to improve Internet access is generally less expensive than building clinics and hiring clinicians, a point that can and should be made to funding sources.

\section{Confidentiality}

While many youth are comfortable sharing information about themselves, health information (especially mental health information) is extremely personal. We need to create infrastructures that allow youth to interact in confidential ways with health care professionals.

\section{Quality of Care}

As with online health information, not all health care is good health care. With the future of our youth at stake, we need to be sure that the health care providers in the digital space are capable ones, and that systems are created that support the best possible care. Part of doing this will be creating innovative partnerships between existing health resources and those who support and create technology. This leads to yet another challenge:

\section{Engaging Healthcare Providers}

Many health care providers are unsure of what technology exists and how best to use it, and many have never even sent an email or text to a patient. For them, the concept of giving care in this space may be intimidating and uncomfortable. They will need education and support. In addition, systems for reimbursement need to be created if online healthcare is to be sustainable, and that is no small task.

These are challenges worth tackling, because the benefits could be tremendous and long-lasting. This is an effort that could improve the health and well-being of youth; it is one that could bring a brighter future to our world.

\section{References / Resources / Links}

Fox, S., \& Duggan, M. (2013, January 15). Health Online 2013. Pew Research Centers Internet American Life Project RSS. Retrieved from http://www.pewinternet.org/2013/01/15/health-online-2013/

World Health Organization. (n.d.). Physicians (per 1,000 people). World Bank: Global Atlas of the Health Workforce. Retrieved from

http://data.worldbank.org/indicator/SH.MED.PHYS.ZS

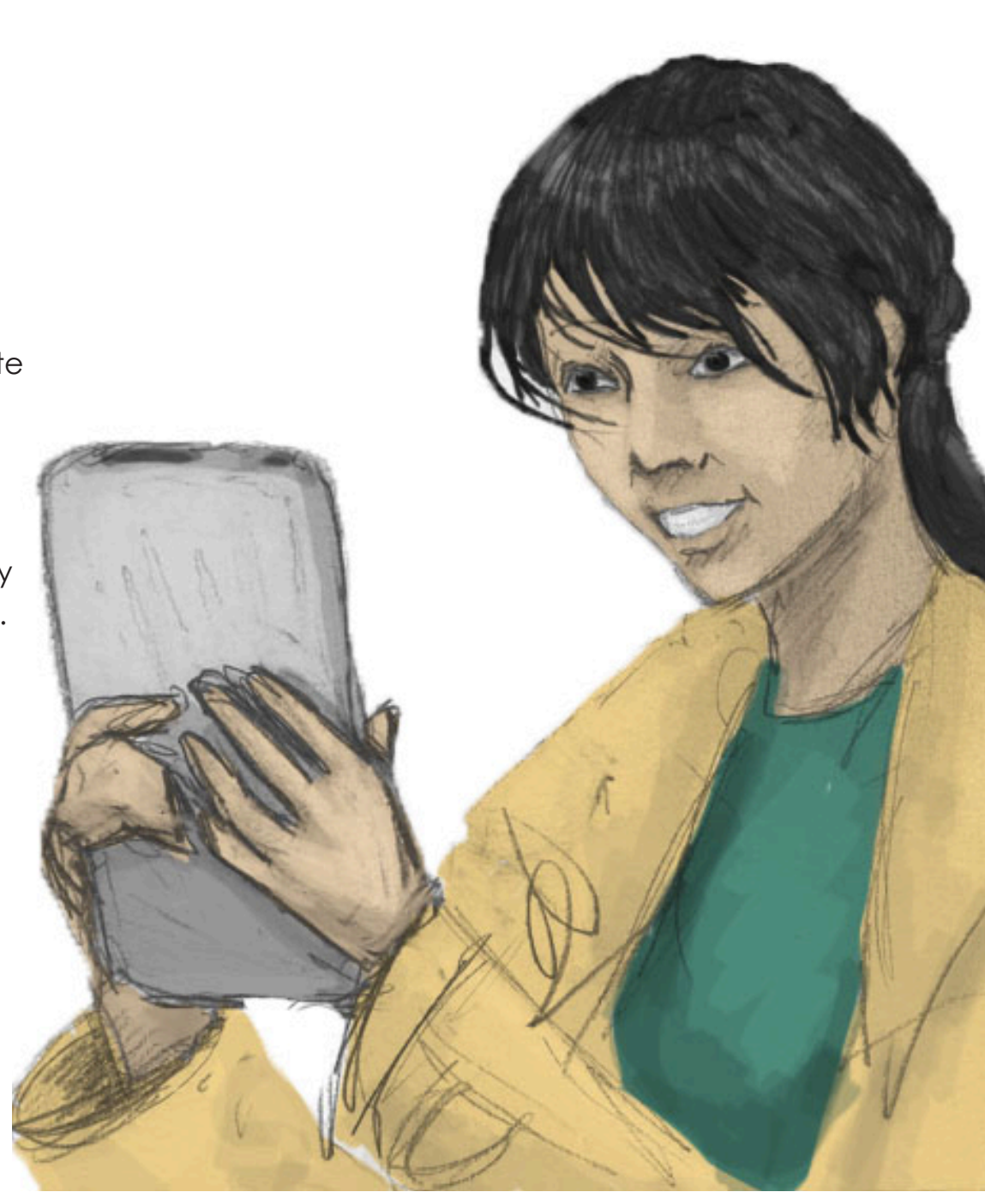

DIGITALLY CONNECTED 33 
CHAPTER 3

ldentity, Privecy,

and Reputation 


\title{
Who Should Take Care of Identity, Privacy and Reputation?
}

\author{
Djordje Krivokapi \\ University of Belgrade \\ Share Foundation
}

\section{Conceptualization of Identity, Privacy \& Reputation}

Identity and reputation are bound together, but there is a need to differentiate these two terms. While personal identity is largely controlled by the individual, reputation as a social identity is earned in society and it is not solely our own creation. That means we have control over our personal identity, which is not entirely the case with reputation. However, among other things, privacy provides opportunity to individuals to control and impact personal data relevant for the creation of reputation. Reputation is a public image created by society, based on available information and ruling social norms. Freedom of information and public interest are limiting our right to privacy, providing opportunity for everybody else to share "reputational information", i.e. "information about an actor's past performance that helps predict the actor's future ability to perform or to satisfy the decision-maker's preferences" (Goldman, 2010, p.294). However, this information can vary from hard facts to subjective opinions.

According to danah boyd (2014, p.11), networked publics create new opportunities and challenges, which include persistence (longevity of online content), visibility (global potential audience), spreadabiltiy (content is easy to share), and searchability (content is easy to find). Further, children and youth are usually unaware of the differences between networked publics and other publics they belong to; it is challenging to distinguish between the online and offline versions of themselves (Palfrey \& Gasser 2008). Teens consider technology as another part of their everyday life, whereas for many adults it reveals changes that are deeply disturbing (boyd 2014, p.14).
Data related to identity which creates reputation can be divided, but not limited, to:

- Information shared by the individual (reputation holder);

- Information shared by third parties that interacted with the individual;

- Online behavioral data collected by intermediaries and ISPs;

- Data available from public registries, etc.

If not restricted by privacy rules and platform design choices, the aforementioned data is, in general, free to be collected and processed by third parties, including being used for creation of reputational information. Therefore it is necessary to develop and implement different regulatory regimes for outlined groups of information, based on privacy regulation, especially in cases concerning children and youth.

\section{Are Identity, Privacy \& Reputation Age- dependent?}

Articles 8 and 16 of the UN Convention on the Rights of the Child claim that identity and privacy are basic human rights created upon birth, granted to individuals regardless of age, while reputation is created in the socialization process by third parties and reputational systems. However, the right to privacy could prevail over other conflicting values, particularly freedom of speech, to prevent data collection related to any reputation creation before a certain age. Namely, in most circumstances there is no clear public interest or competing private interests which would entail third parties to collect and analyze data about children in order to create reputational profiles. Therefore, there are valid arguments why third parties should in my view be restricted to collect data and create an individual's reputation before a certain age of social maturity. 
Related concerns are quite justifiable: just imagine companies running Massive Multiplayer Online Games (MMOGs) selling their data to school/ university submission committees or employers. This could include information about the profiles linked to the child: how many kills he achieved, how brutal were the kills, how loyal was she to her buddies, were there attempts at cheating, etc.

In Eastern Europe, it is "common knowledge" that security agencies and others investigate the adolescent activities of a "target" when they want to create a full profile of that individual in order to blackmail him or ruin his reputation. It is rumored that this is based on the belief that character is created during this period, when youngsters are discovering more about their personality. If data from that early period of life is allowed to be collected, no matter the protection, there is a risk that it could be widely abused during adulthood by the state, employers, or corporations.

Therefore, it is extremely hard to estimate what are the legitimate aims for allowing collection of minors' data and how principles of necessity, adequacy, and proportionality should be applied. In addition, there is special concern related to the outsourcing of data processing to the "professionals" and putting data into the "cloud" which create some complicated legal and regulatory issues regarding the application of the Family Educational Rights and Privacy Act (FERPA) (Mutkovski 2013, p. 6-7). For example, the InBloom project envisioned creating a resource allowing teachers to get a better view of student progress in order to individualize instructions while saving time, effort, and precious resources. The aim was to enable educational institutions to effectively manage storage, processing, and access to students' data, which was in different databases, incompatible formats, and required different passwords. This data included not just grades, but also attendance, disciplinary actions, sports activities, medical records, and so on. However, the project was closed due to general public concerns related to misuse of big data and the potential for selling data to the highest bidders. Consequently, the school system might be left without proper tech solutions, even though these solutions could enable it to better cope with data management and technology while providing interoperability. Although some might see the InBloom case as a "brake" on attempts to use big data to improve education (Economist, 2014), it should go further and change companies' approach to privacy and put special attention on trust maintaining mechanisms.

The majority of online platforms require users to be at least 13 years old, because of the Children's Online Privacy Protection Act (COPPA), but this reason is not explained during sign-up processes (danah boyd et. al, 2010, p.2). Further, these measures can be very easily circumvented, while, ironically, preventing this circumvention requires collection of more information about the minors.

Regarding Internet economy, there are concerns about children using services which are provided "free" in exchange for their data being collected, because they are not authorized to enter into this kind of agreements before a certain age, according to relevant legislation (COPPA). But what happens if such agreements are concluded and services delivered, e.g. When the age requirement is circumvented? Social networking app "Path" decided to settle with the Federal Trade Commission after being charged with, among other things, illegally collecting children's personal data without parental consent, for which the company had to pay $\$ 800,000$ (FTC, 2013). Even if companies enter into lawful collection of children's data, they should not be able to provide aggregate or individual data about minors to third parties, including commercial advertisers and marketing research firms, without an express opt-in that focuses clearly on explaining what the data will be used for. This is especially important because of behavioral advertising and Web platforms which often have users expose more data than they realize (for guidance see boyd et al., 2010).

Marwick et al. (2010) highlight companies (commercial data brokers) whose business models are based on piecing together personal data of individuals to create their "digital dossiers." Therefore, it is not entirely clear from which point online reputation systems could rank children and youth based on their "reputational scores" and when their friends are allowed to contribute to them with their experiences and opinion. 


\section{How Teens and Youth Perceive Privacy and Significance of Reputation?}

In reality, privacy is an individual right, and people in general have very different ideas about what it means to them - it usually depends on their relationship with the public and their existing or desirable social roles (Westin, 1968). Consequently, how children and youth perceive privacy is considered a hard question, especially in the era of a constantly changing information environment. It is hard to estimate the level of awareness teens and youth have of the impact of their online identity, privacy, and reputation on their real world lives. Their present online behavior is not just creating their current reputation, but also contributing to their future adult reputation. Additionally, it seems difficult, if not impossible to, accurately predict how data collected today will impact lives tomorrow.

At the moment, the older individuals get, the more frequently they reveal private information. However, these "sharing" practices are developing with awareness of privacy and reputation risks. Research shows that teens are aware of their privacy and

\section{TEENS AND ONLINE PROFILE MANAGEMENT}

\section{Content Curation /}

Identity and Reputation Curation

$\mathbf{5 9 \%}$ have deleted or edited something that they posted in the past

$\mathbf{5 3 \%}$ have deleted comments from others on their profile or account

$\mathbf{4 5 \%}$ have removed their name from photos that have been tagged to identify them

$31 \%$ have deleted or deactivated and entire profile or account

$19 \%$ have posted updates, comments, photos, or videos that they later regretted posting

\section{Friend Curation / Access Curation}

$\mathbf{7 4 \%}$ of teen social media users have deleted people from their network of friends list

$\mathbf{5 8 \%}$ have blocked people on social media sites concerned about their data being accessed by third parties without them knowing. Therefore, they are actively involved in management of their online profiles, particularly regarding content they make available that is connected to their identity and who has the right to access that content (Madden et. al, 2013).

On the other hand, young adults (age 18-29) are the only age group in the US with a majority that would rather not prosecute Snowden, with $57 \%$ of them having the opinion that the leaks have served rather than harmed the public interest (DeSilver, 2014). The youth position is interesting in that protecting privacy on the Internet and becoming a criminal today often became one and the same (Naughton 2014). The most savvy technology users are aware that protecting privacy and being anonymous online requires various tactics that are sometimes even illegal, especially in repressive regimes.

Consequently, in order for teens and youth to have their online privacy protected, we should provide them with tools that are lawful and can serve their needs, since they are the most digitally connected part of the population and are quite dependent on their online identity and reputation.

\section{Roles and Responsibilities of Parents, Educators and Corporations and Conflict of Laws}

It is clear that the role of parents and educators is crucial for the development of future digital citizens. Youth need help to learn to navigate their online experiences and use technology to protect their identity, privacy, and reputation as early as possible. Nothing can replace the role of parents, educators, and communities in helping youth safely navigate the world they live in; responsibility cannot be entirely shifted to policymakers and companies.

Adults mostly decide what's important for children. However, the youngsters should also be given a chance to speak for themselves in accordance with the principle of participation, since they are growing up in a completely different world compared to their parents, and their social life has a huge online dimension. 
However, the question arises: are parents granted with authority to manage their children's identity and reputation as their "proxies," or do they just have an obligation to protect privacy in best interest? This issue remains under-researched, especially in respect to the regulatory regimes applied across different countries. This could be the result of relevant rules on this issue on major Internet platforms are created in compliance with COPPA, which becomes globally recognized, regardless of different national rules. In practice, online platforms act in accordance with COPPA and delete profiles of users younger than 13 if requested by the parent and reject such request if the user is older than 13, regardless if different national laws govern these terms of service.

Corporations controlling the online space and providing online services to children and youth are expected to provide user-friendly architecture and enable users to control information they share in the way they want. Service providers should also provide tools to youngsters to appropriately manage third party content posted about them. When it comes to collection and protection of data, the privacy of children and youth is respected in relation to 3rd parties. For example, the default sharing option for youth on Google+ is to friends only, while any video can be removed from YouTube at the user's request if the user is recognizable in the video. Also, companies should in my view publish information on how they share this data with third parties, including governments. The main challenges are that online service providers cannot always be aware of the age of their users, which can easily be misrepresented, and they have a lack understanding of what identity, privacy and reputation are from the perspectives of children and youth.

\section{Roles and Responsibilities of Researchers and the Ethical Dilemma}

In order to create a children- and youth-friendly architecture of their services, corporations as creators of online environments need better understandings of what identity, privacy, and reputation actually mean to youth. Surveys about certain issues are usually conducted without understanding the issues themselves. Therefore, it would be helpful to have comprehensive global research on privacy, identity, and reputation at the disposal of companies creating products for youth.
This would provide insight on children/youth online behavior and on which aspects of digital life kids care about. This would help them better design digital spaces. Also, cross-country research on digital literacy should be conducted to map gaps between kids, parents, and teachers, in order to involve everybody in working on improving digital literacy. Researchers have been cautious about partnering with companies in order to keep the sense of neutrality. But because of that, there's so much valuable data not being fully explored and analyzed. It is not easy to establish lightweight collaborations with companies which would not endanger the position of researchers. Also, a question becomes valid: should this data be collected in the first place, especially from children? Everybody, including researchers, has become greedy for data - this has caused youth to disregard not just authorities and parents, but also online platforms and researchers in general.

\section{Global Regulatory Approaches}

When we talk about the Global South and smaller and underdeveloped countries, it seems that it's very hard to influence the digital environment in a sufficient manner and according to local needs. Currently, corporations are in a position to develop specific services and regulatory regimes for particular countries and communities, however, this is not a common outcome. Local researchers usually do not have the opportunity to influence global companies controlling the Web. Global Internet companies are usually not present in their countries and are not interested in spending additional resources to adjust their services to local needs, although they do agree that it could be possible. Further, local research in less developed countries is rare and sometimes not methodologically comparable, which makes this problem even more complex. A unified global research methodology and database of research questions, as well as funding global research, would help the needs of children and youth in underdeveloped regions actually influence global decision making.

On the other hand, pushing local governments to make a change is very risky. In less developed countries which are less than democratic, the youth agenda could easily be hijacked (exploiting youth 
protection to restrict or control speech) and causing unintended consequences of policy that not based on evidence.

When data is collected and policy developed, it seems the best ways to make a change is to develop international instruments and tools (conventions, declarations, guidelines, etc) for creating a framework for national legislation and national/global online services providers, as well as improving the policies of service providers targeting children.

\section{Conclusion}

Because children and youth are an especially vulnerable group both offline but also in cyberspace, there needs to be a consensus regarding them safely using online services and keeping their personal data safe. Parents, legislators, online service providers, and researchers need to be included in this endeavor if it is to succeed. Regulation of collection of minors' data will remain one of the major challenges of regulating a balance between appropriate future reputation and expectations of privacy on one side and ongoing technology development and social innovation on the other.

\section{References / Resources / Links}

boyd, d. (2014). It's complicated: The social lives of networked teens. Yale University Press.

boyd, d., Gasser, U., \& Palfrey, J. (2010). How the COPPA, as implemented, is misinterpreted by the public: A research perspective. Retrieved from http://cyber.law.harvard.edu/ publications/2010/COPPA_Implemented_Is_Misinterpreted_by_ Public

Desilver, D. (2014). Most young Americans say Snowden has served the public interest. Fact Tank. Pew Research Center. Retrieved from http://www.pewresearch.org/fact-tank/2014/01/22/mostyoung-americans-say-snowden-has-served-the-public-interest/

Federal Trade Commission (2013). Path social networking app settles FTC charges it deceived consumers and improperly collected personal information from users' mobile address books.

Press Release. Retrieved from http://www.ftc.gov/news-events/ press-releases/2013/02/path-social-networking-app-settles-ftccharges-it-deceived

Goldman, E. (2010). The Regulation of Reputational Information The Next Digital Decade: Essays on the Future of the Internet leds. B. Szoka, A. Marcus). TechFreedom, Washington, D.C.

K.N.C. (2014). Big data and education: Withered inBloom. The Economist. Retrieved from http://www.economist.com/blogs/ schumpeter/2014/04/big-data-and-education
Madden, M., Lenhart, A., Cortesi, S., Gasser, U., Duggan, M., \& Smith, A. (2013). Teens, social media, and privacy. Pew Internet \& American Life Project. Retrieved from http://pewinternet.org/ Reports/2013/Teens-Social-Media-And-Privacy.aspx

Marwick, A. E., Murgia Diaz, D., \& Palfrey, J. (2010). Youth, privacy, and reputation, Public Law \& Legal Theory Working Paper Series, Paper No. 10-29, Berkman Center Research Publication No. 2010-5. Retrieved from http://ssrn.com/abstract=1588163

Naughton, J. (2014). Attempts to stay anonymous on the web will only put the NSA on your trail. The Guardian. Retrieved from http://www.theguardian.com/world/2014/may/11/anonymousweb-nsa-trail-janet-vertesi

Palfrey, J., \& Gasser, U. (2008). Born Digital: Understanding the first generation of Digital Natives. New York: Basic Books.

United Nations (1989). Convention on the Rights of the Child. Retrieved from http://www.ohchr.org/EN/Professionallnterest/ Pages/CRC.aspx

Westin, A., (1968). Privacy and freedom. New York: Atheneum. 


\section{1:1 Education, Children, and (Lack of) Privacy: The Story of the Fatih Project in Turkey}

Elif Küzeci

Bahcesehir University, Faculty of Law

Istanbul Privacy Platform (IPP)

\section{Introduction}

Today, in the Information Age, the need for children, the adults of the future, to use technology in education increases every day. 1:1 education projects are developed in many countries with the aim of creating equal opportunity, improving education outputs, enhancing the technology skills of students, and monitoring their development accurately. However, while these projects are still being created, the potential problems that may arise should be analyzed carefully; many of these technologies have some "side effects" in addition to their significant benefits.

Projects that are developed within the scope of 1:1 education have certain aspects to consider, such as the health of children, the safe use of the Internet, or environmental problems that may be caused by technological waste (Povezevara et al., 2013). Another remarkable issue is related to the information collected via these systems. Indeed, privacy has become one of the most important basic rights of our age due to new information technologies. 1:1 education initiatives should be carefully analyzed in this respect. Moreover, when we consider some current trends, such as the usage of Big Data, it becomes necessary to discuss the problems that may be caused by $1: 1$ education in the future in the context of such trends.

Privacy and data protection are essential for everyone, but children require particular attention as growing individuals. The primary reason for this is the principle of "the best interest of the child." As mentioned in the UN Convention on the Right of Child (UNICEF, 1989), which is the most rapidly and widely ratified international human rights treaty in history, "the child, by reason of her or his physical and mental immaturity, needs special safeguards and to care appropriate legal protection, before as well as after birth." That's why, in many fields, the protection of a child is more important than the protection of adults. In addition, a large part of children's lives take place in schools (Article 29 Data Protection Working Party, 2009). Therefore, data protection in schools needs to be closely examined and evaluated, especially in the context of 1:1 learning initiatives.

It is quite obvious that privacy and data protection principles (e.g. processing fairly and lawfully; being collected for specific, explicit, and legitimate purposes; being adequate, relevant, and not excessive in relation to the purposes for which they are collected; being kept for no longer than is necessary for the purposes) will be applicable for children a fortiori. However, in addition to the aforementioned principles, some special conditions for children must also be considered. Indeed, child is a human being who has not achieved maturity. However, she/he is developing physically and mentally to become an adult. For that reason, child needs a special care in every area, including data protection and privacy (Article 29 Data Protection Working Party, 2009). Such protections include Internet access restrictions, authorization to give consent and/or amount of data that would be collected. This situation will bring about challenging questions in light of the various applications developed within the scope of 1:1 education projects. This and other similar questions will be briefly evaluated below within the scope of FATIH project, which has just begun implementation efforts in Turkey.

\section{Conquering Education: FATIH Project}

FATIH means the "conqueror" in Turkish and is also an acronym of a large-scale 1:1 learning project in Turkey (Firsatları arttırma ve teknolojiyi iyiletirme hareketi", which means "enhancing opportunities 
and improving technology movement." Besides that, this term is also a reference to Sultan Mehmed II of the Ottoman Empire, who was commonly known as Fatih (the Conqueror) Sultan Mehmed.). The project is a remarkable example of how new communication technologies are followed closely in Turkey. "The Strategy of Information Society and Action Plan, 2014-2018" by the Ministry of Development, which opened public consultation in May 2014, called FATIH one of the most important initiatives in education in Turkey (Ministry of Development, 2014). The Turkish government is implementing the FATIH Project, which has a scope that is unprecedented so far in the world. The budget for the project is 8 billion Turkish Liras (over 3.5 billion US Dollars) and the aim is to distribute over 11 million tablets to students and teachers within the scope of the project (Precidency of Development of Strategy of Ministry of Education, 2012). So far, the Turkish government has delivered LCD Interactive Boards and tablet PCs to 52 schools in 17 provinces in the pilot phase (Ministry of Education, 2012).

The Ministry of Education declared that it was embracing the goals of Information Society Strategy, which has been prepared by State Planning Organization (2006-2010). In order to this, the Ministry of Education targeted the following objectives: (i) Lifelong learning approach, development of the proper structures in which all individuals can improve themselves through e-learning, and development of the e-content; (ii) All students that graduate from secondary education should have the ability to use the basic information and communication technologies; (iii) One of the three individuals in society should benefit from e-education facilities through the effective usage of Internet; (iv) Providing equal opportunities to everybody on learning and usage of the information and communication technologies; ( $v$ ) One of the two individuals in society should be Internet user; (vi) Internet should be made reliable for society (Ministry of Education, 2012).

In this sense, the main objective of FATIH is to achieve equal opportunity in education and improve students' technology use. On the other hand, information sources on the project are inadequate or inconsistent (Povezevara et al., 2013, page 7). Likewise, the organizers haven't yet clearly outlined the quality, type, and scope of data they plan to collect. The project aims to construct an Internet infrastructure in all schools (including pre-school, primary school, and secondary school), provide smart boards in all classrooms, deliver tablet PCs to all students and teachers, create educational digital content as well as share this content via EBA (Educational Informatics Network), and establish a system for student-teacher-parent interaction (Ministry of Development, 2014).

These types of systems involve large scale data sets. In addition, if geo-location is activated in tablet PCs, sensitive data such as location information of students might be possible to collect. E-mail, maps, cloud account, classroom management, EBA (Education Informatics Network) portal, homework sharing, individual production materials, content development studio are also in the works (Ministry of Education, 2014; Education Informatics Network, 2014). In addition, basic student information can be kept in associated databases and the organizers are planning a data center within the project. However, it is not yet clear which types of data will be kept in this center.

\section{Data Protection Landscape in Turkey}

Privacy aspects of this massive project regarding all school-aged children need to be discussed. This must be evaluated with the lack of comprehensive Turkish law on data protection in mind. Indeed, the Data Protection Draft Act is still being examined in the Prime Minister's Office and hasn't come into effect yet. Approval of the Council of Europe's Convention on Protection of Personal Data, which was signed by Turkey in 1981, cannot be finalized (COUNCIL, O. E., 1981). This leads back to Article 4 of the Convention, which says contracting parties are obliged to adopt the principles as a part of their domestic law.

The most significant provision in Turkish legislation regarding the protection of personal data is in the last clause, which was added to 20th Article of the Constitution with 2010 constitutional amendments. The clause states that:

"Everyone has the right to demand the protection of his/her personal data. This right comprises the right to be informed about the personal data concerning himself/herself, 
access to such data, right to request correction or deletion of them as well as the right to be informed if such data is used in accordance with the purposes for which it was collected. Personal data can be processed only in cases regulated in a law and upon explicit consent of the subject individual. Principles and procedures regarding the protection of personal data shall be regulated by a law."

In addition to this amendment, there are also provisions regarding this issue in Turkish legislation. The most notable examples of these provisions are in the Turkish Criminal Code, which regulates the unlawful recording, delivering, publishing, distributing or obtaining of personal data without destroying it after a required period, as crimes. However, these provisions are insufficient to protect the right to privacy, especially in the face of information technologies. This situation is even more critical when it comes to a child's personal data. There are not any special provisions or laws for protecting children's data, whereas the U.S. has FERPA (Family Educational Rights and Privacy Act) and COPPA (Children's Online Privacy Protection Act) (Topelson et al., 2013).

We are obligated to make a special evaluation for children in terms of all protection mechanisms including privacy and data protection. Considering the ongoing-mental development of the child, we must take suitable precautions to allow the child to benefit from the right of personal data protection, which is granted as a constitutional right to everyone in Turkey. It is the responsibility of the state to create awareness among children regarding this issue and especially to allow children to practice the right of personal data protection.

\section{Privacy Risks in FATIH: Personal Data Playground}

First, the government, educators, teachers, parents, and data processors should always consider the best interest of the child. All applications must be arranged to eliminate the risk of a student being discriminated against. One of the issues we should consider is related to "informational selfdetermination." The student must be informed about which data are collected about her/him, how long they are kept, with whom they are shared, and the availability of the information (Article 29 Data Protection Working Party, 2009).

In this context, the "consent," which is one of the grounds of legitimate processing of personal data, must be assessed. One of the most important aspects of consent that we must evaluate is the identity of the person authorized to give consent, especially as it relates to children. It must be stated that acceptance of consent by the related person as a reason for compliance with the law in the protection of personal data was developed on the basis of personal autonomy. Thus, what is protected in the contextual data related to a child is not in the interest of the parents but of that child (Article 29 Data Protection Working Party, 2009). So, if the requisite conditions are present, consent should be taken from the child whose data is processed. On the other hand, parents' giving consent on behalf of their child by guardianship is more related to the concepts of "best interest" and "protection of the child" (International Working Group on Data Protection in Telecommunications, 2002). In addition, according to the Article 12 of the UN Convention on the Right of the Child, every child who has sufficient awareness to constitute his/her personal ideas has the right of explaining his/her opinions in every issue related to him/her (UNICEF, 1989). The ideal solution is to ask the opinion of every child who has reached a certain maturity level, even if this is not mandatory.

On the other hand, the FATIH Project has no legal documentation indicating the proper usage of the personal data of children or conditions to obtain consent. This raises concerns about the usage of personal data by unauthorized persons who could sell the data without the consent of parents and/ or students. For instance, data kept regarding the students has the potential to be used in direct marketing. Specifically, the applications on tablet PCs allows various data that can be used for marketing to be collected. Even in direct marketing activity used within the purpose of education, consent of parents and children depending on his/ her awareness level should be sought (Article 29 Data Protection Working Party, 2009). 
Moreover, benefiting from Internet access could be a component of 1:1 education activities. At this point, an approach should be created that can provide opportunities for students to be raised as free individuals of a democratic state. On the other hand, there may be some restrictions on the healthy development of the child. Privacy should not be violated while monitoring activities, but, when it is necessary to transfer the data of children via Internet, it is important and necessary to take toplevel data security precautions.

Collecting enormous amounts of data and dataintegrated services causes privacy concerns and may affect the achievement of the goals of 1:1 education initiatives. InBloom, which collects the school information of students and shares it with teachers and parents, announced that it will cease operation. This is a remarkable example. InBloom's main objective was to determine the needs of students accurately. Although there was no evidence that the company misused the information, privacy advocates and families expressed they were worried that this information might be marketed and/or stolen

(Dwoskin\& Fleisher, 2014).

\section{Conclusion}

Smart boards and tablets in education are useful tools for the development of children, and the FATIH Project is meaningful and valuable in this respect. But the utmost care must be taken to obtain the desired positive results from such projects. At this point, privacy is a particular concern. As a matter of fact, in Turkey, restrictive decisions on Internet access, based on regulations often said to be for protecting children, have increased gradually, whereas a framework law for protection of personal information is yet to come into effect. In some instances, like the proper use of a child's personal data, a general framework would be insufficient and there should be specific legislation that considers the special condition of the child. In this regard, in addition to comprehensive data protection law, a special regulation that guarantees children's privacy should be implemented immediately.

This large-scale project has the potential to guide 1:1 education projects. However, overlooking privacy issues causes human rights concerns and introduces significant risk for the efficiency and sustainability of the project. In Turkey, some NGOs have pointed out the consequences of FATIH Project. I hope that the government will hear these voices and the project will become a useful reference for the other similar initiatives in the world.

\section{References / Resources / Links}

Article 29 Data Protection Working Party (2009). Opinion 2/2009 on the protection of children's personal data (General Guidelines and the special case of schools), WP 160. Retrieved from http:// ec.europa.eu/justice/policies/privacy/docs/wpdocs/2009/ wp160_en.pdf

COUNCIL, O. E. (1981).Convention for the Protection of Individuals with regard to Automatic Processing of Personal Data. Explanatory Report.

Dwoskin, E., \& Fleisher, L. (2014). Parental Opposition Fells inBloom Education-Software Firm, Privacy Concerns Over Use of Student Data Lead Company to Close. The Wall Street Journal. Retrieved from http://online.wsj.com/news/articles/SB1000142405270230404 9904579516111954826916

Education Informatics Network. (2014). Retrieved from http:// tablet.eba.gov.tr/yardim/files/sss.pdf

FATIH Project (2013). Retrieved from http://fatihprojesi.meb.gov.tr/ tr/english.phph

International Working Group on Data Protection in Telecommunications (2002). Childrens' Privacy Online: The Role of Parental Consent.

Ministry of Development. (2014). The Strategy of Information Society and Action Plan. Retrieved from http:// bilgitoplumustratejisi.org/tr/doc/8a94819842e4657b01464d502 $5 \mathrm{~b} 80002$

Ministry of Education (2014). Prime Minister Erdogan: If There Is Good Education, the Country's Future Is Bright. Retrieved from http://www.meb.gov.tr/basbakan-erdogan-8220okulda-iyiegitim-varsa-o-ulkenin-gelecegi-parlaktir8221/haber/6687

Ministry of Education. FATIH Project. (2012) Retrieved from http:// fatihprojesi.meb.gov.tr/tr/english.php .

Pouezevara, S., Dinçer, A., Kipp, S., \& Samsik, Y. (2013). Turkey's FATIH Project: A Plan to Conquer the Digital Divide or a Technological Leap of Faith? Retrieved from http://erg. sabanciuniv.edu/sites/erg.sabanciuniv.edu/files/Fatih.rapor_. ENG_.son_.pdf

Precidency of Development of Strategy of Ministry of Education. (2012). Formal answer to the written parliamentary question in 4/4/2012. Retrieved from http://www2.tbmm.gov.tr/d24/7/75676 sgc.pdf

Topelson, D., Bavitz, C., Gupta, R., \& Oberman, I. (2013). Privacy and children's data: An overview of the Children's Online Privacy Protection Act and the Family Educational Rights and Privacy Act. Berkman Center Research Publication, (23). Retrieved from http://ssrn.com/abstract=2354339

UNICEF. (1989). Convention on the Rights of the Child. Retrieved from http://www.ohchr.org/en/professionalinterest/pages/crc. aspx 
CHAPTER 4

Skills, Literacies,

and Cultures of

Learning 


\section{What Are Digital Literacies and Why Do They Matter?}

Reynol Junco

lowa State University

Berkman Center for Internet \& Society

Years ago, scholars focused on the issue of the digital divide — that is, divisions between the "haves" and the "have nots" in access to new technologies. Recent research shows that access to information and communication technologies (ICTs) has equalized; however, differences in how people use these technologies remain. Disenfranchised youth are less likely than their more well-to-do peers to use ICTs in ways that help them connect with others, promote their education, and prepare them for work. For instance, youth from lowincome regions are more likely to use computers for academic practice and quizzing, while students from higher income regions are not only more likely to be using them for such activities, but are also learning how to program them (Warschaver, Knobel, \& Stone, 2004). These differences persist throughout a student's educational career. Newer research shows the impact of demographic characteristics on how social technologies are used. A number of examples illustrate these differences:

1 In the United States, African American students and students with greater Internet skills are more likely to use Twitter (Duggan \& Brenner, 2013; Hargittai \& Litt, 2011).

2 Globally, 83 percent of Pinterest users are female (Chrzan, 2012). This platform is more popular among female Internet users in the United States as well, with 25 percent of women using Pinterest compared to 5 percent of men (Duggan \& Brenner, 2013).

3 Women are significantly more likely to use Instagram than men. Additionally, African Americans and Latinos were significantly more likely to use Instagram than Whites (Duggan \& Brenner, 2013).

4 Men are more likely to report using social networking websites to make new friends while women are more likely to report using these sites to maintain current relationships (Muscanell \& Guadagno, 2011).

5 Even though time spent on the site was the same across groups, men were less likely to use
Facebook for communication, African Americans were less likely to use Facebook to check up on friends, and students from lower income levels were less likely to use Facebook for communication and sharing. Communication and sharing activities are directly related to educational outcomes and so these observed differences in uses put these groups at a disadvantage (Junco, 2013).

These findings are particularly disconcerting given abundant research showing that there are substantial educational and psychological benefits of incorporating social media in education (Junco, 2012a; 2012b; Junco, Elavsky \& Heiberger, 2012; Junco, Heiberger \& Loken, 2011). There are also career benefits of using social technologies effectively - for instance, to tap social capital in order to find jobs or to engage in newer forms of work, popular in the developing world, like microwork and crowdsourcing (Coward, Caicedo, Rauch, \& Rodriguez Vega, 2014).

Educators and policy makers often make the mistake of assuming that all youth are technologically savvy. This keeps them from teaching digital skills that are important for youths' civic engagement and that impact how they interact in society. Take for example, a student who uses social technologies like Twitter and Facebook to express his views about a governmental regime in a country or region where personal points of view are not valued. Their online communications, if seen by other members of society or government officials, might cast them as a "dissenter" and at best keep them from lucrative work opportunities and at worst get them imprisoned. Even in the United States where personal freedoms are valued, 37 percent of company hiring managers use social media to screen applicants and make hiring decisions based on what they find online (CareerBuilder.com, 2012).

It is no surprise, then, that digital literacies were a popular topic at the Digitally Connected symposium. 
Scholars, educators, policy makers, and activists from around the world wondered how we could join forces in order to promote stronger digital literacy skills to improve young people's quality of life. While there was near-unanimous agreement that improving digital literacy is an important task, there was little agreement on its definition. This is due in part to the fact that there is a wide range of definitions available in the educational literature, but also because digital literacy skills can mean different things in different regions. For instance, a child in a low-resource region might need to learn how to turn on a computer and how to use the mouse and keyboard; while a child in a high-resource region might need to learn how to be a good digital citizen.

An exhaustive review of definitions of digital literacy are beyond the scope of this essay; however, it is helpful to identify the broader concepts covered by these definitions. Here, they will be summarized as progressive levels within the framework of digital literacies. At the most basic level, computer literacy refers to the skills necessary to operate hardware and software. These are skills like turning the computer on and off, using the keyboard and mouse, and logging into the operating system (Ferrari, 2012). Web literacies involve knowing how to go online, navigating web pages, and using html to create web pages. Related to web literacies, information literacy skills are the ability "to recognize when information is needed and have the ability to locate, evaluate, and use effectively the needed information" (American Library Association, 1989). Gasser, Cortesi, Malik, and Lee (2012) expand the definition of information literacy to a framework for information quality that encompasses the process, contexts, and outputs of youth interaction with information. This framework includes the ability for youth to determine their information needs, search skills to obtain that information, the ability to effectively evaluate information found during the search, and the ability to create new information.

Additionally, the rise of social media has brought with it a reconceptualization of digital literacies. Social media are applications, services, and systems that allow users to create, remix, and share content and they are very popular among youth globally. When they use these sites, youth are informally learning how to: develop a stable sense of identity (Junco, 2014), build and maintain friendships (Ellison,
Steinfield \& Lampe, 2007; 2011 ; Ellison, Vitak, Gray, \& Lampe, 2014), improve their self-esteem (Yu, Tian, Vogel \& Kwok, 2010), and feel more integrated into new educational environments (Yu, Tian, Vogel \& Kwok, 2010). This work has led some to argue that interactions on social media have led to the emergence of new literacy practices. Greenhow and Gleason (2012), for instance, note that new technologies allow for youth to perform new social acts not previously possible; in a chapter in my upcoming book, I propose that social media allow youth to take risks and "try on" different identities in ways they could never have done before (Junco, 2014). With social technologies, youth must also build skills to understand the technical and psychological aspects of privacy (Junco, 2014). Technical aspects of privacy include such matters as knowing how to engage privacy controls on sites like Facebook, while psychological aspects of privacy involve how youth perceive online privacy (or that information seems more private than it actually is).

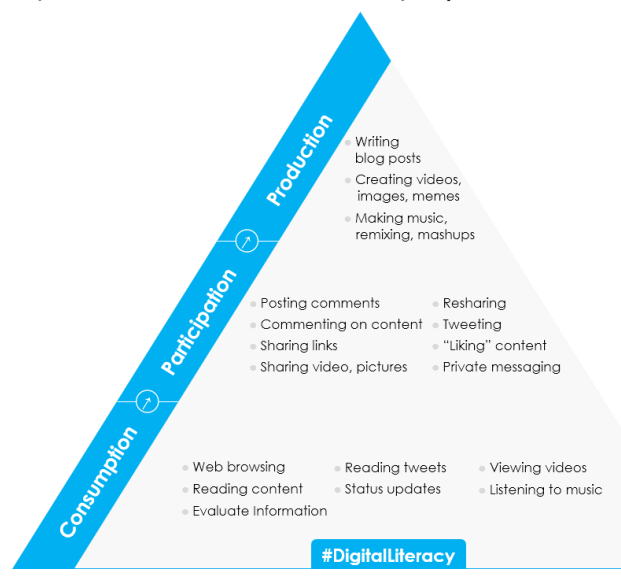

Figure 1. Graphic illustrating the core concepts involved in digital literacy skills. Graphic by Arif Khan (@arifkhan7), Digital Marketer, India: Creative Commons Attribution-NonCommercial-ShareAlike License.

In order to summarize previous work on web literacies, information literacy, information quality, and social media literacies, I developed the framework illustrated in Figure 1 that shows the core concepts involved in digital literacies as progressive levels. At the most basic level, youth consume information-they go online, browse, search, and evaluate information. At the next level, youth participate in online spaces-they interact in online social spaces, share content, comment, and "like" content. At the most advanced level, youth produce their own content-they remix existing videos and music, create mashups, develop memes, and write blog posts. There is a range of skills for the tasks at 
each level. For instance, under the information evaluation task, some youth will use basic heuristics to make credibility assessments about websites, while others will use deeper strategies (Gasser et al., 2012). Educators have the responsibility to promote digital literacies, especially as these literacies relate to youth academic and career success. The International Society for Technology in Education (ISTE, 2014) states that all teachers should "design and develop digital age learning experiences and assessments," "model digital age work and learning," and "promote and model digital citizenship and responsibility." However, teachers often cannot teach more advanced skills because of policy restrictions on the use of social technologies and because of a lack of professional development opportunities. Unfortunately, educators rarely have the necessary skills to teach youth skills beyond consumption.

As supporters of youth development, we must act to improve the avenues by which young people develop digital literacies. Where we can, we must support changes in educational policies and teacher training to improve the teaching of these skills. When resources are not available in the schools, we must develop programs and services to fill these gaps. Given the international, interregional, and inter-individual differences in skills, it is essential to develop assessment programs to provide information about how to best target interventions aimed at promoting digital literacies. However, additional research is needed to evaluate how well skills learned through informal uses of newer technologies transfer to formal settings like the classroom and work environment. It is my hope that through our Digitally Connected collaborations we can begin to break down the policy barriers holding back the development of digital literacy skills to work towards a more equitable digital future for all young people.

\section{References / Resources / Links}

Career Builder.com. (2012). Thirty-seven percent of companies use social networks to research potential job candidates, according to new CareerBuilder Survey. Retrieved from http:// www.careerbuilder.com/share/aboutus/pressreleasesdetail. aspx id=pr691\&sd=4\%2F18\%2F2012\&ed $=4 \% 2 F 18 \% 2 F 2099$

Chrzan, Q. (2012). Pinterest: A review of social media's newest sweetheart. Engauge Insight Report. Retrieved from http://www. engauge.com/assets/pdf/Engauge-Pinterest.pdf

Coward, C., Caicedo, S., Rauch, H., \& Rodriguez Vega, N. (2014). Digital opportunities: Innovative ICT solutions for youth employment. International Telecommunication Union (ITU) Telecommunication Development Sector Report. Retrieved from http://www.itu.int/
en/ITU-D/Digital-Inclusion/Youth-and-Children/Documents/ YouthReport_2014.pdf

Duggan, M., \& Brenner, J. (2013). The Demographics of Social Media Users-2012. Pew Internet and American Life Report. Retrieved from http://www.pewinternet.org/Reports/2013/Socialmedia-users.asp $\mathrm{x}$

Ellison, N. B., Steinfield, C., \& Lampe, C. (2007). The benefits of Facebook "friends": exploring the relationship between college students' use of online social networks and social capital. Journal of Computer Mediated Communication, 12,1 143-1168.

Ellison N. B., Steinfield, C., \& Lampe C. (2011). Connection strategies: Social capital implications of Facebook-enabled communication practices, New Media and Society, 13(6), 873-892.

Ellison, N. B., Vitak, J., Gray, R., \& Lampe, C. (2007). Cultivating social resources on social network sites: Facebook relationship maintenance behaviors and their role in social capital processes. Journal of Computer-Mediated Communication, DOI: 10.1111/ jcc4.12078

Ferrari, A. (2012). Digital Competence in practice: An analysis of frameworks.

European Commission, Joint Research Centre Institute for Prospective Technological Studies Technical Reports. Retrieved from http://ftp.jrc.es/EURdoc/JRC68116.pdf

Gasser, U., Cortesi, S. C., Malik, M., \& Lee, A. (2012). Youth and Digital Media: From Credibility to Information Quality. SSRN Electronic Journal. Retrieved from http://papers.ssrn.com/sol3/ papers.cfm?abstract_id $=\mathbf{2 0 0 5 2 7 2}$

Hargittai, E., \& Litt, E. (2011). The tweet smell of celebrity success : Explaining variation in Twitter adoption among a diverse group of young adults. New Media \& Society, 13(5), 824-842.

ISTE (2014). ISTE Standards: Teachers. Retrieved from: http://www. iste.org/docs/pdfs/20-14_ISTE_Standards-T_PDF.pdf

Junco, R. (2012a). Too much face and not enough books: The relationship between multiple indices of Facebook use and academic performance. Computers in Human Behavior, 28(1), 187-198.

Junco, R. (2012b). The relationship between frequency of Facebook use, participation in Facebook activities, and student engagement. Computers \& Education, 58(1), 162-171.

Junco, R. (2013). Inequalities in Facebook use. Computers in Human Behavior, 29(6), 2328-2336.

Junco, R. (2014). Engaging Students through social media: Evidence based practices for use in student affairs. San Francisco, CA: Wiley/ Jossey-Bass.

Junco, R., Elavsky, C. M., \& Heiberger, G. (2012). Putting Twitter to the test: assessing outcomes for student collaboration, engagement, and success. British Journal of Educational Technology, 44(2), 273-287.

Junco, R., Heiberger, G., \& Loken, E. (2011). The effect of Twitter on college student engagement and grades. Journal of Computer Assisted Learning, 27(2), 119-132.

Muscanell, N. L., \& Guadagno, R. E. (2011). Make new friends or keep the old: Gender and personality differences in social networking use. Computers in Human Behavior, 28(1), 107-112.

Warschaver, M., Knobel, M., \& Stone, L. (2004). Technology and equity in schooling: Deconstructing the digital divide. Educational Policy, 18(4), 562-588.

Yu, A. Y., Tian, S. W., Vogel, D., \& Kwok, R. C.-W. (2010). Can learning be virtually boosted? An investigation of online social networking impacts. Computers \& Education, 55, 1495-1503.

Zhao, S. (2009). Teen adoption of MySpace and IM: Inner-city versus suburban differences. Cyberpsychology \& Behavior, 12 (1), 55-8. 


\section{On the Digital Path: New Experiences, Challenges, and Opportunities to Learn and Practice}

\author{
Gameli Adzaho \\ The Gamelian World Blog
}

\section{Introduction}

Being part of the first Digitally Connected symposium on youth and digital media, co-hosted by the Berkman Center for Internet and Society at Harvard University and UNICEF, was a rare privilege. I had the opportunity to tap into the insights of some of the world's leading thought leaders and practitioners in the youth and online media space. This has led me to reflect on my own "digital journey" and the influence of digital technologies on knowledge acquisition and skills development. This piece synthesises experiences, opportunities, and challenges of using digital media for learning, and examines their implications for our future. To cover a range of viewpoints, contributions from colleagues sourced through a Google Docs form have been included.

\section{Insights From the Symposium}

A standout issue during the three days of the Digitally Connected symposium was the global disparity in technology access mediated by factors such as geography, economics, gender, age, and disability. Although people in developing countries are typically disadvantaged, increasing numbers of young people are getting connected thanks to the mobile revolution. In Brazil, far more young people are online compared to adults. In fact, some teachers' unfamiliarity with technology, combined with the negative media depiction of digital tools, make schools feel threatened by children's access to technology. Consequently, restrictive school policies may be applied to limit access to devices while teachers are unable to integrate the use of technology in the classroom environment. How then do parents and teachers facilitate children's learning and safety in a digital environment? This is an old question for industrialized countries, which has become very important for developing countries as well. At the symposium, Professor Sonia Livingstone of the London School of Economics called for more research exploring how children interact with digital technology in the Global South, in order to drive future policy decisions. While this call was lauded, thoughts were expressed on the danger of generalizing regional experiences, with suggestions for more granular and contextual insights from various countries.

\section{Digital Technologies and Learning}

Ghanaian university students articulate four main uses of ICTs: finding information, discussing course materials, collaborating with colleagues, and publishing online. Outside the classroom, YouTube tutorials and Massive Online Open Courses (MOOCs) help learners pick up new skills at their own paces. This is common even among professionals. The Internet appears to be the central piece in the jigsaw. As Andres Lombana-Bermudez observed at the symposium, the global network allows us "to practice and develop collective intelligence," using tools such as search engines and publishing platforms. The above use cases demonstrate that digital tools are relevant to learning both inside and outside the classroom. This sentiment was shared by all the contributors at the Digitally Connected symposium.

I observed some of our students at Keta Senior High Technical School in Ghana use technology in the manner described above. However, the level of adoption seems to decline as one goes down the educational ladder. This is partly due to limited access to computers, mobile devices, and the Internet in schools. However, in these conditions, access to tools does not guarantee their proper usage by teachers and students. At first glance, it may seem that students are either unaware of the wealth of information they can access on platforms such as the Internet or lack the right research skills. Secondly, there appears to be a disconnect 
between available online content and relevance to the school syllabus. Additionally, unfamiliar language and/or presentation style of some websites may hinder basic understanding among young learners. The above observations also hold for primary and junior high schools notwithstanding the fact that ICT is a school subject at all levels of education. Interestingly, Ghanaian homemade YouTube dance videos uploaded by students evidence some content creation skills. The challenge for teachers and students is to turn this extracurricular hobby into learning opportunities. Currently, students tend to waste their study time on the wrong side of social media, putting them at risk of exposure to online pornography, scams, and cyberbullying. These issues and others need to be explored through extensive research.

Teachers' leadership is important at the pre-university level to help learners develop the right attitude towards technology. Popular uses of technology by Ghanaian secondary level teachers include finding updated information on the Internet, making and delivering presentations, and screening videos of important events or concepts. At Keta Senior High Technical School, one of the popular topics during the weekly "current affairs" series was on social media and the importance of digital literacy. Students also have the opportunity to expand their knowledge and skills through activities of ICT and robotics clubs in the school. Similar programs exist in other institutions but the efforts are not distributed as they could be.

\section{Government Policy and Programs}

It is the government's desire that through the deployment of ICT in education, the culture and practice of traditional memory-based learning will be transformed to education that stimulates the thinking and creativity necessary to meet the challenges of the 21 st century. (Ministry of Education, 2008, p. 4)

On the practical side, the Ghana Investment Fund for Electronic Communications (GIFEC) provides under-served schools with ICT equipment and Internet connection. Also, the Senior High Schools (SHS) connectivity project of the Ghana Education Service (GES) and its partners rolled out Internet services for 400 schools, developed a framework for ICT integration into the curriculum, and trained selected teachers to use educational technologies (Ghana Senior High Schools Internet Access Project, 2012). Finally, the "Better Ghana Laptop Project" distributes free laptops to students at various levels of education. While these initiatives are laudable, many schools still lack the needed technological and human resources.

\section{Broader Challenges}

Barriers to access, restrictive school regulations, teachers' low digital skills, misconceptions of the role of ICT, and a dearth in research are some of the limiting factors to technology integration explored so far. Authorities are faced with a great challenge: to balance children's need to access information against their need to be protected from possible dangers (M. Anim-Nyame, personal communication, May 21, 2014).

Another bottleneck plaguing Ghana, like many African countries, is weak infrastructure often manifested through erratic electricity supply and poor quality Internet connectivity outside urban centers. As the economy grows, demand continues to escalate, leaving many consumers frustrated. Without stable electricity and Internet, talk of using technology for education becomes irrelevant.

Finally, governments of developing economies, now more than ever, need to perfect the art of making shrewd financial investments, yielding maximum benefits, with their scarce financial resources. What are the trade-offs in emphasizing mobile learning over the more traditional e-learning approach? How do we spark innovation in the education space, involving the technology and business communities, without compromising this public good? How should low-income countries respond to the increasing danger of privatization and economic control of the Internet?

\section{Perspectives and the Way Forward}

Children first start learning by exploring their immediate environment and playing with peers. These interactions raise many questions answered through their own observations or by family members. 
With time, school takes over, introducing structure and rigidity. In the part of the world where I grew up, school de-emphasises the natural process of exploration and inquiry in favor of instructions and memorization. The teacher assumes a central position in this model, his or her competence and delivery delimits the knowledge the child imbibes. Opportunities for self-directed learning are limited to information in books and newspapers, which might not be easily understood by young learners. Thankfully, the interactive nature of using digital tools mimics how children learn naturally unlike the traditional school approach. Therefore, it is important to introduce digital literacy early.

Current technological developments make it possible to package educational content in interactive, multimedia formats and not just traditional text. Watching a video of "fertilization in flowering plants" enables students to easily grasp the process compared to cramming it from a book. Furthermore, class discussions can be extended beyond physical buildings with various web 2.0 social technologies (Gamelmag, 2013). For example, the Global Lab Ghana Facebook group is a growing community of students, teachers, and researchers sharing learning resources and discussing scientific concepts virtually. Students are encouraged to ask questions that arise from their learning and life experiences, opening them up to new insights and contacts not ordinarily available. There is great potential in using tools like Google Plus "hangouts" and Twitter hashtags to periodically involve subject matter experts with local classroom discussions (Gamelmag, 2013; Ripp, 2014). Networks like Global Lab have the potential to support students to develop along their independent tracks. MOOCs can also complement school lessons or be used to pursue personal interests such as programming, music, or foreign languages. The possibilities seem to be endless.

Learning should not be allowed to remain in today's abstracted state. Quoting MIT Media Lab director Joi Ito, David Sengeh rightly paraphrased during the symposium, "Education is what somebody does to you. Learning is what you do to yourself." In adopting digital tools, we must de-emphasise technology in favor of learning. Adoption of a problem-based learning (PBL) model favors knowledge acquisition through the completion of contextual tasks (Heick,
2012). Initiatives such as the Ashesi Robotics Experience (ARX, 2012), Robotics Inspired Science Education (RISE), Tech Needs Girls, and Jamlab help to develop critical problem-solving skills among children and engender a "maker mentality." Eyram Tawia and Lesley Kirinya, co-founders of one of Africa's first mobile gaming companies (Leti Arts), are inspiring examples of "learning by doing." Collaborative content creation among teachers and students is relevant for students both in terms of instantaneous and future learning. A good application of this idea is the recording of science practical videos that can be referenced in the future by the creators themselves or other students in resource-limited environments.

According to Viola Kup (personal communication, May 23, 2014), in addition to knowledge acquisition and development of hard skills, digital learning environments foster critical thinking, global awareness, and responsibility. This makes youth well-prepared to contribute to making policies that actually solve problems in society, given the opportunity. This can in turn advance learning. The approach should be focused on empowering youth to effect change and not just co-write policies that never get implemented.

There must be a rethinking of the role of technology in education delivery. The SHS connectivity project showcases fine examples of using digital media in the classroom, but effort needs to go into training many more teachers to use the right tools to teach their subjects. Crucially, outcomes of such projects must be evaluated as done in the Philippines (Lorenzo and Lorenzo, 2013) and elsewhere. The syllabi of certain subjects such as "Social Studies" must be modified to contain digital literacy topics like social networking, online safety, and privacy, to make students aware of the realities of the information age. A consideration for preventing students' abuse of gadgets in the school environment would be making special devices in which the hardware and software is specifically tailored to classroom learning. In addition, as proposed by Benjamin Odoi-Lartey (personal communication, May 21, 2014) and Elizabeth-Patterson (personal communication, May $23,2014)$, strong support should be given to the adoption of assistive technology to facilitate learning by the physically challenged and those with special learning needs. 
Digitally-literate youth are empowered to use their skills and awareness to tackle the challenges of their communities. A major problem in Accra, Ghana, is unsafe processing of electronic waste by very young, informal recyclers at Agbogbloshie. An innovative initiative started by DK Osseo-Asare and colleagues, Agbogbloshie Makerspace Project (AMP), aims to co-create digital resources for safe processing to enable recyclers reduce their risks of exposure to harmful substances (QAMP, 2014). A group of high school students with the right set of skills can be engaged to contribute to the development of these materials. Aside from solving a real life problem, the project presents the opportunity to learn aspects of many school subjects contextually and to develop critical leadership skills and values.

\section{Conclusion}

Digital technologies have become important mediators of formal and informal learning, accompanied by many benefits and risks. This article uses examples from the Ghanaian educational context, as well as insights from the Digitally Connected symposium, to explore experiences, challenges, and opportunities in using digital media tools. Aside from building infrastructure, government needs to expand training opportunities available to teachers while redesigning education to emphasise exploration and contextual learning enhanced by technology. Equipped with the right skills, learners should be encouraged to tackle problems in their communities. More research needs to be done to inform concrete policy decisions in less industrialized countries.

\section{References / Resources / Links}

ARX: The Ashesi Robotics Experience. (2012). Retrieved from http:// ashesi.edu.gh/arx.html

Gamelmag. (2013, November 5). Harnessing the Power of Digital Technology for Education in Ghana [Blog post]. Retrieved from http://gamelmag.blogspot.com/2013/11/harnessing-power-ofdigital-technology.html

Ghana Senior High Schools Internet Access Project. (2012, November). Retrieved from: http://www.gesci.org/ghana-seniorhigh-schools-internet-access-project.html

Heick, T. (2012, November 20).The Inside-Out School: A 21st Century Learning Model [Blog post]. Retrieved from http://www. teachthought.com/learning/inside-out-school-21st-centurylearning-model

Lorenzo, A.R. and Lorenzo, B.U. (2013). Bridging the Digital Divide among Public High School

Teachers: An Adopt-a-school Experience. Procedia - Social and Behavioral Sciences, 103 (2013), 190 - 199. Retrieved from http:// www.sciencedirect.com/science/article/pii/S1877042813037713

Ministry of Education (2008). Ghana ICT in Education Policy. Retrieved from http://www.moe.gov.gh/moe/docs/ICT\%20in\%20 Education\%20policy_NOV\%202008.pdf

QAMP. (2014). Project. Retrieved from http://qamp.net/ projecthttp://qamp.net/project

Ripp, P. (2014, May 22). Why My Students Are Connected [Blog post]. Retrieved from http://pernillesripp.com/2014/05/22/whymy-students-are-connected

Acknowledgement: I am indebted to Benjamin Odoi-Lartey, Michael Anim-Adjei, Akaliza Keza Gara, Nnenna Nwakanma, Nina Chachu, Elizabeth Patterson, Viola Kup and Andres LombanaBermudez for sharing their perspectives on the topic, and thus making it possible for me to cover other viewpoints in this write-up. 


\title{
Building a Global Alliance for Partnerships on Youth and Digital Literacy
}

\author{
Chido Onumah \\ African Centre for Media \& Information Literacy, Abuja, Nigeria \\ Doctoral Candidate, Autonomous University of Barcelona, Spain
}

\section{Introduction}

Every minute, every hour, young people around the world are inundated with information through various digital media platforms. Students and Youth are spending more and more time online than ever before, largely due to increasing accessibility via smartphones, tablets, computers and other technological devices.

While these platforms and devices are important, it is equally important that young people have to have a critical appreciation of the use and impact of these digital platforms on their lives. Digital literacy is the key that unlocks the creative power of young people to appreciate and effectively use digital media. It is a citizenship skill vital to democracy.

\section{"Digitally Connected"}

As a result, it was with great enthusiasm that I attended the Digitally Connected symposium at Harvard University co-hosted by the Berkman Center for Internet \& Society and UNICEF from April 28-30, 2014.

For researchers, educators, students, journalists, media and technology activists, and others who work either directly or indirectly with young people, the symposium was of great interest and very timely.

The focus of this historic conference was on the importance, use, and impact of digital media on youth around the globe. The conference explored the role youth play in the rapidly changing technological world and what can be done to put youth issues on the global agenda using media and information and communications technology (ICT).

\section{African Centre for Media Information \& Literacy}

Participating in the symposium as a representative for the African Centre for Media \& Information
Literacy (AFRICMIL) was quite an enriching experience. It presented an opportunity to build on a proposed project — the MIDLO Project — that seeks to create conditions that promote sustainable digital media literacy in Nigeria.

AFRICMIL is a Nigerian non-profit organization dedicated to media, information and digital literacy research, training and advocacy. The organization was established in July of 2008 following the resolution of the first Africa Media Literacy Conference in Abuja, Nigeria, organized by the Youth Media and Communication Initiative (YMCl) in conjunction with British Council, Nigeria, and the National Film \& Video Censors Board (NFVCB).

Since 2008, AFRICMIL has been at the forefront of promoting media, information and digital literacy in Nigeria. The aim of AFRICMIL is to train citizens students, youth, teachers, and others - to use media, information, and digital literacy skills as agents for social mobilization, social change, and intercultural dialogue. Additionally, AFRICMIL aims to develop citizens' capacity for effective communication and self-expression so that they can positively impact their schools, communities, and society as a whole.

\section{MIDLO Project}

AFRICMIL developed the MIDLO Project in recognition of the roles media, information and digital literacy play in the promotion of participatory democracy and pluralism, freedom of expression, open society, social and economic development, intercultural dialogue and active global citizenship.

MIDLO will build on the broad objectives of AFRICMIL, which include the promotion of media, information, digital and film literacy, media education, and intercultural dialogue amongst students and youth.

MIDLO aims to be a digital hub and observatory for civic participation and intercultural dialogue for teachers, students, social media activists, bloggers, 
young journalists, reporters, and all other individuals interested in understanding the use and impact social and digital media in Africa.

Among other things, MIDLO shall engage in the following activities:

1 Provide media, information and digital literacy training for teachers and students;

2 Research and advocacy of media, information, and digital literacy;

3 Act as a clearing house for youth and young journalists on media, information and digital literacy, and intercultural dialogue;

4 Monitor and make available data related to media, information, and digital literacy in Nigeria;

5 Liaise with media, information, and digital literacy initiatives across Africa to promote the MIDLO experience;

\section{Building a Global Alliance on Youth and Digital Legacy}

New media and information technologies, while offering greater opportunities for new types of citizens' engagement, centered on freedoms and eradicating inequalities, also give rise to issues of safety, security, and privacy. They further create tension between the need to empower or to protect citizens as well as tension between global and local cultural interests that threatens to curtail the free expression and appreciation of cultural diversity, multilingualism, and pluralism (Grizzle, A. and others: 2013).

Considering the above, it is clear that civil society needs to mobilize human and material resources, leverage capacities, and harmonize skills and competencies to strengthen and build consensus around a global platform on youth and digital literacy if we are to take advantage of the benefits of digital media.

The goal of such a platform is to help create conditions that promote a global digital literacy movement by bringing together government agencies, institutions, researchers, youth, media experts, and development partners in the fields of digital media, education, journalism, communication, and youth development.

This global platform on youth and digital literacy can help galvanize the debate on the impact of ICT on young people and the creation of policy and strategy guidelines on digital literacy that various countries can adapt. Additionally, it can help facilitate global mapping of digital literacy initiatives, as well as explore the integration of digital literacy into secondary schools and teacher training curriculum in different regions of the world.

The global platform on youth and digital literacy will be a network of educators, students, youth, experts, professionals, journalists, media-makers, parents, activists, and other citizens joined as an independent, nonprofit educational coalition that can inspire active civic participation using digital media.

\section{Conclusion}

The Digitally Connected symposium was a great opportunity for digital literacy enthusiasts to come together to discuss the endless potential of digital technologies to empower youth around the world. These enthusiasts are the fulcrum around which we can hinge a global advocacy network on youth and digital literacy.

The global platform on youth and digital literacy can create a functional platform for supporting and engaging civil society for effective and constructive inputs in the digital literacy debate; it can strengthen the capacity of CSOs for research, intervention, collaboration, and consensus on a global digital literacy agenda.

Additionally, through thematic, national, continental and regional forums, the global platform on youth and digital literacy can encourage sharing of best practices, knowledge, and skills. This platform can also monitor, research, and document the impact of digital media on issues such as youth health, lifestyle, drug abuse, violence, and religious intolerance.

\section{References / Resources / Links}

\footnotetext{
African Centre for Media \& Information Literacy. http://www.africmil.org/
}

DCMF Junior Reporters. http://junior-reporters.org/tag/dcmf/ Global Young Journalists http://youngjournalists.org

Grizzle, A., Moore, P., Dezuanni, M., Asthana, S., Wilson, C., Banda, F., \& Onumah, C. (2013). Media and information policy and strategy guidelines. Paris: UNESCO.

Onumah, C. (2004). Making your voice heard: A media toolkit for children \& youth. Lagos: Mace Books.

The Nigerian National Information Technology Policy, ICT4D Plan (March 9, 2012). Retrieved from http://www.jidaw.com/policy.html 


\section{Local Games, Local Content, Local Applications On Mobile: ICTs for Informal Learning in Rural Africa}

\author{
Maletsabisa Molapo \\ University of Cape Town
}

Imagine Taole, a 12-year-old boy living in Kolabocha, a rural village in the highlands of Lesotho. Taole has never watched television, he has never been on a motor vehicle, he has never seen a multi-story building, he has never ridden a bicycle, but he as an idea of what a bicycle looks like, from the pictures he saw in a textbook at school. There is no electricity in Taole's home, or in any home in his village, but there are three recently installed solar power systems in his village - at his primary school, at a local store, and at the village clinic. Taole's mother owns a Nokia C2-01, which she bought two years ago when she worked the "fato-fato," a temporary manual labor job on a government-funded community project. This device, the only mobile phone in his family of seven, is the closest Taole has ever been to anything digital. The phone is not always on, because sometimes when the battery runs out, his mother does not have the M5 (\$0.50) to charge it at the local store. But Taole is brilliant and curious; he is the kind of person who fixes radio sets for everyone in the village — the one that the adults in the village call to "fix" their mobile phones when they have taken up strange settings.

Low-resource regions like Kolabocha, which make up the huge rural proportion of many African countries, are home to thousands of children like Taole. As the global community discusses the role of information and communications technologies (ICTs) in learning, the unique needs of children in similar situations to Taole, too, must make it to the drawing board. In this essay, written in reflection following the Digitally Connected symposium, I discuss the needs of children like Taole, regarding the use of ICTs in supporting informal, outside-the-classroom learning.

Research on informal learning through technology continues to demonstrate the benefits of allowing children and youth to learn independently with educational technologies, such as educational games, outside the classroom. Gaming as a learning technique is undoubtedly universal-all children play, all children can learn through games-but the contexts in which children grow up, and the experiences of their daily lives, are definitely not universal.

Children like Taole are hard-fought to find digital games and lessons in their own languages or that reflect their unique cultural values. When Taole plays the preloaded games on his mother's phone, he has to imagine many parameters of the games and assume the meanings of the games' elements - elements that are foreign to his experience, but familiar to the game designers. In places like Kolabocha, boys compete over whose sheep and cattle look better fed, or whose garden has the better crops, and girls compete over who can gather the most firewood, or who can make the most beautiful cloth dolls. Children in these regions deserve relatable digital games/digital lessons that capture these local experiences, and are designed to fit their local cultures and match their levels of exposure, without limiting their thinking and innovation to the rural setting alone.

Even with current, great efforts by African governments, the infrastructural challenges that face Kolabocha and similar African villages will take years to resolve; so we, rural technology designers, should be thinking of how to work within the existing limitations. The reality is, many children still grow up in areas where there is no electric power, and many families (and schools) still cannot afford Internet connection costs, or desktop/tablet computers. The only computing device many youth from rural areas will have access to in the next several years is the mobile phone. If Taole will read e-books, or if he will play educational games, or if he will watch informational videos, it will be on a mobile handset, probably on an offline platform. So beyond the challenge of creating locally relevant educational content and games, is the challenge to make the 
content available on mobile phones, and accessible at low/no data costs.

It is also worth noting that not all children in Taole's world have been (or will go) to high school, or will even complete primary school. Still, uneducated youth can benefit from informal learning on the mobile phone. In the 2014 "Reading in The Mobile Era Report," UNESCO estimates that 123 million youth in the world cannot read or write. Currently, there is little evidence of the presence of locally relevant mobile content and applications targeted at the rural youth with little literacy.

Through our "Bophelo Haeso" project in Lesotho, we created an easy-to-use computer application that local authorities and professionals who serve rural communities can use to independently create mobile multimedia content for the rural public. For example, nurses use the software to create videos that address community-specific health knowledge gaps and misconceptions. The videos are distributed via Bluetooth to community health workers and patients when they visit the community clinics. The same software is also used by an NGO that recruits low literate youth from villages, equips them with driving skills, and helps them find jobs as drivers of public transport. The driving school instructor at the NGO creates digital driving lessons, and young men, who are unable to read written driving manuals, can watch the instructional videos on their $\$ 40$ mobile phones to prepare for their license tests.

I draw one major lesson from this project - it should not be difficult for local authorities like nurses, teachers, driving school instructors, support group leaders, etc., to create mobile digital content for their local communities. We must shift the rural technology landscape from its current configuration: where before any new digital content or application is rolled out, there must be outside intervention. There is a wealth of knowledge, experience, and wisdom within rural Africa, which can be disseminated to the youth and children in the form of mobile multimedia content, applications, and games, and we must be thinking of building technologies that empower communities to independently create their own mobile games, digital stories, and multimedia content.
During the cluster discussions at the Digitally Connected symposium, we realized that, while games that address local issues and teach locally relevant lessons lead to great educational outcomes, it is still not easy for a typical professional (teacher, public health nurse, social worker, agricultural extension officer) to create a game for mobile phones. We asked: What if it were easy to create educational games for feature phones? We envisaged a platform, perhaps one that could run on desktops, tablets, or even smart phones, that would allow the easy creation of locally relevant games in an easy-to-use, drag-and-drop type of editor. We imagined what the benefits would be, if local authorities and professionals (who are not highly proficient computer users, but are the best people to identify and address local information needs) had the opportunity to interact with such a tool, to create and distribute mobile games and interactive lessons to their respective target groups.

This, for me, is the ultimate dream for informal learning in rural Africa: local applications, local games, and local multimedia content on mobile handsets, produced locally, with a degree of independence, by local authorities and professionals, addressing local information and education needs.

\section{References / Resources / Links}

Lifeline Products, educational devices that disseminate educational content where there is no power: http://www. lifelinetrading.net/products

Moraba, a locally relevant educational game for Southern Africa: http://www.afroes.com/moraba/

The Bophelo Haeso Project, a blended multimedia content creation and distribution system in rural Lesotho:

http://maletsabisam.me/research and coming soon, http://bophelohaeso.org/

UNESCO (2014). Reading in the Mobile Era. Retrieved from http:// www.unesco.org/new/en/unesco/themes/icts $/ \mathrm{m} 4 \mathrm{ed} / \mathrm{mobile-}$ reading/reading-in-the-mobile-era/

ZEduPad, a tablet with thousands of local curriculum-based lessons for primary school learners in Zambia: http://www.zedupad.com/

Zimbile, a site that allows anyone to easily create a mobile website, built in South Africa: http://www.zimbile.com/ 
CHAPTER 5

Creativity 


\title{
Connecting Creativity and Coding: Creativity in the Context of Skills, Literacy, and Learning
}

\author{
Ricarose Roque \\ MIT Media Lab
}

"Should everyone learn to code?"

Someone posed this question to me at a recent conference I attended. I was sharing my research with Scratch, a programming language that allows young people to create their own interactive media such as games, animations, and stories. I hesitated before answering. A similar question was asked during the Digitally Connected symposium at the "Skills, Digital Literacy, and Cultures of Learning" breakout session, when someone asked, "Are there some things that everyone should learn?"

I hesitated because I wondered if this question "should everyone learn to code?" - should be the first question we're asking. I want to reframe these questions: Why would someone want to learn to code? And how can it be personally meaningful to everyone - when everyone comes from different backgrounds, ages, and interests?

In the last decade, as technology has increasingly mediated the ways in which people connect, engage, and learn, coding has gained recognition and momentum. Rather than only interacting with technology through playing games or using mobile apps, people can make their own technology coding allows them to make apps or media that they and others can use and interact with. Many people working in industry, policy, and education today highlight coding as an important literacy to develop. Code.org, an initiative backed by many industry leaders, aims to spread coding to all schools. Technology companies are emphasizing the employment opportunities that exist for a workforce with relevant coding skills. Policy makers are mandating that computer science and coding become part of the K-12 curriculum in order to raise innovation and global competitiveness. Thought leaders are also pointing to the increasingly digital and networked nature of our society. As people become more dependent on technology, they must not only use but also understand the inner workings and biases of technologies; it is increasingly a case of "program or be programmed" (Rushkoff, 2011).

Educators and researchers also highlight that learning to code teaches mathematical and computational thinking such as sequencing, variables, and debugging. And, as learners build projects with code, they can practice breaking down complex ideas into simpler ones, problem solving, and reusing and building on top of others' ideas. These are skills and practices that are valuable to anyone, regardless of whether they decide to pursue careers in computing (Wing, 2006; Brennan \& Resnick, 2012).

While jobs, economic competitiveness, and computational thinking are important motivations for learning to code, I want to highlight a motivation more personal and more fundamental: being creative and expressing what you care about. And this motivation can also be an engaging entry point for people from many backgrounds and interests.

When I was 16 years old, I fell in love with coding. And, while I happened to be taking my first course on coding called Advanced Placement Computer Science, it wasn't because of this course that I fell in love. In fact, my experience with coding in that class created multiple reasons to give up on it all together. Being a total newcomer, I was discouraged when my classmates bragged about how quickly they completed the exercises, while I struggled to make sense of all the different constructs like looping, variables, and pointers in C++ (I didn't know at the time that many had already had some coding experience at home). And our assignments to sort numbers and make calculators were not exactly thrilling to me.

However, around that time a friend introduced me to a book called Maeda@Media, which shared the 
art and philosophy of John Maeda, who was then a professor at the MIT Media Lab. What I found so compelling was how the art featured in the book was created through coding. By coding patterns to draw, transform, and cross the screen in whichever sequence I desired, I found I could be as or even more expressive than I had been with pencils, markers, and paper. And as I became more curious and began to look up resources online, I found others who had similar interests, people who I could look up to and also learn from. They shared their work and their code, which I examined and remixed myself.

For me, learning to code was not the prime motivator, but rather, a means for me to pursue my interest in new ways. Today, we see young people doing just this with coding in the Scratch online community. Scratch (http://scratch.mit.edu) is a programming language in which people can create their own interactive media such as stories, art, and games (Resnick et al, 2009). Developed by the Lifelong Kindergarten research group directed by Mitchel Resnick at the MIT Media Lab, Scratch has become a dynamic community since it launched in 2007. Young people from all over the world, who are primarily between the ages of 8 and 16, have created and shared over 6 million projects.

For example, one young member of the Scratch online community with the username NightCat wanted a way to animate her artwork featuring cats. Not just ordinary cats, but cats inspired by Erin Hunter's Warrior Cats book series. When she began sharing her projects, she started getting comments from other Scratchers complimenting her art and animation. Soon people started asking her to share how she created her cats and animations, and she created tutorial projects showing her process step by step.

At the same time, she connected with a group of Scratchers who also loved the Warrior Cats series. Together, they created a gallery of projects on the Scratch website that featured their different adaptations of characters from the series. They also role-played their cat characters in the gallery comments, improvising stories about the characters in their imagined world.
NightCat's experiences are just one of the many ways young people have created and connected with others in the community. Scratchers have created a diverse range of projects that include music videos visually expressing popular music, interactive holiday cards for their friends and family, musical instruments, informational projects raising awareness about animal testing, biology simulations, newspapers based on their social network, slideshows of their favorite things, and adaptations of popular mobile games. Additionally, they have connected to each other in many ways, including discussing projects in the forums, leaving constructive comments about other's work, and building on ideas by remixing pre-existing projects. Some have even formed collaborative groups to create more sophisticated projects that go beyond what one person could have done on their own.

The experiences of these Scratchers as well as my own personal experience illustrate how pursuing what you care about can be both an entry point into coding as well as a reason to learn to code. And when people engage in coding to design, build, and express what they care about, what emerges will represent their diverse interests, needs, and backgrounds.

With this in mind, I return to my earlier questions: Why would someone want to learn to code? And how can coding be personally meaningful to everyone when everyone comes from different backgrounds, ages, and interests? The reasons I described earlier (access to job opportunities, contributing to economic competitiveness, and more importantly, engaging in powerful learning opportunities that have use beyond computing contexts) are all valuable motivations to learn to code. I do not intend to dismiss them in this essay. Rather, I mean to highlight another reason that is both a motivation and an approach to engage a variety of people in personally meaningful ways: leveraging coding to express their creativity and invent things that connects to their lives. Everybody should have such abilities to get their voice and ideas out in the world. And opportunities with learning and personal trajectories will follow. 
To make coding meaningful, we need to make coding personal and social. It needs to enable people to create and express their experiences, ideas, and interests. By making coding social, we allow people to connect to others with similar interests - people who can help spark ideas, give feedback, share resources, or even collaborate on the project. When coding is personal and social, people will have their own motivations and social contexts to learn and sustain their engagement. More importantly, people can express their creative potential and connect with communities through shared interests, historical traditions, and cultural identities. As we continue discussions about the nature of digital literacy, these are abilities and capacities that will enable people to participate in and contribute their voices and innovations to a rapidly changing digital society.

\section{References / Resources / Links}

Brennan, K., \& Resnick, M. (2012). New frameworks for studying and assessing the development of computational thinking. Presented at the American Education Researchers Association, Vancouver, Canada.

Resnick, M., Silverman, B., Kafai, Y., Maloney, J., MonroyHernández, A., Rusk, N., Eastmond, E., Brennan, K., Millner, A., Rosenbaum, E., \& Silver, J. (2009). Scratch: Programming for all. Communications of the ACM, 52, 60.

Rushkoff, D. (2011). Program or be programmed: Ten commands for the digital age. Berkeley, CA: Soft Skull Press.

Wing, J. M. (2006). Computational thinking. Communications of the ACM, 49(3), 33-35. 


\section{Mapping Danger, Making Connections}

\author{
Matthew Battles \\ metaLAB at Harvard \\ Sarah Newman \\ metaLAB at Harvard \\ Luca Simeone \\ metaLAB at Harvard
}

Tables and chairs, markers and glve, the slicing afternoon light of Cambridge in early Spring there's a hush fallen at NuVu Studio, an innovation hub for young people in Central Square, bracketed by the hum of a laser printer and the snick, snick, snick of scissors. Teens cluster here and there beneath the high ceilings, some sitting at tables, other propped on hands and knees on the floor, delicately constructing collages from hundreds of printed photographs. The images they're piecing together chart the everyday weirdness of the city: scattered litter, cracked walls and sodden streets, a gallery of tired and beautifully broken faces. Patiently, with X-ACTO blades and glve, they're arranging these pictures together into expressive portraits of life in Central Square - maps of another kind, charting the evanescent geography of danger and curiosity in the city.

A few weeks earlier, in air-conditioned spaces far away in the sunny, broiling-hot, metropolitan Emirate of Abu Dhabi, another clutch of young people had labored over maps of danger of their own. Students at New York University's (NYU) Abu Dhabi campus, representing a global cohort of incoming freshmen, used digital imagery to express a wide-ranging geography of danger: bodies of animals and computer viruses, discarded shoes and cigarette packs, the charged prospect of a kiss. Having just arrived from around the world, these students brought a variety of ideas of danger (and dangerous ideas) to a new and different place, one with its own highly specific notions of danger, risk, and wrong. Their work, in the form of digital files printed and distributed, enlivened the discussion that later took place in chilly Massachusetts.
These interwoven acts of making and encountering took place in the context of Media Art Knowledge Engaged (MAKE), a project fostered by a group of artists and researchers affiliated with Harvard, the Massachusetts Institute of Technology (MIT) and a host of global partners, who together created a series of workshops to explore themes such as copyright laws, privacy, danger, and gender equality. Their interest in fostering this set of encounters was piqued during the planning phase of the Digitally Connected symposium, which unfolded at the Berkman Center for Internet \& Society over the course of the academic year 2013-14. The symposium's goal was a comprehensive one: "to map and explore the global state of relevant research and practice, share and discuss insights and ideas from the developing and industrialized world, and encourage collaboration between participants across regions and continents." (www. digitallyconnected.org) In the fall of 2013, several of us (including the authors of this essay) started thinking about ways to bring those goals to life in an engaged way, collaborating with young people around the world by employing art, media, and digital skills.

In dialogue with the symposium's organizers, a group came together around the idea of shaping a series of workshops, hosted by youth arts and media programs in the Boston area in partnership with sites around the world. The coordinating team included the following: Matthew Battles (metaLAB), Dalida Maria Benfield (Berkman Center); Giuliana Cucinelli (MIT); Tim Davies (Berkman Center); Primavera de Filippi (Berkman Center); Sarah Newman (metaLAB); and Luca Simeone (metaLAB). Meeting frequently throughout the academic year, this group collectively forged a vocabulary for collaborative 
A

; at gry ingosistis

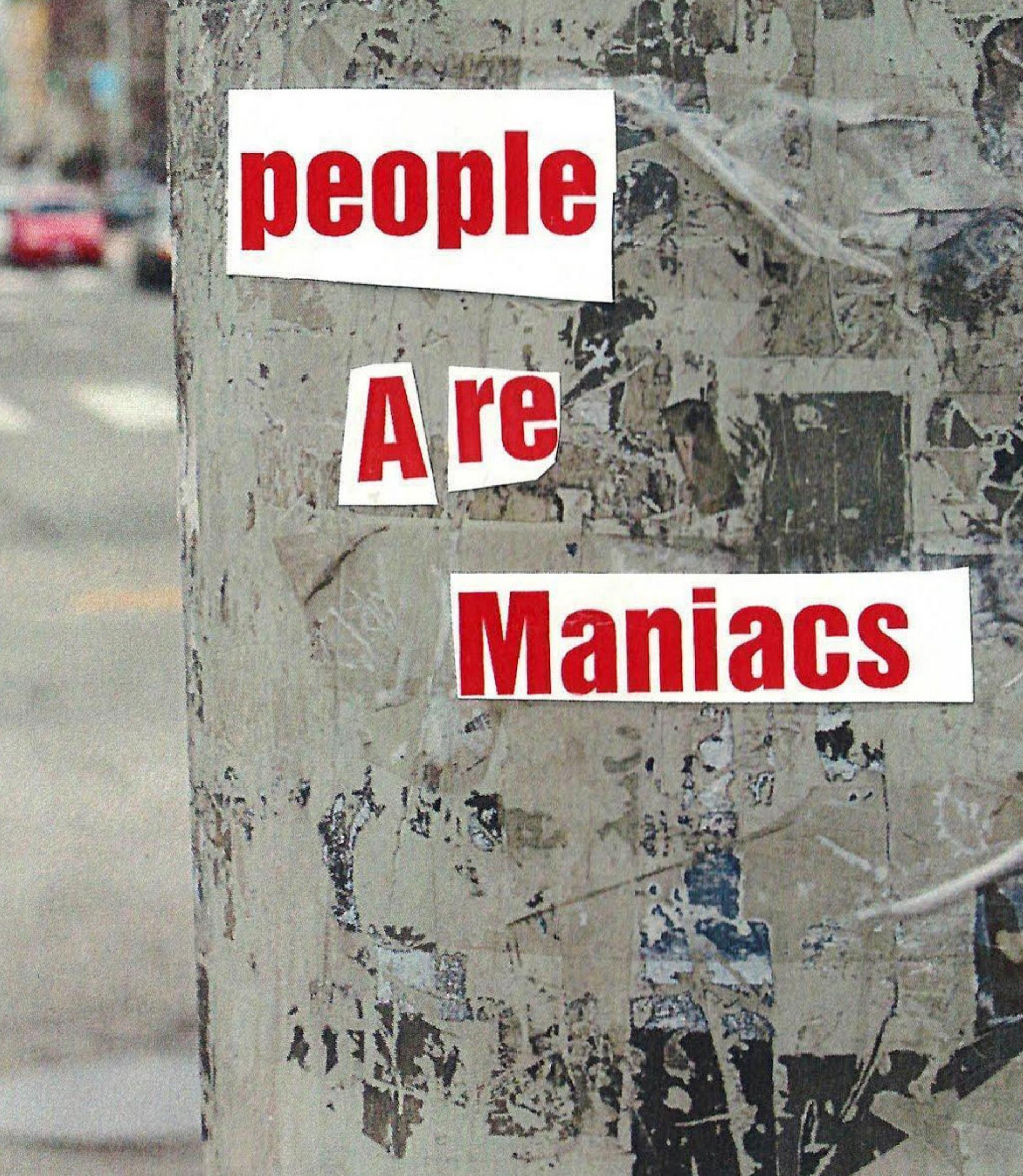


work, sought global partners, and settled on a design for the program as a whole: paired workshops in local and global sites, with each fostering a dialogue through art- and media-making, whose work would come together in a pop-up exhibition staged at the Digitally Connected symposium at Harvard in April,

2014. Together, we also settled on the name for the initiative as a whole - MAKE - an affirmation of the emphasis of the project on crafting, making, and enskillment in digital media and the materiality of art, and (retrospectively) an acronym, standing for Media Art Knowledge Engaged.

MAKE workshops have since been hosted in several cities (including Bogotá, Colombia; Quito, Ecuador; and Abu Dhabi, UAE), where young people have had the opportunity not only to work in local groups, but also to share their experiences with their peers at mirroring sites around the globe. These workshops consisted of three clusters, each facilitated by Berkman Center affiliates with colleagues from around the world, and each focused on a particular theme and set of art-making practices and media methodologies. The Public Domain Remix, which took place in Somerville, MA and then Dakar, Senegal, encouraged people to remix, use, and reuse public domain works in a creative way by encouraging the shift from one medium to another (such as illustrating a song, or creating a sculpture out of a story). Mapping Networks, Making Worlds, in Boston and then in Bogotà, Colombia and Quito, Ecuador, engaged children and youth in an exercise of critically mapping their communication networks, working to understand with whom they communicate using information communication technologies, as both transmitters and receivers of information. Mapping Danger, located in Cambridge, MA and NYU Abu Dhabi, UAE, explored how photography can inform and shape our understandings of danger.

The initial impulse to map ideas of danger through photography and collage belonged to one of the authors of the present paper, Sarah Newman, a fellow at metaLAB at Harvard, a Berkman-affiliated research group exploring technology's changing roles in the arts and humanities. Acknowledging that the meaning of "danger" differs with gender, class, and culture, it seemed a charged and fruitful focus for a global dialogue through art. Sarah was joined by the other authors of this paper: Matthew Battles, associate director of metaLAB, and Luca Simeone, another metaLAB fellow, both with experience in collaborative design processes.

In seeking a partner internationally, they turned to Mo Ogrodnik, a filmmaker, NYU professor, and the Founder/Director of FIND, a hybrid cultural lab dedicated to creating a transnational portrait of the UAE through the lens of artists, scholars and technologists. Ogrodnik and her colleagues agreed to host a parallel instance of the "Mapping Danger" workshop tuned to the unique setting of NYU Abu Dhabi. Ogrodnik and her colleagues contributed richly to the process of shaping a workshop to the needs and capacities of their students, keeping in mind the fraught cultural and political context of the Emirates, both for Emiratis and students from abroad. At the Nuvu Studio in Cambridge, high-school age students from that program, as well as the City Studio Program at the School of the Museum of Fine Arts, Boston, and the Boston Arts Academy, gathered on Saturday, April 5 in Central Square. Over the course of the day, they surveyed the practices of a variety of dynamic visual artists whose photographic work courts widely-defined notions of danger, and discussed their own notions of the dangerous, from the fanciful (lions, alien invaders) to the tangible (illness, accident, and crime). Then, they went out into the diverse, sometimes-challenging urban fabric of Cambridge's Central Square to find their own images of danger. Taking hundreds of photos, the students explored the specters of homelessness, gender disparity, traffic, pollution, and surveillance through imagery they gathered on the streets. In the balance of the workshop, they combined those materials into large, expressive collages. They also looked at the work produced by Mo Ogrodnik's students in Abu Dhabi. An older cohort, with skill in digital art-making, Ogrodnik's students had produced work that was charged and complex, expressing a range of encounters with danger as it arises in the context of gender, travel, and unbending cultural mores. With her students, Ogrodnik had also designed a work of art that took the form of a survey posing questions on the nature of the dangerous, which they distributed on the buses that carry commuting NYU students and staff in Abu Dhabi. 

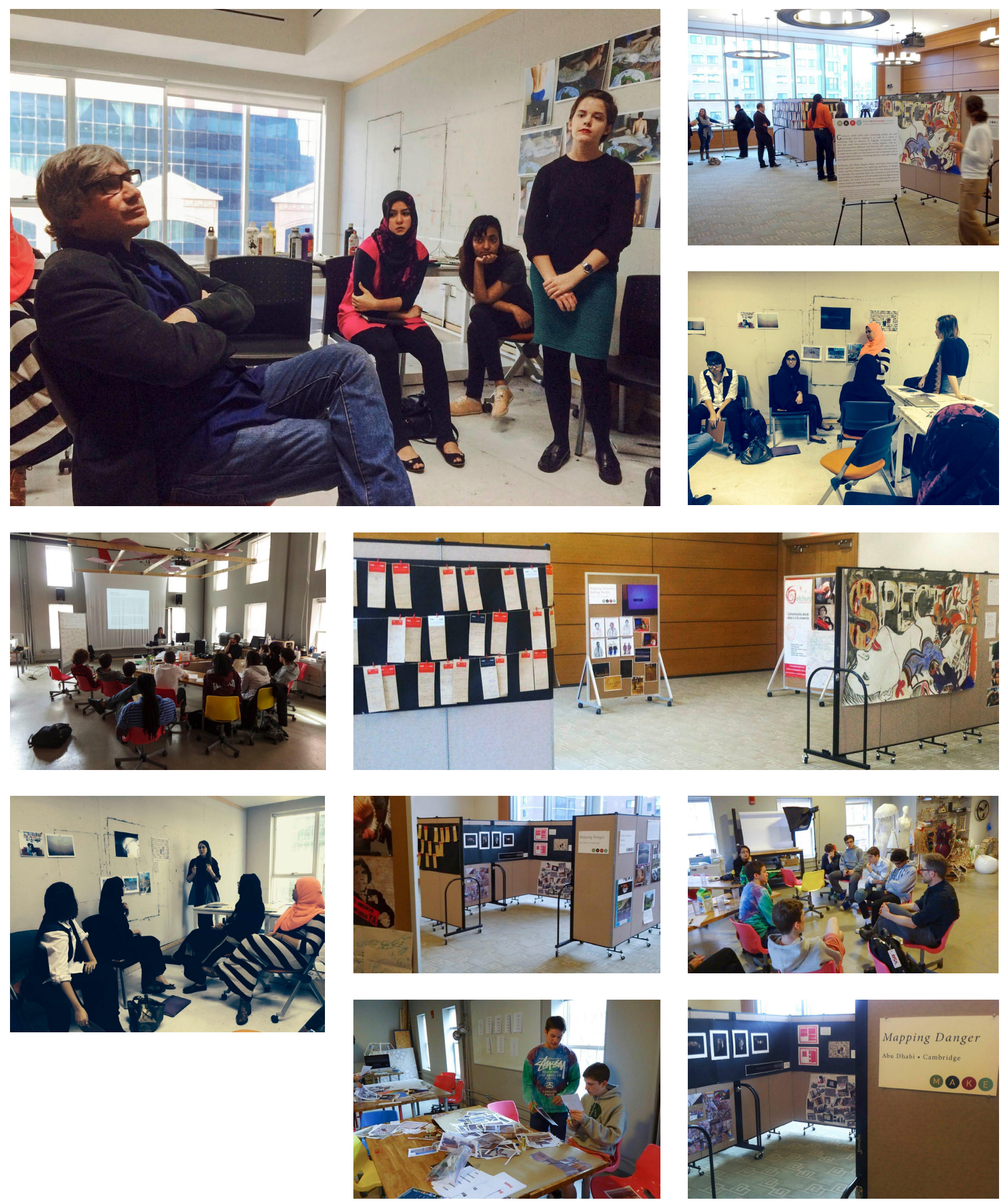


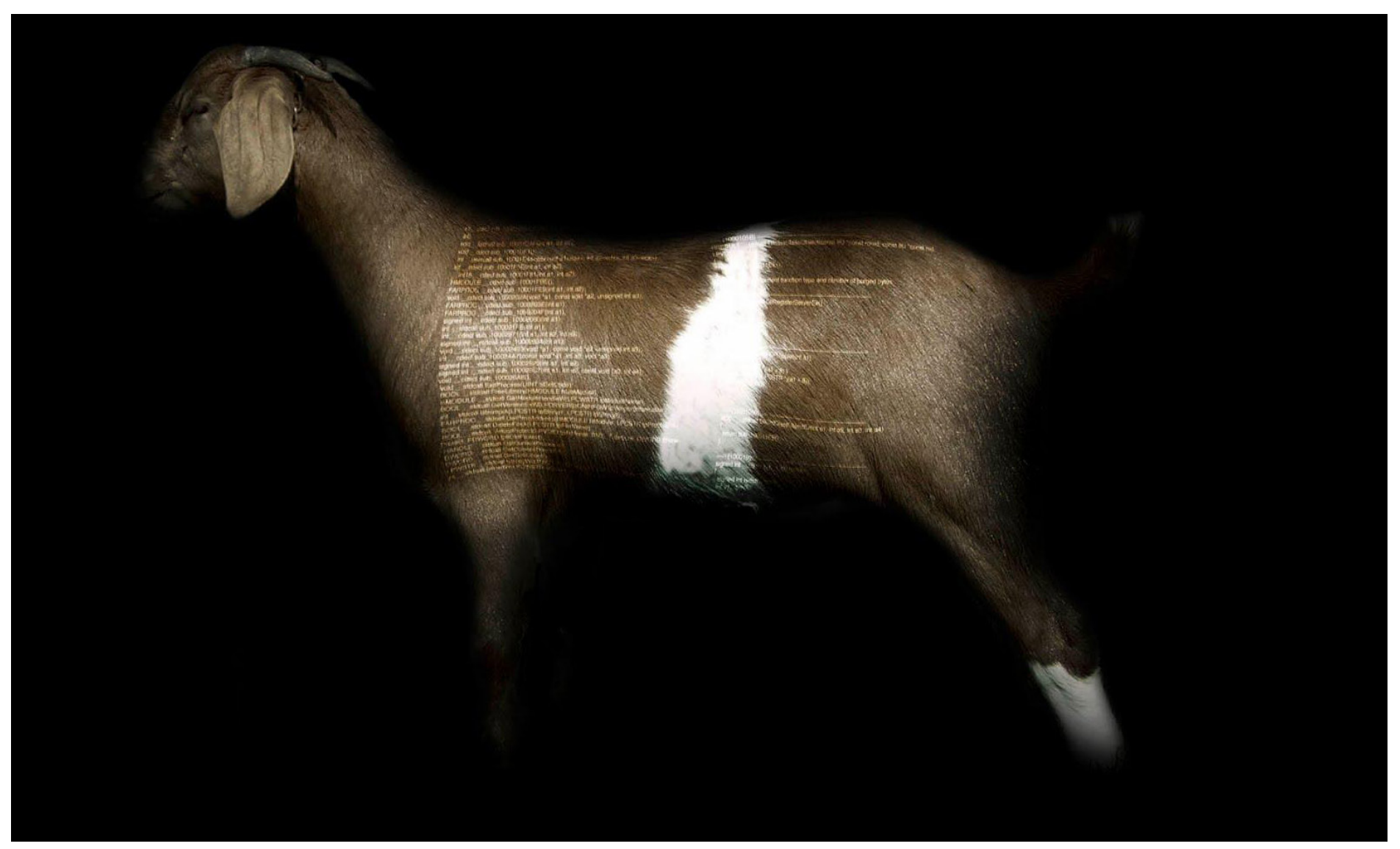

At the symposium at Harvard Law School, co-hosted by UNICEF and the Berkman Center, these works finally came together with those produced by the other workshop teams, taking the form of a pop-up exhibition. This material culmination was a crucial part of the MAKE initiative, allowing local participants to come together (with Mo Ogrodnik, who traveled from the Emirates to participate in the symposium, and who contributed instrumentally to the design and installation of the show). There, the theme of "Mapping Danger" came into dialogue with the themes of the other workshops, whose organizers and participants all contributed to the impact and outcome of the show.

Ultimately, the exhibition became a conduit for injecting the voice and vision of young people themselves at the Digitally Connected symposium. Through the exhibition itself and a reception held for the young artists during the conference, participants had the chance to explore a couple of key conjectures: first, that technical enskillment is never a neutral thing, but is always bound up in civic engagement, social and economic empowerment, and cultural attitudes toward work and value; and second, that any pedagogy that seeks to build skills and knowledge also models social norms and ideals. Art and design, which represent fundamental modes of knowledge-production and enskillment, also entail networks of social relations that can empower students not only to express themselves, but also to forge meaningful ties with others. With these assertions in mind, MAKE's organizers designed encounters with collaborative art and design work that prioritized affirmative, reflective sociality and sensitivity to global connectedness and difference. Thus the idea was born to foster a series of artmaking workshops that not only focused on topics of vital interest to digitally-connected youth, but also offered young people the chance to make, share, and reflect upon work in tandem with peers in geographically-distant sites around the world.

MAKE greatly benefited from the support of: UNICEF, The Berkman Center for Internet \& Society, Open Knowledge Foundation France, Wikimedia France, Parts and Crafts, NYUAD, NuVu Studio, Univ. Distrital Francisco Jose de Caldas, El Churo Colectivo, City Studio program, School of the Museum of Fine Arts, British School Boston, and Kër Thiossane. 

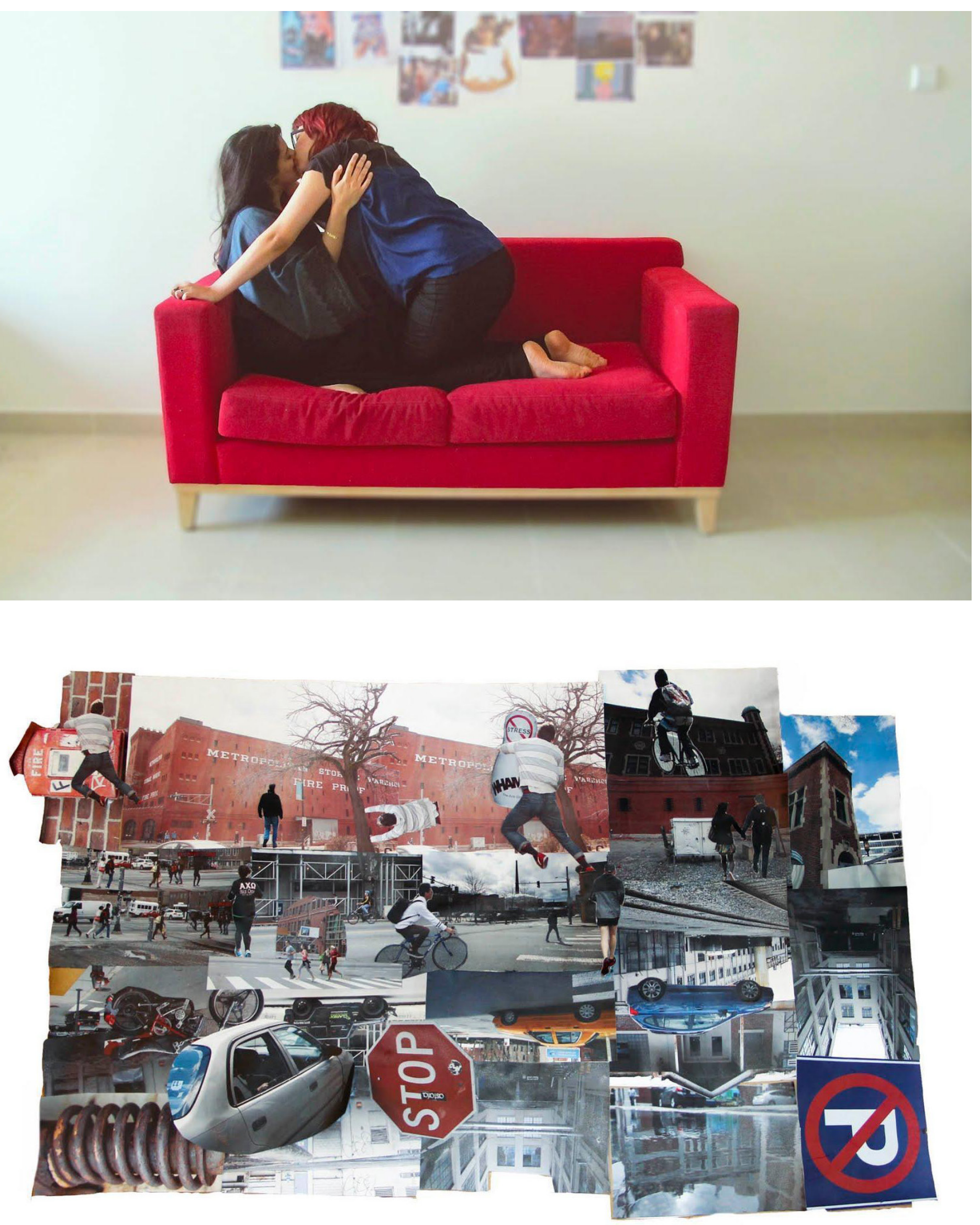


\section{New Media, Sharing and the Potential of Context}

Joseph Douillette

Institute of Contemporary Art, Boston

\section{Introduction}

The Institute of Contemporary Art's (ICA) Teen New Media Program exists within the context of a contemporary art museum in the newly developed waterfront area of Boston. This setting influences our suggested approach to working with the medium; our various new media workshop curricula are designed to have a connection to the artists currently on view in the galleries. We encourage creative freedom and improvisation with a tendency towards conceptual and experimental work.

An essential component of the teens' investment in the creation of digital work is new media's inherent potential to gather an audience through the Internet. The teens are engaging in Participatory Culture, "one in which members believe their contributions matter, and feel some degree of social connection with one another" (Jenkins, 2009). Even though we encourage complete freedom, this essential element of new media compels teens to ultimately choose content that reflects their perceived issues from the context that they bring to the program.

\section{The Promise of Art}

At the 2014 Digitally Connected symposium, I was fortunate to connect with Dr. Chérie Rivers Ndaliko, an assistant professor at the University of North Carolina-Chapel Hill. While living and carrying out research in the Eastern Congo, she served as co-director of the Yolé!Africa cultural center. Yolé!Africa was founded in 2000 in the midst of the Second Congo War by the Congolese filmmaker Petna Ndaliko and Dutch anthropologist Ellen Lammers. Ndaliko founded Alkebu Film Productions simultaneously as a way to help promote and distribute the work created by the Yolé!Africa participants. Despite the obvious differences between our two programs, what struck me most were the similarities.
The mission of each organization promises a relationship with art and an experience with artmaking. Yolé!Africa directly references the promotion of peace, while the ICA strives to share "the pleasures of reflection, inspiration, provocation, and imagination," possibly offering a definition of peace (ICA Boston, 2014).

Each program is committed to taking participants from where they are and transporting them into a new way of presenting themselves in their world. Both programs introduce participants to the potential of the medium, incorporating their knowledge and desire with the culture and potential of the program context.

\section{Teen Film Program Structure and Curriculum}

The Teen New Media Program's advanced filmmaking program is called Fast Forward. Open to students who live in and around Boston, the program reserves 80 percent of its slots for Boston teens, a ratio that seems to match the application pool. Each year, accepted participants represent a diverse racial and socioeconomic mix. Accepted students agree to a full school year of weekly meetings with the expectation that they will produce two new media works.

The first project requires students to work together in small groups. The students are introduced to the tools of digital audio recording while being exposed, sometimes for the first time, to outlooks of students very different from their own. The students are learning about these diverse viewpoints as they create work in response to contemporary artists on display in the ICA galleries.

At first, students seem to rally around their shared experiences and demographics, and differences among them do not appear to dominate their interactions. But as they become more comfortable 
with themselves, with each other, and with their roles as new media artists and filmmakers, they feel compelled to use the medium to begin to introduce more difficult or private situations. The Fast Forward program has never had as its design to foster the creation of work that addresses social justice issues. But, as the description of Yolé!Africa's film program ALT2TV suggests,

Cinema is one of the most efficient means of expression. Thus it is a perfect tool for developing young peoples' potential to enact social changes. It plays a vital role in bringing people together in mutual understanding, thus encouraging the first steps toward reconciliation after years of prolonged conflict (Yole!Africa, 2014).

The participants come from strikingly different situations. Yolé!Africa, based in Goma DCR, has recently witnessed two wars, a rebellion overtaking, and the genocide of neighboring Rwanda. Boston has experienced decades of national peace, but has had its struggles with desegregation and reform within the education system. With the possibilities of new media in each environment, the perspective of the participants' own context becomes less localized as they place themselves within the culture that an online experience offers, and they recognize the role of the audience in both the creation and the reception of their work.

\section{The Role of New Media in this Exploration}

Because of access to the Internet, youth are exposed to a global range of both injustices and common experiences more quickly. They encounter someone like Rene Silva, another attendee at the symposium. From his beginnings as a pre-teen making a paper-based school newspaper in a small town in Brazil to his time as a teenager ultimately taking advantage of the audience potential of Twitter to report on the battle between drug cartels and government forces in his town, he serves as an inspiration for these students from afar (DMLCentral, 2014). Fifteen years ago, a participant in my program would not have had access to stories of such power and influence that another teen can have on his particular situation. Previously, teens entered with experience watching TV and movies. The resulting projects more often emulated that experience. With access to the Internet, teens in all environments witness this power, and are forced to consider more broadly what impact their work might have on their own lives and that of others.

For example, one former student of mine arrived at this consideration more quickly than others. He lived in a less-resourced neighborhood in Boston, and came to the Fast Forward program with much humility and appreciation. While he wandered the galleries experiencing work from various artists, he also wandered the burgeoning Internet, possibly further recognizing the disparity between his situation and those that have easier access to resources.

In his experimental piece Cause and Effect, he takes a poem by Peter Spiro and adds autobiographical imagery heavy with digital filtering. Branden is aware of the challenges he faces as a young black man in Boston. But he is also aware of the potential power of the context of creating art within an institution such as the ICA. The freedom of contemporary art allows him to explore this self-perception in a non-traditional way, aiding him in removing himself just enough to maintain comfort. The immediacy of the

Internet helps Branden to continue to distribute this piece quickly and widely. Equally as important, his classmates are now forced to reconcile their understanding of the privileges and challenges that are present in this microcosm of a class.

My curriculum does not require work to confront personal perspectives of social injustice, but in the 12 years I have been directing this program, it has become clear to me that the medium mixed with the globalization of interaction, drives most students to confront this. The following represent just a few of the examples of students' works:

- The Countdown is a spoken word video which questions each of our roles in the September 11 th attacks;

- Public Enemy \#1 is a daughter's public tribute to her father from whom she draws much inspiration;

- Iron Face is an autobiographical piece by Abraham who uses the piece to come to terms with the violence he faced as a child in Monrovia, Liberia; 
- Breaking the Cycle is another autobiographical piece by Maxwell where he confronts the similarities he has with his father who was a Vietnam War photographer.

In all of these examples, the students are revealing personal or cultural struggles while acknowledging their roles in challenging circumstances, or they are celebrating the overcoming of those challenges.

In one last example, Cartago, a work by Monty Alcott, Monty creates his own library of visual allegories to reimagine the relationship between Aeneas and Dido in Virgil's Aeneid. He is confronting the other students in the class with the struggles that one can assume within the context of philosophy. $\mathrm{He}$ is confronted with Branden's struggles with poverty, while Branden is confronted with Monty's philosophical conundrums. This absurdity represents the myth and promise of peace, prosperity, and first-world status. This is the potential of the context of the Institute of Contemporary Art and the beautiful promise of art.

All of these pieces are performative in style, demonstrating the impact that the ICA has had on the student. The students are encouraged to improvise so that they do not feel encumbered by conventions. They take issues that are of importance to them and begin to develop new modes to explore them. They imagine an audience informed by contemporary art. All the while they anticipate the potential of a web-based audience and desire a dialogue that considers what they have to say as well as the way in which they say it.

Yolé!Africa's video series "Art on the Frontline" presents a variety of examples of art and activity with a backdrop of tension and hope. As described on their website, the videomakers are "a collection of artists and cultural curators from the Great Lakes Region who stand for peace in the face of war and injustice and believe in the power of art to cultivate critical thought, encourage nonviolent self-expression, and catalyze positive social transformation."

Episode 9 in this series, Faraja on the Frontline, is a story of entrepreneurship by a school-aged boy who, after school, rents bicycles to people in his town of Goma. Through its setting the film serves as a document to the scarcity of goods and less-developed conditions of Goma, but more deliberately it serves to reveal the spirit of the residents in portrayals of ambition, celebration, and a desire for fun. The protagonist of the film notes some of his challenges and fears, which range from the fear of being killed in war, to the occasional theft of the bicycles. Yet his focus, and that of his family, is his enterprising nature and what it might lead to. Created for a YouTube Channel film series, and subtitled in English, the film is intended for a global audience. The boy and his business are metaphors for the residents of the town, and portraying their spirit is a clear goal of the film series. The possibilities of Participatory Culture invite this personal exploration for public reception and, like the youth artists in the ICA program, the anticipation of the audience seems to encourage both the filmmaker and the subjects to perform at a heightened level. Participatory culture through new media cannot exist solely in the virtual world. In 2005, Ndaliko founded the Congo's first international film festival, Salaam Kivu International Film Festival (SKIFF). The 2008 festival occurred as the rebel general was advancing towards Goma, but Ndaliko was determined to maintain the normalcy of the annual festival and hosted more than 9000 people throughout the event (Power of Culture, 2014)

The U.S. has more than 150 international festivals, with some over 60 years old. Whether one festival or 150 , the desire and ability to peacefully gather in person, to share and celebrate the stories of those around you and those around the world, is an important gauge of the cultural strength of one's community.

\section{Conclusion}

My interactions at the symposium allowed me to see that my work can help to unearth buried personal conflicts within my students. Civil war and the racially motivated brutality of the civil rights movement might be considered history in the United States, but the ills of that historical context reverberate enough to allow us to draw comparisons with a new media program working in a much more volatile environment. 
Sharing "the pleasures of reflection, inspiration, provocation, and imagination" in the context of a contemporary art museum is the benefit we gain from legislation, social movements, and social conventions. As we embrace our context, we must always acknowledge that people old and young are drawn to new media for interpersonal reasons. Digital improvisation can encourage creative freedom in new mediums, but the traditions of interaction and desire for validity and audience are embedded within these creations.

\section{References / Resources / Links}

Art on the Frontline. Retrieved from http://yoleafrica.org/projects/art-on-the-frontline/

Breaking the Cycle. Retrieved from http://www.icateens.org/video/breaking-cycle

\section{Cartago. http://icateens.org/video/cartago}

DMLcentral (2014). A Teenager Taps Social Media to Help Change His Struggling Community. Retrieved from http://dmlcentral.net/ blog/raquel-recuero/teenager-taps-social-media-help-changehis-struggling-community

Faraja on the Frontline. Retrieved from https://www.youtube.com/ watch?v=BT+B95-xBYA\&feature=youtu.be

ICA (2014). Mission, History and Programming. Retrieved from http://www.icaboston.org/about/history/

Iron Face. Retrieved from http://icateens.org/video/ironface

Jenkins, H. (2009). Confronting the Challenges of Participatory Culture: Media Education for the 21st Century. Cambridge, MA: MIT.

Public Enemy \# 1. Retrieved from http://icateens.org/video/public-enemy-1

The Countdown. Retrieved from http://icateens.org/video/countdown

The Power of Culture. (2014). Even Nkunda Could Not Hinder the SKIFF Festival in Goma. Retrieved from http://www.powerofculture.nl/en/current/2008/november/skiff

YoleAfrica. (2014). Projects. Retrieved from http://yoleafrica.org/projects/ 
CHAPTER 6

Innovation and Entrepreneurship 


\title{
Small Big Things.
}

\section{The Challenges of Being Creative in a Slum}

\author{
Viola Kup \\ USANII LAB
}

\author{
Nicholas Kimeu \\ Shootback, Mwelu Foundation, USANII LAB \\ Illustration by Nicholas Kimeu
}

The last thing people from Africa need, is a European speaking for them. Instead, I speak for myself, a German student who is trying to be a social entrepreneur in Kenya. Or, better: someone who thinks that with passion, creativity and art, one can make a difference. While I still believe in these principles, and I still believe in the value of capacity building, my recent experiences founding Zoom Magazine and USANII LAB (an Arts and Design project in Kenya) gave me a glimpse into the harsh side of reality.

Why do slums still exist? The people I met in the Eastlands of Nairobi are clever, creative, and innovative; they are not so different from my friends in Germany. Several young Nairobians who come from slums have a good school education and know many languages; most of them speak English more fluently than I do. These facts made me wonder: What makes it so difficult to get out of a slum? And how can young Nairobians empower themselves and be innovative entrepreneurs?

I was more than happy when the Berkman Center for Internet \& Society and UNICEF invited Edlyne AkUmu, James Ekwam Chemose, and myself to the Digitally Connected symposium. Unfortunately, I was the only one who could attend after American Embassy denied Chemose's visa and Edlyne had difficulties with her passport at the immigration office.
This could have been a coincidence or just bad luck, but my short experiences in Africa tell me something else. It was not the first time friends of mine had great opportunities overseas but couldn't attend because of denied visas or passport issues. What was the American embassy afraid of: the next Obama? Christopher Fabian, Co-Lead of UNICEF Innovation Unit, presented the fantastic u-report, in which he pointed out the importance of promoting local leaders, designers and innovators:

"We need to get away from the idea of projects and 'projects for people.' It's not about some people doing a project for others." (Vosloo, 2014).

But why is it that several successful projects still do need support "from outside"?

Working in an environment like the Eastlands of Nairobi, I got only a glimpse into the difficulties that the people who live in the slums are facing. There is a lack of infrastructure - no electricity or electricity cuts, no water or water restrictions, no sanitation, criminality, and slow Internet - all of these problems and more slow projects down. But there are also challenges that I, as a European or privileged Kenyans, will most likely never get to know. They are invisible to outsiders, and so I wonder where and how they will ever be verbalized or included as part of a report. As an outsider myself, I only heard some of these challenges through my friends at USANII LAB.

You might not receive a visa because officials worry you might not return to your home country. If you want to register a community-based organization, you would not be able to do so without an address or a P.O. Box, which most likely you don't have if you live in a slum. How can you officially look for funds without being registered? Say you are starting to publish a youth magazine and want to find 
advertising for financial support. You are worried that Big companies may not believe you can set up a magazine. But you don't even get the chance to tell your idea because they don't even let you enter the building in order to hand over a proposal. If you are walking along the street with your laptop in your backpack, you may suddenly find yourself on the ground with a gun in your mouth, and if you can't show the receipt of your laptop, the police will think you have stolen it.

All of these obstacles might not stop you from being creative and innovative, but they will slow you down. You are forced to look for creative solutions and alternatives daily.

\section{A Kenyan UNICEF report says:}

"Social media, to those who know the term, is "a place to chat with friends." Interacting with others via SMS or Facebook are the most important online activities that children and young people in Kenya are engaged in" (UNICEF, 2013).

I learned in the Eastlands of Nairobi that this "chatting" is not just making conversation but also networking. We all need networking to build up a career, but in environments like a slum, you need networking to survive. Your network is everything. It's your security and your insurance. Without health insurance, if you get sick you must rely on the support of your friends and family. For every problem you have, you need to know someone who knows someone who can help.

I was amazed how often I got help from my friends" networks. Without them, I couldn't even have made one step. But sadly, I also saw how many times my European background and my white skin color helped me. I was never asked by a policeman to open my backpack, and even if I had been, I doubt that they would have suspected my possessions were stolen.

Coming from a humbled background doesn't mean you can't be a creative entrepreneur in Kenya. In addition to help from networking, local youth organizations like MYSA and particularly media projects like Nairobits, Shootback, Mwelu Foundation or K-Youth Media offer great support. They provide infrastructure such as a P.O. boxes, Internet, and football playgrounds. They provide you with skills, but most importantly, they give you self-esteem, which allows youth to empower themselves and be part of something larger.

David Sengeh, who founded Innovative Salone in Sierra Leone, spoke at the symposium. In a recent CNN article, he said:

"As a Sierra Leonean who was given an opportunity to pursue biomedical engineering at Harvard and now a Ph.D. at MIT, I understand that a basic set of tools and a supporting platform are needed to transform good ideas into projects that impact an entire community" (Sengeh, 2012).

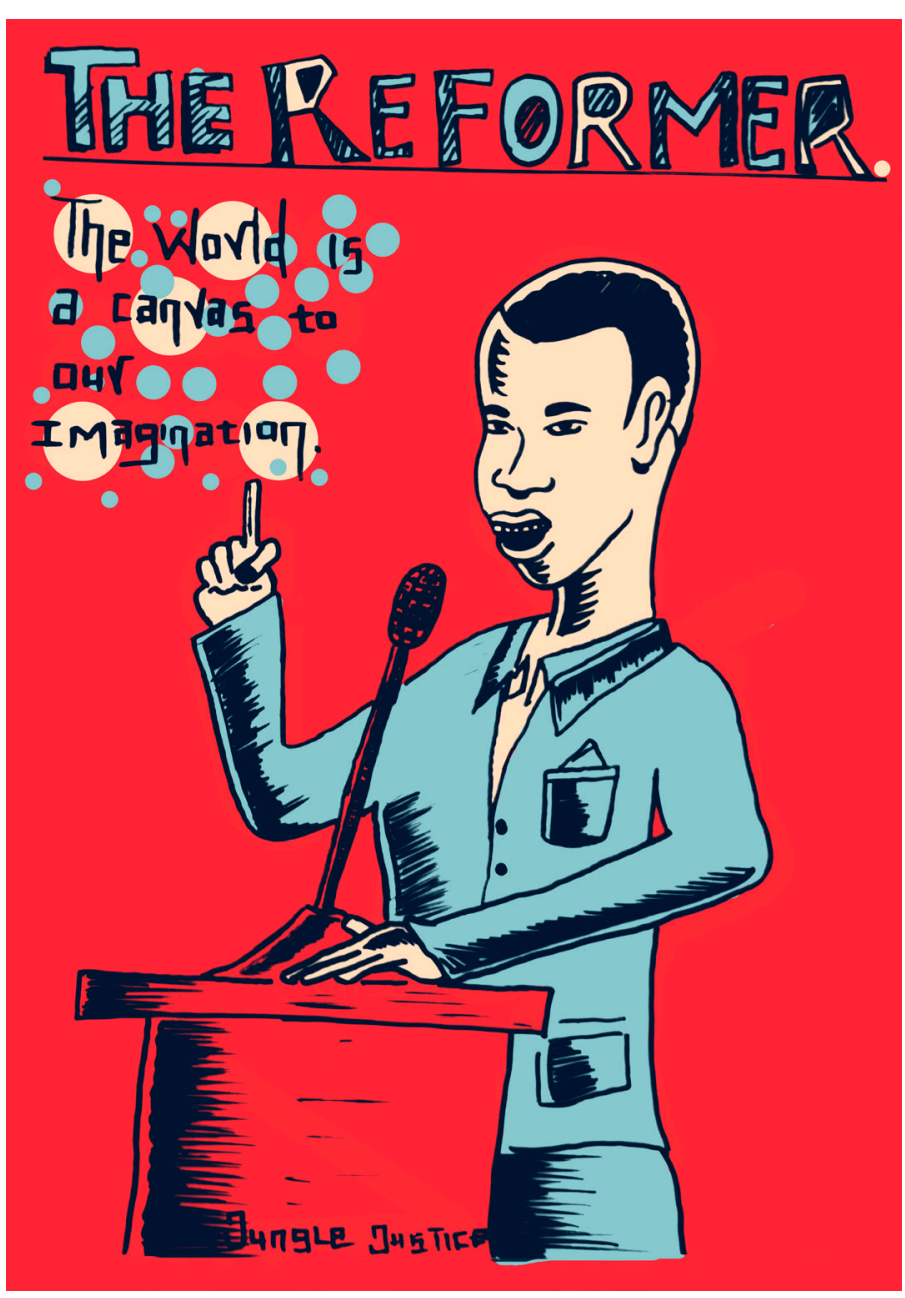


In addition, at the symposium, UNICEF's Christopher Fabian let a woman from Uganda explain how u-report brought impact to her life, noting that she could explain it much better than him. But she wasn' $t$ at the symposium to explain; instead, he had to show a video. It's sad and embarrassing and speaks for itself that I can't even remember her name. I have to describe her as the woman from Uganda. She couldn't be part of the discussions or comment on the symposium.

Co-creation was a keyword often used at the Digitally Connected symposium. Solutions must be found locally, as outsiders don't even know what exactly the problems are, no matter how many surveys we do and reports we read. We must listen and work together with locals, many of whom have creative ideas that are not given a chance to get started because there isn't awareness or support.

To illustrate the perspective not usually given voice, I now hand over the words to one of my friends, Nicholas Kimeu, from USANII LAB:

For us here in Kenya, we all have our code like any other person around the globe which connects us together despite the ups and downs, and that's creativity.

When things change, we all have to bend our imagination to fit to our course. We're living in a time in which we are forced to use our energy and brain every second to reach our purpose in life, for instance in the field, in the library, kitchen, etc. When everything matters, an extra diversion of the brain comes not from education that takes us to a more constrained level, but from within - from creativity. And as the whole world is becoming a small global village, communication in different ways is being shared constantly and simultaneously, and this increases cultural diversity from one end to another. All of this is a theory of my own, as a creative individual.
Digital media mainly has become a major tool for enhancing creativity. For example, in the slums of Mathare (Kenya), Mumbai (India), and Manila (Philippines), the data encoded in social media and the visibility it creates pushes people to their limits when making their daily routines in one way or another easier and more faster. For example, designers and innovative young people around the world form a social network, which helps showcase what we do all around the world. That's where digital media plays a vital role in terms of art coming to place. In the slums of Mathare where I come from and live, it's the creativity that determines how you fit into the system that still pushes the poor to the edge of life, but who, at the end of the day, still need our services. These people spend more time and work extra hard and form kinds of resistance in one way or another. For example, people in the slum learn how to hack the Internet, steal electricity and cable TV too. They are also able to run businesses that sustain their families in places with poor banking system and poor roads. If you wonder how they will tell you that they never ask why they do it, but what happens when they don't do what they have to do. However, hard times calls upon desperate people in a way that forces them to do anything - and I mean anything - to survive and follow our destiny to live. By this I am trying to tell you that it's only in the downtown that you will find a creative individual operating a coffee shop or a small car wash next to a police check point. Why? It's because when the police are doing their job, it will take time, and a cup of coffee and maybe snacks will kill the time, as the guy in the car wash wipes your dirty windscreen, which makes them turn up an event to sustain their needs.

Just because we come from the shack doesn't mean that our brains are shaped that way. USANII Lab is what defines us in what we do; what others call challenges is our method of learning new ways. The challenges mentioned above (and the ones maybe not highlighted there) are ways of making it through in life. We all need a cup of water, because life is a hard pill to swallow, especially for the less fortunate in the society, i.e. the youths due the poor sight of the society. But if only things would be looked at from a third eye perspective, then we would think twice of the slums and the so-called ghettos. From our perspective, the "slum" means "silver lies under me", while the "ghetto" means "getting higher 
education to teach others." In this way, we can all learn to appreciate one another and inspire one another through the small and large networks we create all around. Digital media will act as a safe haven for our dreams and goals in life. We will be able to push on and infect each other with our own syndromes of creativity. Although I have no proper proof to sustain my theory, I have one example and that's USANII LAB, where we are in hold of our purpose and share together what we know and find what we don't know from others. The most knowledge we have acquired in the street is more valuable than what we got from school. And with many more organizations like USANII LAB, MYSA and Mwelu, the network will keep growing and educate society about its ignorance and teach the world that at the end of the day the challenges won't solve themselves, so all we can do is to work hard and be there for each other while changing our environments and forever remain STUPID, or as we call it: "special talented unique persons in demand."

\section{References / Resources / Links}

Kleine, D., Hollow, D., \& Poveda, S. (2014). Children, ICT and development: Capturing the potential, meeting the challenges. Retrieved from http://www.unicef-irc.org/publications/ pdf/unicef_royalholloway_ict4dreport_final.pdf

UNICEF (2013). A (Private) Public space: Examining the use and impact of digital and social media among adolescents in Kenya. Retrieved from http://www.intermedia.org/wp-content/ uploads/2013/09/A-Private-Public_Voices-of-Youth-Kenya-study.pdf Sengeh, D. (2012). DIY Africa: Empowering a new Sierra Leone. Retrieved from http://whatsnext.blogs.cnn.com/2012/11/14/ diy-africa-empowering-a-new-sierra-leone

\section{Projects/Youth Organizations Mentioned}

Innovate Salone: http://innovatesalone.org/

Innovate Salone is about igniting and supporting the creativity in Sierra Leone youth.

Mwelu foundation: http://www.mwelu.org/

Youth organisation for Photography, film production and community projects in the Mathare Valley slum of Nairobi, Kenya

MYSA/Shootback: http://www.mysakenya.org/

MYSA (Mathare Youth Sports Association) is one of the world's leading sport for development organisation. Their activities also include Arts and culture like the photography and film project Shootback.

Nairobits: http://www.nairobits.com/

NairoBits Trust is a youth based organization that uses ICT multimedia creatively to improve the lives of less privileged children and youth from the non-formal settlement.

K-Youth Media: https://www.facebook.com/kyouth

$\mathrm{K}$-Youth is a youth organization whose main goal is to equip young people from the urban slums of Nairobi with skills on media and communication for their personal and community development.

Ureport: http://www.ureport.ug/

Ureport is a free SMS-based system that allows young Ugandans to speak out on what's happening in communities across the country, and work together with other community leaders for positive change.

USANII LAB/ZOOM magazine: http://www.usanii-lab.com/.

USANII LAB is a collective of young creatives from the eastlands of Nairobi, and ZOOM Magazine is a youth magazine designed, written and founded by USANII LAB. 


\section{Software, Hardware, and Farming: A Personal Journey with Open Innovation}

David Li

Xinchejian Hackerspace

Open Innovation is a term coined by Henry Chesbrough, director of the Center for Open Innovation at the Haas School of Business at the University of California. In his book Open Innovation: The New Imperative for Creating and Profiting from Technology, he defined Open Innovation as: "A paradigm that assumes that firms can and should use external ideas as well as internal ideas, and internal and external paths to market, as the firms look to advance their technology." Alternatively, he defines it as "innovating with partners by sharing risk and sharing reward." The boundaries between a firm and its environment have become more permeable; innovations can easily transfer inward and outward.

The idea of open innovation has been around since the 1960s. However, it is only since the Internet greatly improved the communication efficiency across organizations and countries that the power of the paradigm has started to be unleashed.

The first significant piece of evidence was the opensource software movement, which grew out of Free Software, founded by Richard Stillman. Less then two decades after Richard Stillman published the GNU Manifesto calling for support and contribution to the GNU project he started in the Artificial Intelligence Lab at MIT, free software and open-source software now run the backbone of Internet, inside our computers and smart phones.

As a student of computer science and an active contributor to free software and open-source projects since the 90s, I have witnessed the transformative power of open innovation firsthand, and it has significantly impacted my personal view on innovation. I firmly believe that open innovation will change the world, not just in software, but in all areas.
In 2010, I co-founded XinCheJian (http://xinchejian. $\mathrm{com} /$ ), the first hackerspace in Shanghai, China. The Maker movement brought the open innovation model to hardware. The Maker movement grew out of the wide adoption of the Internet by people who felt comfortable sharing their knowledge on making physical objects. The Maker movement grew with the rapid increase of building information online, as well as the increasing availability of open source hardware, notably Arduino, which enabled people without backgrounds in electronics and programming to quickly build their own interactive objects.

The Maker movement started to turn into an industrial paradigm with the publishing of Makers: The New Industrial Revolution by Chris Anderson in 2012. Silvia Lindtner, Anna Greenspan and I, researching innovations in China started Hacked Matter, a think tank based in Shanghai, to look into how the Maker movement will relate to innovation in China.

The Hacked Matter research has taken us to Shenzhen, the mega manufacturing city in southern China that is home to Foxconn and others producing the majority of the world's electronics. In Shenzhen, we discovered the Shanzhai ecosystem, which embodies the open innovation paradigm. It grew from a mobile phone copycatting industry into a fully open innovation ecosystem composed of tens of thousands of collaborating companies that quickly transformed and spread the latest information technologies around the world. As Eric Schmidt stated in his new book The New Digital Age: Reshaping the Future of People, Nations and Business: 
"Even if the prices for sophisticated smart phones and robots to perform household tasks like vacuuming remain high, illicit markets like China's expansive "shanzhai" network for knock-off consumer electronics will produce and distribute imitations that bridge the gap. And technologies that emerged in first-world contexts will find renewed purpose in developing countries."

The open innovation paradigm has extended beyond just information technology and into agriculture and farming. Global communities have formed around aquaponics, lead by the Sweet Water Foundation as part of the "Aquapons Across the Water" initiative. Unlike the traditional farming technologies, aquaponics were developed openly with active online communities documenting and sharing their experience, and aquaponics has become a force to change industrial farming practices.

Being "digitally connected" is one of the major forces pushing open innovation into all areas. Open innovation provides the transformative power of being digitally connected with the open sharing of knowledge and community building. The two will work hand-in-hand to reshape the future and bring new prosperity to those who can bring it to the masses, as Edmund Phelps stated in his book Mass Flourishing: How Grassroots Innovation Created Jobs, Challenge, and Change.

\section{References / Resources / Links}

Chesbrough, H. W. (2005). Open innovation: The new imperative for creating and profiting from technology. Cambridge: Harvard Business Review Press

GNU Operating System. The GNU Manifesto. Retrieved from https://www.gnu.org/gnu/manifesto.html

Hacked Matter. State of Shanzhai. Retrieved from http://www. hackedmatter.com/news/2014/5/19/state-of-shanzhai

IBM's Smarter Cities Challenge. Milwaukee Report. Retrieved from http://city.milwaukee.gov/ImageLibrary/Groups/cityDCD/UrbanAgriculture/IBMSmarterCitiesChallenge-Milw.pdf

Lindtner, S., \& Li, D. (2014, May 18). Shanzhai: China's collaborative electronics design ecosystem. The Atlantic. Retrieved from http://www.theatlantic.com/technology/archive/2014/05/chinasmass-production-system/370898/

Phelps, E. (2013). Mass flourishing: How grassroots innovation created jobs, challenge, and change. See http://press.princeton. edu/titles/10058.html

Schmidt, E., \& Cohen, J. (2013). The new digital age: Reshaping the future of people, nations and business. London, UK: John Murray.

Sweet Water Foundation. Aquapons. Retrieved from http://sweetwaterfoundation.com/aquapons/

Thomas, D., \& Brown, J. S. (2011). A new culture of learning:

Cultivating the imagination for a world of constant change.

CreateSpace Independent Publishing Platform.

Von Hippel, E. (2005). Democratizing Innovation. Retrieved from http://web.mit.edu/evhippel/www/democ1.htm 


\section{Innovation and Entrepreneurship}

\section{Minu Limbu \\ Emergency Specialist/Innovation, UNICEF Kenya}

\section{Kanyankore Marcel Rudasingwa}

Former Representative, UNICEF Kenya

\section{Abstract}

The essay highlights the key discussions from the 2014 Digitally Connected symposium at Harvard University on innovative approaches to connect digitally unconnected children and youth. For areas where youth are digitally connected, the debate is more about ethics, raising awareness, and social good. However, for children living in geographic locations with no connectivity, the challenge is more about finding alternative approaches to help them access the most basic information. The convention of the Rights of the Child states that access to information is as important as access to food and water. Then how can we connect the most deprived children and youth in the most vulnerable areas? The authors highlight the direct correlation between the digital disconnect and the status of children in the most marginalized communities in Kenya. The essay further explores the possibility of reaching the most vulnerable children in Kenya and urges readers to share best practices, engage in conducive partnerships and collaboration for "connecting the dots" between policy makers, practitioners (including children and youth), and researchers to advocate for the rights of the child - even in the most deprived communities.

\section{Innovations to Connect the Most Deprived Children}

The 2014 Digitally Connected symposium cohosted by the Berkman Center for Internet \& Society and UNICEF — was a perfect melting point for humanitarian practitioners and relief workers, government agencies, national and international NGOs, social activists, academics, innovation entrepreneurs, and thought leaders from across the globe. As UNICEF has declared 2014 as the Year of Innovation for Equity' to focus the world's attention on showcasing and developing innovative solutions for children's well-being, one of many highlights from the Symposium was its clear focus on the youth agenda and linkages to the Convention on the Right of the Child (UNICEF, 2009).

Nearly 150 participants from income-rich and income-poor countries brainstormed on the multitude of challenges and opportunities for children and youth in the digital environment. Along with UNICEF participants, Silicon Valley giants like Google, Microsoft, and Facebook, and with academic experts from Harvard Law School, London School of Economics, Royal Holloway, Oxford Internet Institute, including thought leaders from universities and government representatives from around the world, debated the importance of connecting the unconnected global youth through technological and traditional innovative approaches. Dr. Dorothea Kleine, highlighting the recently published UNICEF Innocenti report (Kleine, Hollow, Poveda, \& others, 2014), elaborated on how Information Communication Technologies (ICT) can contribute to meeting child focused development goals. UNICEF innovation co - leader Christopher Fabian gave examples on innovative development work across 135 countries where technology is "not the end-product of innovation, but a principal driver of new ways of thinking about development problems" (Fabian, 2013). Technology is important but it might not be the answer for the digital divide between urban and rural dwellers, between men and women, and, particularly, between boys and girls (Livingstone \& Bulger, 2013).

Then, how can we advocate for the rights of the child in the 21 st century - digital age - when there are more mobile subscriptions and internet users than the total population of the world (GSMA, 2014a)? UNICEF's TED-style live \#UNICEFActivate (Berkman Center \& UNICEF, 2014a) was launched during the Digitally Connected symposium to debate this question. Experts from Inverno, Instituto Midia Etnica, 
Soronko Solutaions, ITU and UNICEF highlighted the latest ICT focused innovations for connecting the unconnected global youth. Dr. Sharad Sapra, the Principal Adviser on Innovation for UNICEF kick started the keynote address on equity focused innovation for children. He went on to explain that "technology is the big game changer" when advocating for the rights of the child. Dr. Sapra further provoked the audiences by saying that "the higher the inequities, the easier it is for (innovation) to actually make a difference", especially for countries that are lagging behind in terms of reaching the Millennium Development Goals. This might be true for communities with access to technologies. How can we then bridge the digital divide, if at all, between children living in rural and urban settings, developed and developing countries, and so on? Dr. Sapra echoed this idea, stating, "how do we engage with those unconnected $50 \%$ of the world's population?" During the live discussions, information from twitter feeds and the online questions (Berkman Center \& UNICEF, 2014b) from around the world proved (at least virtually) that people beyond the symposium were also seeking answers regarding how to reduce the digital divide, especially for those geographic areas where there is no connectivity at all.

When $47 \%$ of the world population live in rural settings and $55 \%$ of this group are children (WorldBank, 2014) - not to mention the varied geographical terrains they live in - one can argue that digital connectivity is one thing but access to information for children and youth is a whole different challenge all together. This is especially true for countries like Kenya. Like adults, access to information is as important as access to food and water for children (IFRC, 2013). Yes, the United Nations Convention on the Rights of the Child article 13 does talk about children's rights to get information and to share information. Yes, article 17 states that children must have access to reliable information (CRC \& UNICEF, 1990). The 2010 Constitution of Kenya, through its Bill of Rights that promotes the United Nations Convention on the Rights of the Child, has created great potential for improvement by recognizing children and young people's rights for all stakeholders. However, $76 \%$ people in Kenya live in rural settlement (WorldBank, 2014) and less than $5 \%$ of the people living in rural areas use the internet in spite of growth of the number of internet users from 1.7 million in 2007 to
10 million by June 2011 (UNICEF, 2013a). Hence, digital connectivity and information access in those communities still remains a major challenge for children and adults alike.

Mobile phones are fueling positive change in the developing world (Zambrano, Seward, Ludwig, \& UNDP, 2010) including in Kenya (Economist, 2012). Mobile phones are becoming more accessible as the costs of services are getting progressively cheaper. For geographic locations with some degree of access to mobile connections, emerging local entrepreneurs have come up with different ways to engage with the children and youth via two way information sharing in the most marginalized communities. In rural communities, dumb phones are being used as a major tool to access information, which adds value to lives and livelihoods through SMS and (increasingly) the Internet. In Kenya, the adoption and use of mobile phones has increased from 12.9 per hundred people in 2005 to 71.2 per hundred people in 2012 (ITU, 2013; Livingstone \& Bulger, 2013; WorldBank, 2012a). Similarly access to the Internet has also reached 32.1 per 100 people, which is very promising considering the global average is 35.5 (WorldBank, 2012b). In 2010, almost 7 out of 10 children attending primary school owned a mobile phones. In 2013, the UNICEF country office in Kenya conducted research to examine the use and impact of digital and social media among adolescents in Kenya (UNICEF, 2013a). For better or worse, as (Livingstone \& Bulger, 2013) put it, the Kenya UNICEF report confirmed that more and more children are using internet and mobile technologies in their daily lives and are increasingly relying on them to learn, engage, participate, play, work, and socialize. This is also true for children in rural areas with access to mobile technology or other forms of ICTs.

Even though the rate of mobile subscriptions have increased from $16.8 \%$ in 2006 to $35.9 \%$ in economically poor areas of Kenya (Aker \& Mbiti, 2010), the mobile telephone network coverage map (InfoAsAid \& GSMA, 2010) clearly highlights that not all parts of the country are covered for texts and voice services. When you overlay the $2 \mathrm{G}$ network coverage of Kenya (Map B) on top of the Kenya Child Deprivation Indices ${ }^{2}$ (map A) for all 47 counties (UNICEF \& Limbu, 2013), one can see that the areas 


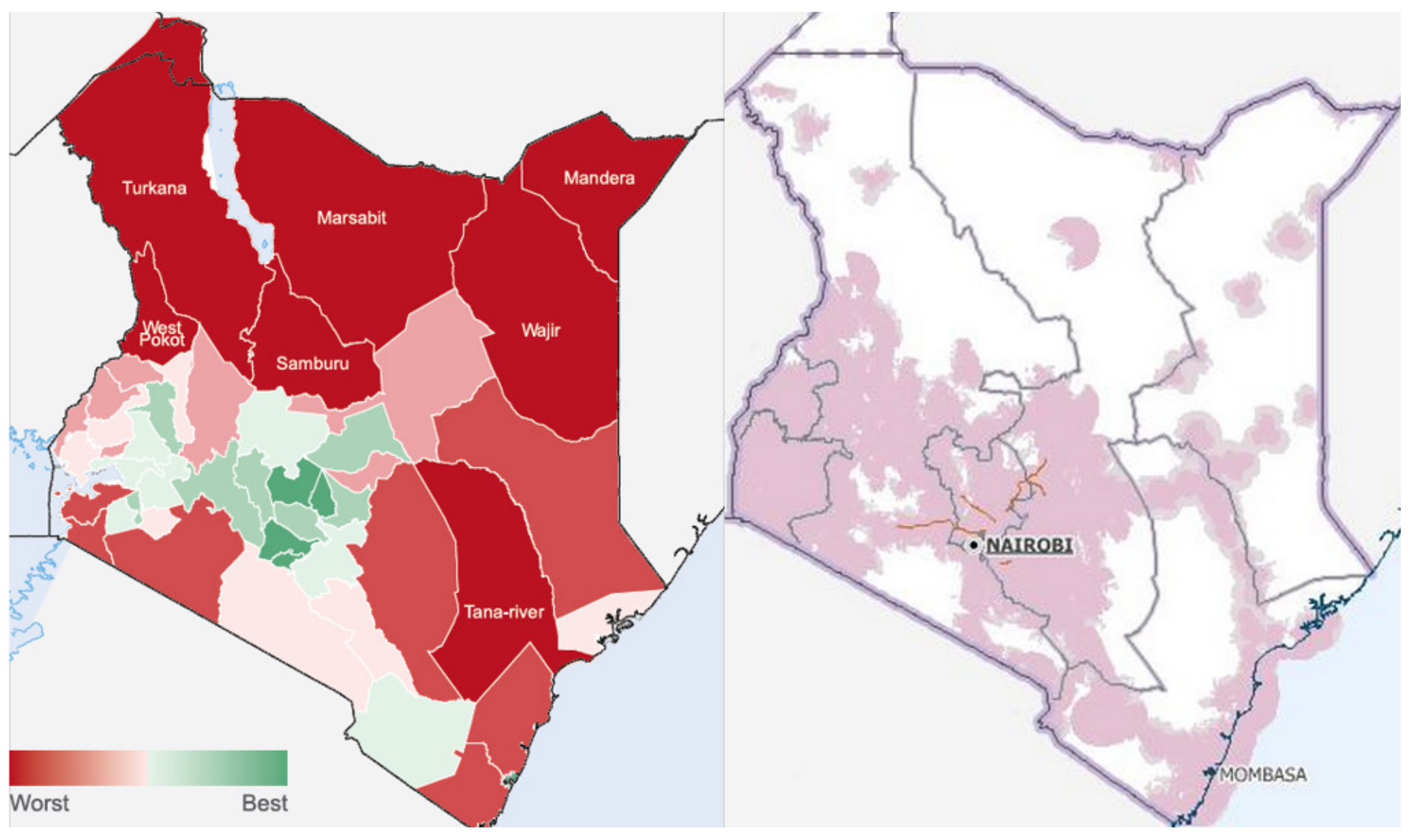

Map A Kenya: Child Deprivation Index | Map B: Mobile Telephone Network Coverage

where children are subjected to multiple deprivation are also the locations where there are partial or no access to mobile network and vice versa. For example, the child deprivation analysis shows that children in Turkana County in the North East of Kenya bordering South Sudan and Ethiopia are the most deprived in Kenya. In terms of connectivity, all the mobile network service providers in Turkana confirmed limited or no services (GSMA \& Safaricom, 2012; GSMA, 2014b) in the area. Hence, mobile communication is only one part of the story for connecting with the youth and children in Kenya.

When the UNICEF Innovation team met in Kosovo in December 2013, Ms. Erica Kochi, the UNICEF Innovation Co - Lead, highlighted that "one shoe does not fit all" while innovating for children and youth. This is very true in the case of digitally divided Kenya as well. UNICEF globally leads hundreds of innovation projects for children that are very much grounded in the principle of innovation (UNICEF, 2013b) and putting children at the center of the planning processes (UNICEF, 2011, 2012, 2013b). Among others, UNICEF has been exploring and advocating (where necessary) for the use of mobile technology based tools throughout its country offices. There are a number of mobile technology based system and tools currently being used in sectors like education, health, nutrition, child protection, communications monitoring, and evaluation for development and humanitarian action focused on children.

At the same time, through partnership and collaborations with local entrepreneurs, UNICEF has also ventured into products and services targeted for traditionally remote and inaccessible areas where children are even more in need of access to basic information. For example, the solar powered "Digital Drum" (UNICEF, 2012) is designed to help rural communities in Uganda that have difficulty getting information about health, education and other issues. The Mobi-Case (UNICEF, 2013b), known as the "the class room in the suitcase", which was featured in the Wired Magazine (Cheshire, 2014), is another good example of taking technology to children in marginalized communities. The UNICEF Innovation Lab in Burundi is also currently exploring new ways of harnessing alternative sources of energy (UNICEF, 2014). The BRCK, designed by the local entrepreneurs at Ushahidi at the iHub Kenya and also featured in the WIRED magazine and the Ted 
Talk series (Stedman, 2013; TedTalk, 2013), is another great example of appropriate technology design to support access to information in marginalized communities with unreliable electricity. This, again, highlights the paramount importance of collaboration and partnership when innovating for the most vulnerable (Becker, Niebuhr, \& Global, 2010; Dodgson \& Gann, 2010; Moyle, 2010; Ness, 2012; Volosencu, 2012).

In conclusion, to advocate for the rights of the children and provide information access to the youth and children in the most marginalized communities in Kenya - from the digital connectivity prospective - innovators and entrepreneurs will have to engage in both technological and non-technological (or traditional) solutions to bring about better and more equitable solutions for children. As next steps following the symposium, the Berkman Center's Professor Dr. Urs Gasser righty emphasized the importance of collective, collaborative identification of innovative approaches for "connecting the dots" between policy makers, practitioners (including children and youth) and researchers ${ }^{4}$. Albert Einstein once said that "problems cannot be solved by thinking within the framework in which the problems were created." If a certain challenge calls for a truly original response, rather than thinking about how to make innovation happen, it might be more appropriate to think about setting the stage for possible future joint, collaborative, risk shared innovations (Hill, Brandeau, Truelove, \& Lineback, 2014). UNICEF Kenya is keen to engage with all of you in our joint effort to give a voice to the most vulnerable and deprived children and youth. Share with us your ideas, tell us about experiences, and, most importantly, open up to your failures so that we can learn and innovate together for the better future of the children and youth!

NOTE OF THANK YOU: The authors would like to thank the Berkman Center for Internet and Society for supporting advocacy for the rights of the child, especially focused on digital connectivity — its opportunities and challenges. Thank you Dr. Sharad Sapra, Principal Advisor on innovation for UNICEF and the Director of the UNICEF Innovation Centre for your insights and constructive suggestions on the essay. The Kenya Child Deprivation Index led by Ms. Joanne Bosworth, the Chief Social Policy, Monitoring and Evaluation has been a major influence on this essay. Thank you Ms. Edita Nsubuga, Chief of Communications and Ms. Bosworth for their edits. This report would not have been completed without the support of Mr. Fred Ogwal-Oyee, Chief of Emergency and Field Operations and Ms. Madhavi Ashok, Deputy Representative of UNICEF Kenya.

\section{In Text}

1 Innovation at UNICEF is collaboration that translates ideas, technologies, and partnerships into products, services, and processes to bring about better, more equitable results for children. UNICEF creates and guides approaches that are transformative, at scale, for the world's most vulnerable children. (UNICEF, 2013b)

2 Child Deprivation Index: The child deprivation index is an innovative way of measuring multi-dimensional poverty and rights deprivation for children by county. The child deprivation index and other data at county level were collated and used to generate county data sheets and infographics which were then presented to county governments. The Infographics present national and county indicators in thematic areas including demographics, education, water and sanitation, maternal and child health and HIV, nutrition and child protection. In the heat map, the red color indicates counties with high level of child deprivation.

\section{3 https://storify.com/DigConnect/cluster-meetings}

4 To learn more about the key action points, please visit the www.digitallyconnected.org

\section{References / Resources / Links}

Aker, J., \& Mbiti, I. (2010). Mobile phones and economic development in Africa. Center for Global Development Working Paper, (21 1). Retrieved from http://sites.tufts.edu/jennyaker/ files/2010/09/aker_mobileafrica.pdf

Becker, S. A., Niebuhr, R. E., \& Global, I. (2010). Cases on technology innovation: entrepreneurial successes and pitfalls. Business Science Reference.

Berkman Center \& UNICEF. (2014a). UNICEF and Harvard Convene Innovators and Thought Leaders for an Activate Talk. Retrieved from http://talk.unicef.org/news/unicef-harvard-conveneinnovators-thought-leaders-activate-talk/

Berkman Center \& UNICEF. (2014b). Activate Talk, Boston - How to connect the disconnected? Retrieved June 10, 2014, from http://goo.gl/6eAspp

Cheshire, T. (2014). WIRED - The classroom in a suitcase. Retrieved from http://www.wired.co.uk/magazine/archive/2014/05/start/ classroom-suitcase

CRC \& UNICEF (1990). UNICEF - A simplified version of the United Nations Convention on the Rights of the Child. Retrieved from https://www.unicef.org.au/Discover/What-we-do/Convention-onthe-Rights-of-the-Child/childfriendlycrc.aspx

Dodgson, M., \& Gann, D. (2010). Innovation: a very short introduction. Oxford University Press.

Economist (2012). Innovation in Africa - Upwardly mobile, Kenya's 
technology start-up scene is about to take off. Retrieved from http://www.economist.com/node/21560912

Fabian, C. (2013). UNICEF Global Best Practices. Retrieved from http://unicefinnovation.org/case-studies

GSMA (2014a). Definitive data and analysis for the mobile industry. Retrieved from https://gsmaintelligence.com/

GSMA (2014b). GSMA - Mobile for Development Impact. Retrieved from https://mobiledevelopmentintelligence.com/network_ coverage

GSMA \& Safaricom. (2012). Safaricom: Kenya - Feasibility Study. Retrieved from http://www.gsma.com/mobilefordevelopment/wpcontent/uploads/2013/02/Safaricom-Feasibility-Study.pdf

Hill, L. A., Brandeau, G., Truelove, E., \& Lineback, K. (2014). Collective Genius: The Art and Practice of Leading Innovation. Harvard Business Press Books, Harvard University: Harvard Business Press Books.

IFRC (2013). World Disasters Report 2013 - Focus on Technology and the future of Humanitarian Action. IFRC. Retrieved from http:// www.ifrc.org/PageFiles/134658/WDR\%202013\%20complete.pdf

InfoAsAid, \& GSMA (2010). Telecommunications Overview: Mobile telephone network coverage of Kenya in 2010. Retrieved from http://infoasaid.org/guide/kenya/telecommunications-overview

ITU (2013). ICT Facts and Figures - 6.8 billion mobile-cellular subscriptions. Retrieved from http://www.itu.int/en/ITU-D/Statistics/ Documents/facts/ICTFactsFigures2013-e.pdf

Kleine, D., Hollow, D., \& Poveda, S. (2014). Children, ICT and development: Capturing the potential, meeting the challenges. Retrieved from http://www.unicef-irc.org/ publications/pdf/unicef_royalholloway_ict4dreport_final.pdf

Livingstone, S., \& Bulger, M. (2013). A Global Agenda for Children's Rights in the Digital Age: Recommendations for Developing UNICEF's Research Strategy. Retrieved from http://www.unicef-irc. org/publications/pdf/lse\%20olol\%20final3.pdf

Moyle, K. (2010). Building innovation: learning with technologies. Australian Council for Educational Research 19 Prospect Hill Road, Camberwell, Victoria, 3124: ACER Press. Retrieved from www.acer.edu.au

Ness, R. B. (2012). Innovation generation: how to produce creative and useful scientific ideas. Oxford University Press.

Stedman, I. (2013). WIRED: Ushahidi's rugged BRCK, "the backup generator for the internet." Retrieved from http://www.wired. co.uk/news/archive/2013-05/13/brck

TedTalk (2013). Ted Talk: Meet BRCK, Internet access built for Africa. Retrieved from https://www.ted.com/talks/juliana_rotich_meet_ brck_internet_access_built_for_africa

UNICEF (2009). State of the World's Children: Celebrating 20 years of the Convention on the Rights of the Child. UNICEF. Retrieved from http://www.unicef.org/publications/index_51772.html

UNICEF (2011). Unicef Resource materials: Tech Innovation, 2010-201 1. Retrieved from http://unicefstories.files.wordpress. com/2013/08/v7.pdf

UNICEF (2012). UNICEF Tech Innovation, Resource Materials and Case Studies. Retrieved from http://unicefstories.files.wordpress. com/2013/08/v10.pdf

UNICEF. (2013a). Examining the Use and Impact of Digital and Social Media among Adolescents in Kenya. Retrieved from http://www.intermedia.org/wp-content/uploads/2013/09/

\section{A-Private-Public_Voices-of-Youth-Kenya-study.pdf}

UNICEF. (2013b). UNICEF Innovation Unit - Annual Report 2012 - 2013. Retrieved from http://unicefstories.org/2013/07/30/unicefinnovation-unit-annual-report/

UNICEF (2014). Innovating for children, innovating for equity: Alternative Solutions to Energy Poverty in Burundi. Retrieved from http://talk.unicef.org/events/alternative-solutions-energy-povertyburundi/\#.U51-8ZSSySo

UNICEF \& Limbu, M. (2013). Children Matter - Child Deprivation Index, Presentation @ United Nations Information Management and GIS Conference, New York October 2013. Retrieved http://goo.gl/4YvchY

Volosencu, C. (2012). New Technologies, Trends, Innovation and Research. InTech, Janeza Trdine 9, 51000 Rijeka, Croatia.

WorldBank (2012a). Data - Mobile cellular subscriptions (per 100 people). Retrieved from http://data.worldbank.org/indicator/ IT.CEL.SETS.P2/countries/1W-KE?display=graph

WorldBank (2012b). Data - Internet users (per 100 people). Retrieved from http://data.worldbank.org/indicator/IT.NET.USER. $\mathrm{P} 2 /$ countries/1W-KE-A4?display=graph

WorldBank (2014). Data - Rural population (\% of total population) Retrieved from http://data.worldbank.org/indicator/SP.RUR.TOTL. ZS/countries/1W-KE?display=graph

Zambrano, R., Seward, R. K., Ludwig, S., \& UNDP (2010). Mobile technologies and empowerment: Enhancing human development through participation and innovation. Retrieved from https://www.undpegov.org/sites/undpegov.org/files/undp_ mobile_technology_primer.pdf
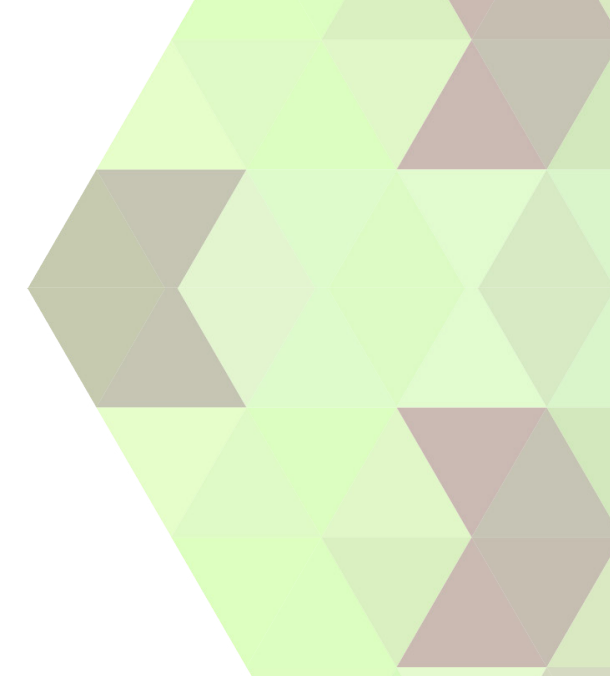


\section{Ways to Help ICT Projects Succeed for Youth}

\section{Bruce Baikie}

Inveneo

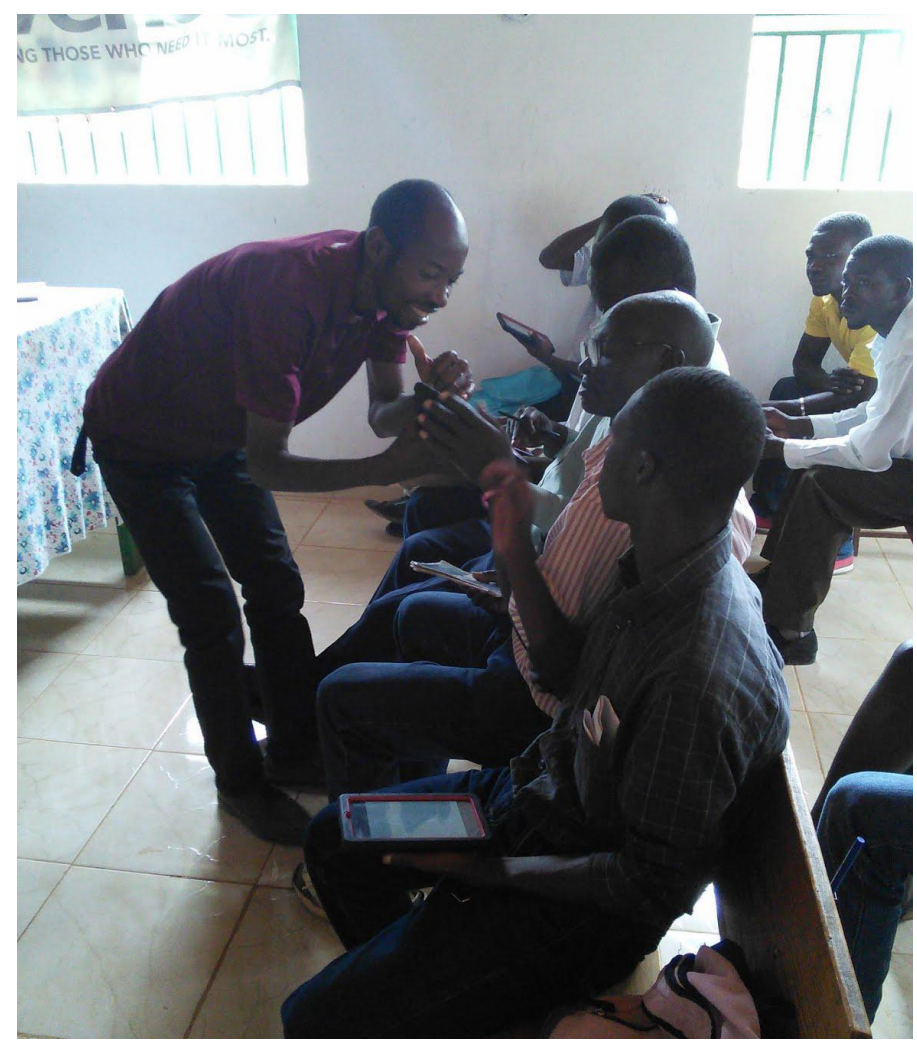

It is safe to say that in 2014 , Information

Communication Technologies (ICTs) have become firmly embedded in all working sectors: education, healthcare, agriculture, government, and more. Youth are the first to grab on to new technologies and apply them to their daily lives. Internet-based communications via social media are today's driving force for youth to get their voices out into their communities, cities, countries, and around the world. As most of us in the computing world know, personal computers are very "old school" in comparison to smartphones and tablets. Almost gone are the days when computer learning started with keyboard skills and file management, then progressed to office-type applications. Android-based apps on smartphones and tablets now allow users to move straight to using their favorite applications without employing these typing or file management skills.

To make this possible, there is an even greater need for Internet connectivity to access cloud-based systems for this new generation of applications. Outside the major cities in rural regions, Internet connectivity and electricity are the greatest challenges to any ICT project, because no electricity = no Internet.

What are the "big five key success factors" when planning a project that involves youth and ICT?
1) ICT Hardware
2) Applications \& Content
3) Infrastructure
4) Training
5) Support 


\section{ICT Hardware}

The proper hardware is key in emerging regions, as ICT projects are usually carried out in hot, humid, and dusty areas. Often these places even have high salt content in the air. All these conditions can cause computers we use in the United States to fail. Key features are:

1) Passive cooling: users need to avoid having a fan, so dust, bugs, and critters do not get sucked in and short-circuit the system.

2) Low power usage and $12 \mathrm{~V} D C$ operation, so it can be powered affordably with a smaller solar photovoltaic (PV) solution.

3) A low price point.

4) Local support and maintenance because things always break. The good news is the computer hardware industry is building computers/devices that can better survive harsh environments.

\section{Applications \& Content}

The application set is changing; it is moving from office-based applications to social media. Facebook, Twitter, Snapchat, Instagram, and YouTube are what the youth want to use today. Integrating these platforms into an educational project, for example, will gain more widespread acceptance, interest, and adoption compared to simply using word processing. Content is always king, so ICT practitioners should use locally based content like "Rachel server on Raspberry Pi" for easy access even in the absence of Internet connectivity. In addition, content should always be in the official and local language.

\section{Infrastructure}

"The economies in developing regions in the past five years have outstripped the local power grid, causing daily outages, wide voltage swings, and higher prices" (Hosman, 2014).

To plan a successful project, ICT workers need to use solar PV solutions as the grid power situation is only predicted to get worse. Also, without planning for the power issue, Internet connectivity will never happen.

\section{Training}

The ability and pace at which youth can learn ICTs always seems to outstrip the local teachers' abilities. It cannot be stressed enough that training courses need an ICT professional - not necessarily an expert who can stay ahead of, engage with, and challenge the youth-and the teachers.

\section{Support}

Local support is a key feature. Things go wrong, break, or are used incorrectly. Having local community members who become trained ICT professionals to support the project needs to be a high priority. An ICT project will not have long-term success unless there is local leadership and capacity.

If ICT practitioners can plan, fund, and implement these five ideas, their projects' success will be on track for long-term sustainability.

\section{References / Resources / Links}

Hosman, L. (2014). The Centrality Of Electricity For Internet Uptake in Low-Income Countries. Presented at the PTC Annual Conference, Waikiki, Hawaii. Retrieved from http://www.ptc.org/ ptc 14/images/papers/upload/Paper_TS4_HosmanLaura.pdf

Get more updates by following Bruce on Twitter: @BrucelCT4D 
CHAPTER 7

Participation and

Civic Engagement 


\section{Participation and Engagement: Defining Programs and Values}

Eric Gordon

Engagement Lab, Emerson College

I had the opportunity to moderate a discussion at the Digitally Connected symposium on the topic of Researching Youth Participation and Civic Engagement. This was a significant challenge for a number of reasons, but two in particular stood out: not everyone in the room was a researcher-so there was no common understanding of "doing research"- and people came from a variety of professional and disciplinary backgrounds-so there was a healthy variety of "problems" in need of researching. As such, our strategy was to find common ground or common tensions in doing the work of designing, facilitating, and understanding participation and engagement among youth. The workshop was an opportunity to solicit narratives around its two titular terms: participation and engagement.

As it turns out, participation and engagement have very different meanings. Through our conversation, it became clear that participation was associated with a discrete or ongoing action that an individual takes within a civic or political context, whereas engagement typically referred to the resulting desire of an individual to be meaningfully and continually connected to the larger process, institution, or community that the activity is associated with. The workshop participants struggled to sort out the distinctions between these terms, but quickly realized that each embodied a fairly clear value proposition. Participation was seen as a pathway to engagement-not an end in itself - and engagement was seen as the resulting relationships and habits created through acts of participation.

Most participants had not thought much about these terms prior to the workshop. But the exercise of teasing out semantic distinctions allowed nuances in values and strategic emphases to emerge, forcing a consideration of the intentionality of organizational priorities. When does an organization seek to "increase participation" and when does it seek to "create engagement?" And what ends do each of these serve? Most people in the room suggested that their organizations use the language of engagement to define this area of work, yet the same organizations tend to resort to measuring participation because it is far easier to quantify. Especially within the context of digital media, actions such as clicks, retweets and likes are easy to report, but they alone do not fully capture stated engagement goals. Measuring engagement is much more difficult, and reportable outcomes are less clear. Moreover, popular discourse has made the term 'engagement' (even the goal) seem at times disingenuous, too readily associated with marketing and commercial enterprise. For example, that the advertising industry uses the term engagement to refer to paying attention to an ad significantly challenges the depth of meaning for people working in humanitarian or development contexts. For these people, engagement should be associated with having taken care, not having been manipulated.

The distinction between participation and engagement is more than academic.

Understanding semantic distinctions can shed light on what institutions mean when they define programs and how programs shape the problems they are meant to address. When an NGO, for example, labels youth engagement as a priority, they are articulating the need for ongoing connection with a thing (process, institution, or community) in a context of disconnection and fragmentation. There are value judgments inherent in defining the need as such, but if they proceed to measure participation, then values get blurred and goals confused. Are such organizations simply trying to get youth to do things (participate) or are they trying to empower youth to connect (engage) meaningfully and on their own terms to the world around them? Most importantly, are they measuring the thing they want to accomplish? 
This line of questioning has become central to my own work. I explored some of these questions in a white paper released through the Berkman Center last year (Gordon, Baldwin-Philippi, \& Balestra, 2013). And while writing a book about location-based media in 2010 (Gordon \& de Souza e Silva, 2011), I began to question how mobile devices, and the uncanny ability for them to precisely locate their users, was transforming how people engaged in their local communities. The experience of being in place, mediated by devices, was impacting how people considered local issues, participated in local politics, and connected to local cultures. The possibility of gaining information about one's city or neighborhood, in place and in real time, was forcing the reconsideration of everyday civic engagement. What's more, the affordances of new, location-based technologies suggested that technologists and media designers, not just urban planners and architects, could help structure meaningful experiences of local spaces. One particularly interesting phenomenon I focused on in the book was location-based games. These were games, often played on mobile devices, which overlaid digital interface onto the physical world or incorporated the physical world into digital interface. Most importantly, these projects used game mechanics to structure a playful experience of urban space; and through play, encouraged people not just to navigate, but also to explore, discover and invent in familiar spaces.

I began to ask how games, in particular, could engage people in their local communities and institutions. Was there something in the experience of structured play that allowed for reflective learning and investment in community outcomes? And, could the unique qualities of games-clear goals, feedback, and ability to fail safely towards mastery-provide insight into what engagement in public processes could mean? I founded the Engagement Lab, originally called the Engagement Game Lab (http://engagementlab.emerson.edu) in 2010 at Emerson College in Boston, MA to serve as a platform for design and research around these questions. My work at the lab has combined actual game design and implementation in civic and public contexts with research on the efficacy and impact of the approach (Gordon \& Baldwin-Philippi,
2013; Gordon \& Schirra, 2012). After dozens of game-based interventions with governments, NGOs and community organizations, including the United Nations Development Program, the International Red Cross/Red Crescent and the World Bank, the value of play for place-based engagement in official planning processes became quite clear.

However, this value was not without its tensions. The tension within specific organizations between the efficiency of online participation and the potential depth of a particular sort of playful engagement was consistent. Games motivated participation through clear incentives, such as leaderboards and the possibility of overcoming system obstacles, but they also introduced a particularly refined ability to cultivate engagement through play, which can be defined as self-motivated interactions in a malleable system. Playful engagement, therefore, became a design goal, one that combined ongoing participation with the care and sense of accomplishment needed for players to feel connected to process, institution, or community. In my experience working with organizations to design and implement playful engagement strategies, organizational actors are caught in between their desire to go deeper through play and the pressure to quantify participation in such a way that satisfies upper management and/or funders.

After my experience at the Digitally Connected symposium listening to the remarkable richness in how people defined the terms participation and engagement, I am even more convinced that there is value in articulating the difference between them. There is value for an emerging field of scholars and practitioners working in the area of youth participation and engagement to better understand the ideological frameworks through which institutional programs, goals, and evaluations are crafted. The possibilities of the Internet and digitally connected youth have sparked remarkable enthusiasm in supporting programs that encourage youth participation and engagement. That same level of enthusiasm should be channeled into understanding broad trends in this space, and assuring that there is common language and measures that can properly assess the impact of these programs. The resources devoted to structuring 
common language and knowledge creation should match the opportunity we have to make a difference in young people's lives through digital connections.

\section{References / Resources / Links}

Gordon, E., \& Baldwin-Philippi, J. (2014). Playful civic learning: Enabling lateral trust and reflection in game-based public participation.

Gordon, E., Baldwin-Philippi, J., \& Balestra, M. (2013). Why We Engage: How Theories of Human Behavior Contribute to Our Understanding of Civic Engagement in a Digital Era. Berkman Center Research Publication, No. 21. SSRN Electronic Journal.

Gordon, E., \& de Souza e Silva, A. (2011). Net locality: Why location matters in a networked world. Boston, MA. Wiley-Blackwell.

Gordon, E., \& Schirra, S. (2012). Playing with Empathy: Digital Role Playing Games in Public Meetings. In Communities and Technologies 2011. 


\title{
Re-thinking Youth Participation and Civic Engagement in the Digital Age
}

\author{
Andres Lombana-Bermudez \\ University of Texas at Austin
}

Participation and youth are contested terms. Because they have plural definitions it is important that we mind the "semantic" gap when talking about them. While we continue to seek a common ground that works globally and across cultures and disciplines, we should also embrace, as designers, policy makers, and researchers, the fluidity and nuances of each of these concepts. We should not take these terms for granted, but instead question them with critical lenses. When talking about participation, we should always ask, participating in what? Under what conditions? Through which platforms? Participation, at its core, is about power and agency, and when we examine it, it is necessary to consider power differentials in terms of social class, age, gender, and race-ethnicity because they affect both offline and online worlds and constrain access to opportunities. Not all youth and children have access to the same social, cultural, human, financial, and technology resources. When talking about youth, we need to not only differentiate a particular segment of the population according to age, but also according to their demographic characteristics and geographic location.

One of the promises of the digital age is that as youth grow up in a networked media environment, increasingly using digital tools for creating, circulating, searching and consuming content, they will participate more. Many children and youths are in fact enthusiast users of mobile devices and computers, and invest a considerable amount of time communicating and socializing with peers; creating and sharing multimodal content; seeking information online with search engines; and consuming entertainment through web platforms (e.g., videos, games, and music). However, as scholars of digital inequalities have revealed, in contemporary societies accesses to technology, skills, motivations, and usage, are not homogenous. (Hargittai, 2011 ; Hargittai \& Walejko, 2008; Schradie, 2011 ; Jenkins et al., 2006; Van Dijk, 2005; Watkins, 2012) The opportunity structures that support participation are not equal for all youth. (Livingston, Couldry, \& Marknam, 2007) Several disparities exist according to demographic conditions and geographies, and certain youth populations around the world, in both developed and developing nations, lack access to the necessary resources to meaningfully participate. Such inequalities persist even in countries like the U.S., and several quantitative and qualitative studies have found evidence of how disparities affect youth populations across lines of race-ethnicity, class, and education. For instance, a recent report from the Pew Hispanic Center (2013) revealed that although cellphone ownership has increased the access to Internet connectivity among the Latino/Hispanic and Black youth in the U.S., differences in home computer ownership continue to exist. While $83 \%$ of White households have access to desktop or laptop computers, only $72 \%$ of Latino/Hispanic and $70 \%$ of Black households have access to that technology (Lopez et al., 2013).

However, despite the persistence of social and digital inequalities, opportunities for youth participation across several social domains, such as culture, economy, art, and education, are certainly becoming more available in the changing context of a networked communication environment. As diverse youths access Information Communication Technologies (ICTs), develop new media literacy skills, become motivated, and interact within online/ offline spaces and publics, more opportunities for meaningful participation are indeed being created. Hence, because the new networked media environment and ICTs expand the communication power of the young people who have access to the tools and skills, the potential for participating across several social domains is, in fact, diversifying.

It is precisely in this context of expanded opportunities where civic engagement becomes a key area of analysis, design, and policymaking in relation to youth and participation. Helping 
local communities, cultivating solidarity, becoming aware of real world problems, or taking part of a political process, are civic activities that require youth agency, power, and opportunity to be taken seriously. Thinking about civic engagement allows us to re-consider the conditions of participation, to rearticulate media practices with democratic values (e.g., equality, justice, peace, and empowerment), and to reimagine the relationship between youth and citizenship. Moreover, addressing civic engagement pushes us to critically analyze the opportunity structures and ecosystems of support that children and youth have in both online platforms (e.g., Facebook, YouTube, Flickr, MMORPGs) and offline worlds (e.g., home, family, work, school, community, cities). The critical analysis and design of such structures and ecosystems can help us to better understand how participation is organized; what the rules of engagement are and who is responsible for creating them; what the resources available are and who has authority over them; who decides the goals and tasks; and, ultimately, how youth are exercising their agency and being empowered.

At the 2014 Digitally Connected symposium, we learned about several participatory projects that are supporting youth civic engagement, expanding structures of opportunity, and strengthening ecosystems of support in many parts of the world Although it is not my intention to elaborate case studies of these projects, I would like to briefly mention four of them and paint a brief sketch of how youth participation and civic engagement look in the current phase of the digital age.

\section{Public Policy and Mobilization}

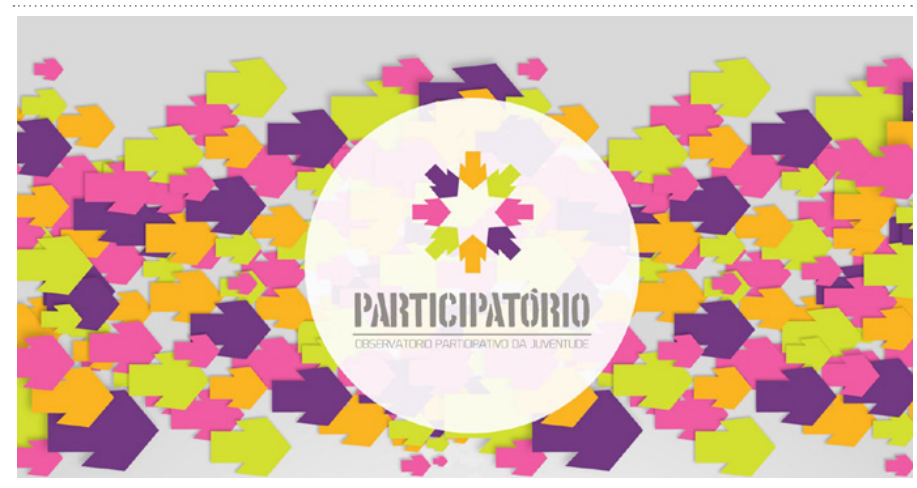

The Participatorio or Participatory Observatory of Youth (Observatório Participativo da Juventude)' is an online platform, created by the Brazilian government and the National Youth Secretary, that supports democratic discussion, mobilization, and participation in youth-oriented public policies and related themes. This platform is open to all Brazilian youth and its design resembles a Social Networking Site. It supports sociability, networking, and communication through a range of features such as forums, blogs, videos, and personal profiles. Besides being open to all of the diverse Brazilian youth population, the Participatorio is also open to researchers, parliament members, activists, and any Brazilian citizen interested in discussing youth public policy. Academic institutions such as the Universidade Federal do Paraná and the Universidade Federal do Rio de Janeiro provide the technical support for maintaining the online platform and ensure that all the data generated within the Participatorio is open and freely available. As Murilo Amatneeks, the secretary of Conselho Nacional de Juventude, said at the \#DigitallyConnected civic engagement roundtable, the Participatorio platform, in the past year, has allowed thousands of Brazilian youth to actively become engaged in the discussion of public policies, laws, and even street protests.

\section{Community Reporting}

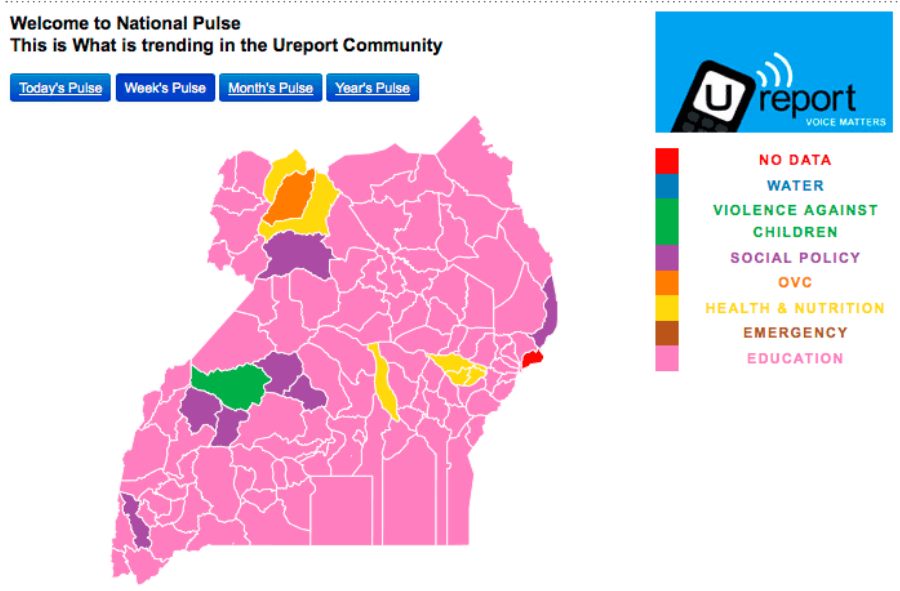

The U-report ${ }^{2}$ is a project created by UNICEF Uganda that leverages the popularity of mobile phones and SMS-messaging among youth. The project supports the discussion of issues relevant to communities across the country and provides an ICT platform to monitor local resources and developmental programs. Although anyone with a mobile phone can freely participate in U-report, the majority of participants are young Ugandans. On a weekly basis, the participants of the project make their voices heard by answering questions related to education, health, outbreaks of disease, and other crucial 
issues for the development of their communities. The UNICEF team and other partner organizations collaborate in analyzing the data collected by the U-report system and produce public maps and reports that are distributed through different media outlets. For instance, the information produced by U-report is shared in radio and TV programs, community dialogues, youth events, and through a dedicated website (with maps and graphs). U-report has become a successful system for information exchange about local communities in Uganda and has demonstrated that youth participation and civic engagement can actively contribute to identifying and solving real world problems. An example of that is how young U-reporters in a northern region of the country quickly identified the outbreak of a children epilepsy-related illness in 2012 and alerted aid organizations to take immediate action.

\section{Education and Connected Learning}

Education is a key social domain for designing ecosystems of support and expanding the structures of opportunity in democratic societies. Progressive and critical pedagogies have always emphasized the importance of empowering youth, fostering hands-on projects, supporting peer learning and collaboration, and situating learning activities in local contexts. Building on that tradition, a group of researchers, educators, and designers, has recently proposed the "connected learning" model. They emphasize the potential that ICTs and a more distributed knowledge ecology offer for supporting learning experiences that are socially connected, interest-driven, and oriented towards the creation of opportunities (Ito et al., 2013) Applying the principles of the connected learning model, in summer 2012 I helped to design and implement an action-research intervention in a majority Latino/Hispanic public high school in the Austin metropolitan area. During three weeks, a team from the University of Texas collaborated with a high school teacher and a group of 16 students in running a social innovation studio that we named DGZiN (Digital + Design). Although media production was central in our studio and our major goal was to produce an interactive book rich in multimedia content, we structured a context in which designing and making reflected a disposition that was both creative and critical of the challenges the local community faced. For structuring the learning activities at DGZiN, we used a real world challenge that connected all of the research, ideation work, and design processes to one essential question: is the pervasiveness of sugar creating a toxic food environment? Addressing this question allowed us to tell a research-driven, civic engaging, and interactive story about a social problem that affected the everyday lives of children and youth, their families, and their community. Equipped with mobile devices with multimedia capabilities, young designers researched the real world in order to validate what they were learning. They investigated their homes, school, and neighborhoods, finding out added sugars in the foods and beverages that members of their community consumed, and mapping the resources of their food environment. As a result, participants of the project were able to express critical thinking perspectives and insights through the design and production of digital media artifacts such as digital photos, animation, graphic art, interactive maps, podcasts, video, and memes.

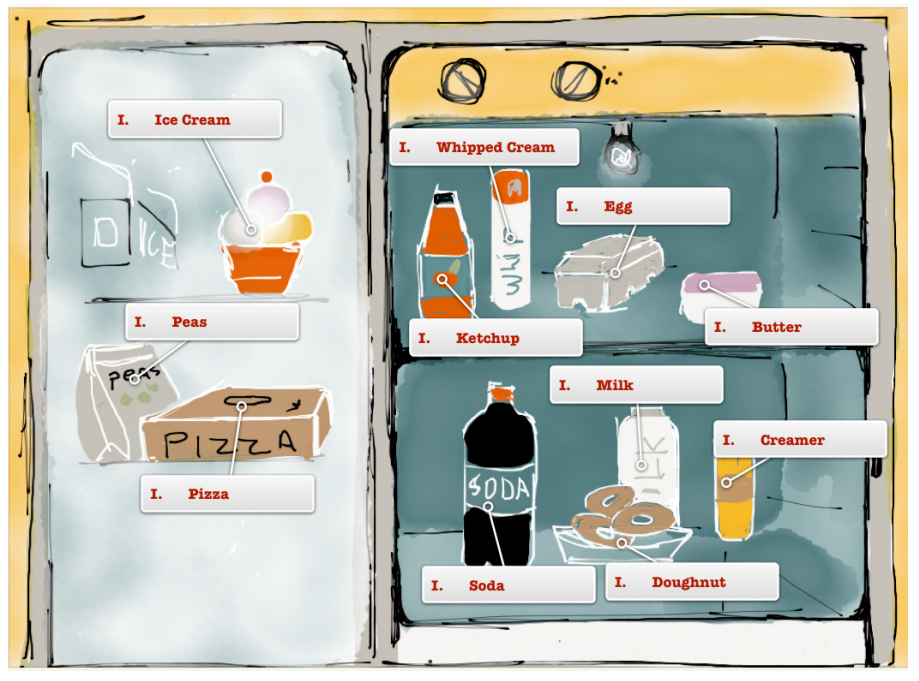

Digital Culture, Remix, and Humor: Political Memes

Finally, my last example is not precisely a single project, but a collection of participatory initiatives that can be grouped under the category of political memes. Memes are multimodal designs, usually a combination of visual imagery and text, which people make, circulate, remix, and imitate widely on the World Wide Web. From photographs of political figures to cute images of animals, memes have become one of the most popular cultural artifacts 
produced, shared, and transformed in the digital age. Among all the participants in the Internet memes cultures, young people from all corners of the world are some of the most active contributors. They actively channel their creative energy and humor in the curation, circulation, and making of memes, and they seriously enjoy engaging in visually driven conversations. By being engaged in meme-related media practices, youngsters are finding a gateway to political debates, activism, and social movements. Hence, it could be said that collective and distributed meme projects such as the \#AnnaHazare in India, the \#CasuallyPepperSprayingCop in the United States, the \#CandiGato in Mexico, and the \#GrassMudHorse in China, do foster youth participation and civic engagement by allowing young people to actively make, remix, and share multimodal designs with a political message. The meme-related media practices that emerge from these initiatives are empowering diverse youth around the world. They support the development of tactics and workarounds that address political debates and complex social challenges (e.g., immigration reform, income inequality, freedom of expression in authoritarian regimes, etc.) leveraging youth voices and tastes.

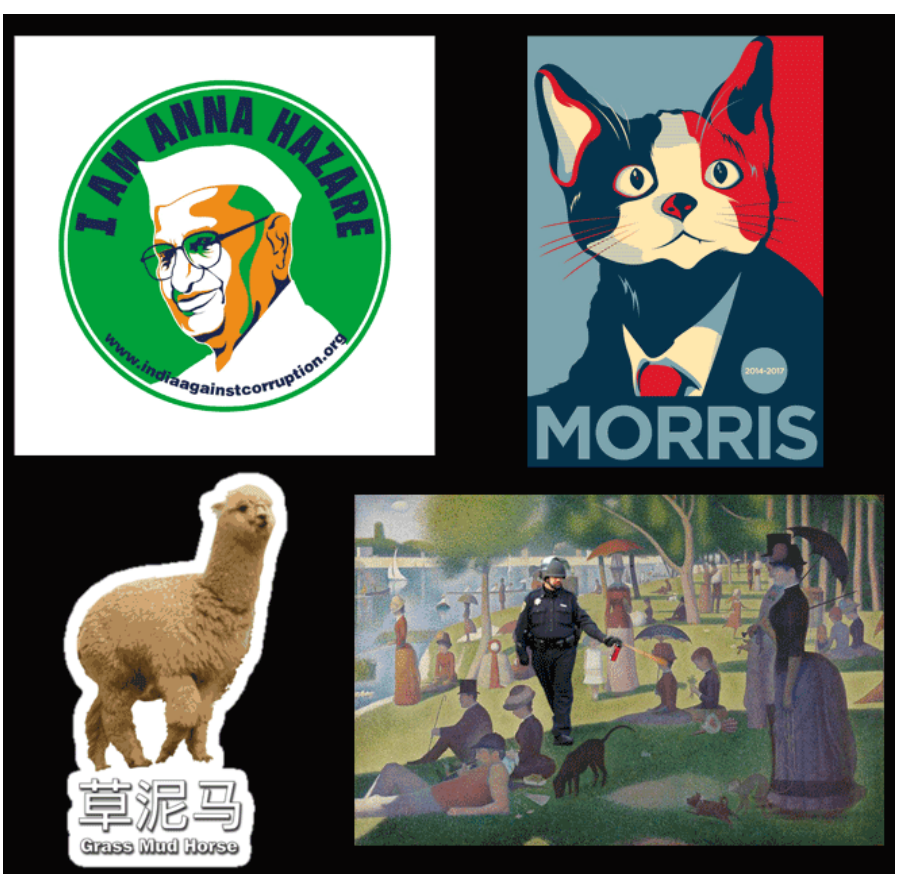

In Text

1 http://participatorio.juventude.gov.br

2 http://www.ureport.ug

References / Resources / Links

Hargittai, E. (201 1). Digital Na(t)ives? Variation in Internet skills and uses among members of the 'Net Generation'. Sociological Inquiry, 80.1.

Hargittai, E., \& Walejko, G., (2008). The participation divide. Information, Communication and Society, 11 (2), 239-256.

Jenkins, H., et al. (2006). Confronting the challenges of participatory culture: Media education for the 21 st century. Cambridge, MA: MIT Press.

Ito, M. et al. (2013). Connected Learning: An Agenda for Research and Design. Irvine, CA: Digital Media and Learning Research Hub.

Livingstone, S., Couldry, N., \& Marknam, T. (2007). Youthful steps towards civic participation: does the Internet help? In Loader, Brian D., (ed.) Young Citizens in the Digital Age: Political Engagement, Young People and New Media. Routledge, London, UK, pp. 21-34.

Lopez, M.H., Gonzalez-Barrera, A., \& Patten, E. (2013). Closing the Digital Divide: Latinos and Technology Adoption. Pew Hispanic Center: Washington, DC.

Schradie, J. (2011). The Digital Production Gap: the Digital Divide and Web 2.0 Collide, Poetics. 39, 145-168.

Van Dijk, P. J. A. G. M. (2005). The Deepening Divide: Inequality in the Information Society. Thousand Oaks, CA: Sage Publications, Inc.

Watkins, S. C. (2012). Digital divide: Navigating the digital edge. International Journal of Learning and. Media, 3(2), 1-12.

\#AnnaHazare: See for instance these collection of stories from the Guardian: http://www.theguardian.com/world/anna-hazare and this Wikipedia entry http://en.wikipedia.org/wiki/2011_Indian_anticorruption_movement

\#CasuallyPepperSprayingCop: For further reference refer to the Tumblr where many of these memes were published: http://peppersprayingcop.tumblr.com/

\#CandiGato: See more information at http://knowyourmeme. $\mathrm{com} / \mathrm{memes} / \mathrm{el}$-candigato-morris-morris-the-cat-idate

\#GrassMudHorse: See more information at http://en.wikipedia.org/wiki/Grass_Mud_Horse 
CHAPTER 8

Youth Participation

\section{and Policy}




\section{Children, ICT and Development: Innovation for Equity on the Basis of Participatory Practice}

Dorothea Kleine

ICT4D Centre, Royal Holloway, University of London
This short essay is based on my keynote 'Using ICTs to support child- and youth-related development work: Collective learning from practice and remaining research needs' at the Digitally Connected symposium, Harvard University, 28-30 April, 2014. The related report we produced in collaboration with UNICEF: 'Children, ICTs and Development' (by Dorothea Kleine, David Hollow and Sammia Poveda), is available here: www.unicef-irc.org/ publications/pdf/unicef_royalholloway_ict4dreport_ final.pdf

Information and communication technologies, and here we can think of the Internet, mobile phones, tablets, radio, participatory video, social media etc. can support a variety of child- and youth related development projects. Examples include mobile learning, online support for teachers and health workers, birth registration and health checks, to helping children and youths express their views and participate in public debates. This is a thriving, diverse, multidisciplinary and multi-sector field of work, and the different communities do not always talk to each other. Further, we have to keep in mind of course that technology is not a silver bullet, but always only one ingredient in wider systemic social change.

Let's ask experts and practitioners coming from different angles about what works and what doesn't in child-and youth related development projects. That was the key idea with which UNICEF Office of Research approached our ICT4D Centre at Royal Holloway, University of London. The resulting report was a co-production by the ICT4D Centre at Royal Holloway (Sammia Poveda and myself), JigsawConsult (Dr David Hollow) and UNICEF Office of Research (James Elder, Patrizia Faustini and Dale Rutstein). 133 items of literature were reviewed and 35 experts interviewed. This essay summarises some key findings.

\section{Demand-Driven, User-Centred, Participatory}

One of the strongest themes that came out of the expert interviews was the insistence of most interviewees that for project success it was vital to not start with the technology and then look for a problem to use it on, but to start with the challenge and identify what might be the appropriate technology.

Further, they stressed the need to understand the existing contexts, systems and stakeholders. An ICT and development practitioner from a UN agency explained that reflecting on the birth registration project they had been involved in, it would have been worth investing more time in exploring existing initiatives and potential partners:

[Going back to the beginning] I would have done much more, sort of explore the landscape of birth registration, who can be a possible stakeholder, I should have done much better homework. If I had the chance to go back I would do that.

In addition, there was a view by many that ICT4D should seek to work with local people, and where possible with local designers of the technology. Within this participation theme, there was strong support for engaging with children as users, and where appropriate as co-creators.

Obviously, children and youths are not a homogenous group and differ in for example age, gender and educational opportunities. Interviewed experts stressed the importance of "actually listening to the child's perspective" rather than designing development programmes from an adult perspective. On the other hand, there was a call to acknowledge the key role that intermediaries such as parents and relatives, teachers, health worker and youth workers play in guiding children and youth. 


\section{Equity}

There was a real concern among the experts we interviewed that rather than achieving more equality, the current spread of ICTs was exacerbating pre-existing inequalities. Dimensions of this inequality include for example: gender, disability, education and literacy, dominant and less dominant languages, rural and urban, low-income and high-income households.

Gender was a particular theme when discussing access in the interviews. Gerster and Zimmermann (2013) speak about affordability, availability and skills for access and Linda Raftree also points to the issue of relevant content. Further, interviewees pointed to the importance of safe access spaces. Some experts also raised the issue of time, in particular girls' time. This is how one tech designer put it:

Children, particularly the girls we worked with [...] are so busy [...] many of them are not in school because they are tending to the farm, they are tending to other children, they are taking care of the household, their time is so valuable and limited. You are designing services, we tend to think about the luxury market, the person who has all the money in the world is the most demanding consumer, but I would argue that young girls in these environments are probably the most demanding end user you can probably design for in the world.

So a "design for equity" approach would actively focus on the more marginalised when designing at programme, project and indeed technology level. However most ICT projects do not go and seek out the most marginalised children.

Why is that? Well, a lot of it is down to incentives - These groups may be more costly to reach, less "ready for uptake" and indeed they may be less able to pay user fees which would be one way to ensure the longer-term financial sustainability of the project once donor-funding runs out. So they are riskier to work with.

So all else being equal, unless funders explicitly see the focus on, or at least the inclusion of harder-toreach groups as a priority, the current incentive structure will continue to support an equity-blind and in some cases anti-equity approach. This is a real systemic challenge which both the funding and the practice side need to address.

\section{Pilots and Scaling Up}

With many interviewees, the express urge was to get away from lots and lots of small pilots. A practitioner from a multilateral agency explained:

Uganda is a graveyard of successful pilots. I could list off about 40-50 projects who met all of the donor objectives and succeeded based on every metric they put in place, but disappeared months after the funding dried up and didn't scale.

However experts were divided in their views as to whether only a scaled-up project was a successful project. A representative of an international children's NGO said:

I am really afraid of these large-scale solutions that a lot of people talk about, and I really feel a lot of it has to be context specific.

Which brings us to the role of the private sector. The private sector, in particular technology companies, are often indispensable partners in ICT for development projects. Interviewees highlighted the opportunities that ICTs brought for stimulating private enterprise and job creation, but there were also concerns. Two issues were highlighted in particular:

Firstly, the tension between the commercial interests such as market expansion and the ambition to target the most marginalised, who often have least ability to pay. Some bottom-of-the pyramid business models exist, but they were not seen as the norm. Secondly, technology companies' understandable commitment to "their" product can lead back to a technocentric approach which starts with the technology rather than the problem it is meant to help solve.

Here is a quote from a technology company representative who told us they wanted to remain anonymous:

[Company name] has come in pretty hard and said, you know we'll do a free training for all teachers on [company name] products, well they 
didn't say that but that is what they'll do, they'll train teachers on how to use [company name] products which is another huge expense if they decide to go that way rather than something open source.

\section{Failure}

Many interviewees pointed to Failfairs as useful events that help make failure in ICT4D projects visible and share learning. There is a temptation to categorise projects as either successes or failures and the hype cycles and failfairs contribute to that. Interviewees highlighted some high-profile failures and some projects they admired. However, the strongest emphasis was on a culture of ongoing learning. Most successes contain elements of failure and many so-called failures contain things that did work, and the seeds for a future success.

Experts said that monitoring and evaluation research too often is tagged onto the end of projects as an afterthought. However, it needs to be integrated into all stages and indeed we should evaluate projects two, three, five years after the end of the initial funding period to get a true picture of local uptake.

\section{Points of Consensus and Future Research Agenda}

Overall, what we might be seeing is a new consensus forming around more context-aware, participatory, child-focused and equity-sensitive approaches for ICTs in child-related development work.

To conclude, I will offer some observations on what further research is needed in this space:

- The first thing to note is that there still is not enough systematic data on ICT access by children and youths in the global South. We need to urgently overcome the Euro-North American bias in the data.

- Secondly, we need to move away from aggregate statistics at country level and better understand the comparative life realities of the most disadvantaged compared to the most disadvantaged children and youths. We should use quantitative and qualitative research to do this. Based on this information, donors will be in a better position to appreciate the challenges faced when projects work with harder-to-reach children and youths. Donors need this information to reliably "cost" that risk.

- Apart from the mapping of the status quo, I believe passionately that researchers can play a role in being partners in action research. Beyond understanding the world, we want to also play our part in changing it. Researchers can help with Monitoring, Evaluation, and Learning - not as know-it-all inspectors who fly in for spot checks without a grasp of just how challenging the dayto-day work is, but as critical-constructive friends and partners in ongoing learning what works, where and why - and what doesn't.

- Finally, projects don't operate in a vacuum research on policy is vital to understand which are the truly enabling environments for this work to flourish.

So more research needs to be done on all these aspects - on mapping access and use, on policy, and on action and constructive Monitoring, Evaluation, and Learning research.

From the ensuing discussions at the Digitally Connected symposium at Harvard University where we presented the report, I took away these further points:

1) There is considerably more research data available not just on the relatively more privileged children and youths in the global North, but also among elites in the global South. With vast inequalities not just between countries but also within societies everywhere, we need to move away from a binary of global North and South and think more in continua, or rather fragmented, co-evolving life realities.

2) In ICT4D projects, working with the harder to reach carries greater risks that projects fail because of e.g. infrastructure challenges, less IT literacy and time and money pressures which draw potential participants away. If funders such as UNICEF, with their clear commitment to equity, want projects to be directed towards the more marginalised, they will need to accept the higher risk of project failure. This will take courage and leadership, and UNICEF have a key role to play 
in undertaking of commissioning research into the comparative life realities of children and youths in urban vs rural areas, and among highincome and low-income groups, "cost the risk", and then consciously working with the more marginalised groups.

3) With technology evolving so fast, project "failures" will also occur. Traditionally, development agencies have had an uneasy relationship with failure and have tended to hush it up instead of developing systems of learning through trial and error. At the symposium, there was talk about how Silicon Valley tech culture recognises the value of "failing fast" to evolve new ideas quickly. This second approach is beneficial for learning, however a distinction needs to be made between failure in consumer product design and failure in development-related projects. Hopes, aspirations and dreams, particularly among disadvantaged children and youths are not infinite, but precious and vital psychological resources which form / the basis of their agency. So when working with children and youths in projects which involve new technology, we need to find ethical ways to allow failures and learning to happen without destroying hope. Funders have a vital role in providing both "venture capital" and "patient money" so that while projects and technologies come, succeed or fail, practitioners can remain committed and develop long-term partnerships with a community. At the symposium, it was suggested that we should invest in people and partnerships, rather than just technologies and projects.

I look forward to continuing this conversation, in order to together shape this vital agenda for research and action - in the interests of children and youths everywhere. 


\section{Risky Business? Emerging Policy and Young People's Agency in Online Safety: From Risk to Harm in the South African Context}

\author{
Patrick Burton \\ Centre for Justice \& Crime Prevention
}

The paper builds on the discussions on the important shift in focus from online risk to harm and harm reduction discussed at the symposium and will provide a critical analysis of the current environment in South Africa, as well as discussing challenges and opportunities for generating new ways of thinking within the policy environment. While the paper draws on emerging South African policy, it allows for some generalization to regional countries facing similar challenges.

An emerging theme in recent literature on young people's online safety is the importance of shifting the emphasis away from the risks that they may encounter online to the actual harms resulting from online interactions (Mitchel et al., 2014). This is not to say that the strategies to address risk that may exist for bullying, harassment, and other forms of aggression or anti-social behavior online should be abandoned. Instead, greater emphasis should be placed on preventing those actions that result in harmful outcomes for children, while at the same time building young peoples' sense of agency to manage and respond to online "threats" appropriately. This theme, and the importance of concentrating on harms, was reflected at the recent Digitally Connected symposium, co-hosted by the Berkman Center for Internet \& Society and UNICEF, and was raised in a number of discussions, ranging from online safety to digital citizenship.

These conversations are particularly relevant to South Africa as it starts to address some of these issues in policy. South Africa has seen exponential growth in the use of ICTs and, in particular, social media. Mobile telephony has offered the opportunity to bridge communication gaps and make a meaningfully contribution to universal service obligations. With this increase in access to mobile phones, there has been a concomitant increase in access to the Internet, using mobile platforms, both on smart- and non-smartphones. Four out of five (81.1\%) school-going children have access to a mobile phone, while almost half (46.2\%) access the Internet via their mobile phone (C JCP, 2013). Indeed, since 2012, mobile phones have been the most common point of Internet access for many children in South Africa, particularly those living in rural and peri-urban areas (World Wide Worx, 2012).

With this growth in access, there has been a concomitant increase in concern about the risks and dangers that lurk online, particularly through social media. This has been fuelled by reports both locally and internationally on high profile stalking and cyberbullying cases, and in the most extreme of cases, related suicides. In South Africa, several high profile cases have been defined by their relationship to specific social media, the best example being the case of the "Facebook murderer," although similar nomenclature has been applied to several similar cases, in other countries, including the United States and the United Kingdom.' With such cases receiving so much media attention, it is these outliers, together with several sexting cases, that have largely defined the approach adopted by policy makers to addressing online safety.

These cases, however, have little bearing on the everyday, lived, experiences of young people (online). There has been little empirical research conducted on the risks that young people encounter and take online, how often they result in harm, and how young people deal with both these risks and harms. Similarly, there is little attempt to understand how young people themselves conceptualize online safety, risk, and the various forms of harms that may result from their online interactions (CJCP, 2013). Rather, a somewhat simplistic (or in some instances, no) conceptualization of risks, harms, and even 
online safety itself, is informing the policy approach that government is moving towards adopting. The integration of well-meaning, but uninformed, measures of child protection into a policy framework that promotes restriction and control, and limits access, is likely to adversely shape young peoples' online experience, undermine the development of any form of resilience, and negatively impact on the development of healthy, exploratory social exchanges and experiences.

In South Africa, this discussion has bearing on two particular policy papers that are under development. The first is a strategy under development by the National Department of Communication on Children and ICTs. This paper explores all aspect of children's engagement with ICTs, but also includes other digital and broadcast media. The second is the Green Paper on Information Communication Technology, published for comment in February 2014.2

The first paper, as its name suggests, specifically focused on young people. Its current draft form describes a "balance between the right to freedom of expression with a responsibility to protect children from exposure to potentially disturbing, harmful and inappropriate materials, as well as to protect children from sexual exploitation through the deployment of ICTs." (Dept. of Communication, 2013). The paper offers an important and ideal opportunity to build on young people's own understanding and experience, their priorities and concerns, and to acknowledge and leverage their own approaches and strategies in order to inform policy. It could also argue for a much more nuanced understanding of the language, and concepts, relating to online safety, that can in turn be incorporated into national policy. Further, the paper offers an ideal platform from which a consolidated approach to building young people's resilience online can be framed while balancing this with the more conventional protection approaches. Unfortunately, in its current form, there is little recognition of the agency that young people themselves have in determining the outcomes of their online experiences. Rather, the strategy's focus is more on child participation as a means to achieve that balance between the protection of freedoms, and the protection of children. This is primarily to be achieved through children generating media content, rather than through unpacking different meanings, priorities and experiences that children generate or may have online.

The second important policy document is the Information Communication Technology Policy Green Paper. Despite the exponential growth of the Internet in South Africa, there is almost no consideration of children, the Internet, and/or social media in this policy document, beyond reference to the reporting of inappropriate content to the Broadcasting Complaints Commission of South Africa and the Independent Complaints Commission Codes. These also both refer specifically to broadcast media rather than the Internet and online environment and relate to reporting and complaints regarding content. There are passing references made to other policies that focus on content control, such as the Films and Publications Act. As this ICT Policy paper will be the foremost policy governing the ICT industry in South Africa, the omission of how the policy relates to and impacts children and their online experiences constitutes a considerable gap in what is potentially an important piece of pending legislation.

In short, within the current policy framework, there is no consideration paid to the manner in which young people learn from their online experiences; the importance of building young people's resilience; the importance of providing young people with the skills to negotiate their way online successfully and safely; or the skills, capacity, or agency that already resides with young people in relation to their online experiences and behaviors.

On its current trajectory, policy in South Africa is most likely to maintain this focus on protection, wasting the vast potential for learning, building responsible and safe behaviors, and enhancing young people's resilience to everyday experiences. As boyd argues in relation to surveillance of children's online activities by parents, "teens are configured by the surveillance they experience. It shapes their understanding of the social context and undermines their agency" (boyd, 2014, p.74). In short, by overemphasizing the control and management of young people's online experiences, we are in fact doing young people a major disservice, undermining their capacity to learn, to keep themselves safe, and to understand the 
contexts in which they do and will continue to live. Doing so also undermines the formation of positive relationships online and offline, and the capacity to deal with conflict encountered on a daily basis.

A final aspect, which was also raised repeatedly at the Digitally Connected symposium, is the voice of young people - children and teens - in the policy discussions that directly impact them. Exclusion of children's voices is likely to result in policies that are irrelevant, misguided, and unlikely to achieve any meaningful long-term policy outcomes. Effective policies will require acknowledgment of young people's agency; understanding of their experiences online; and what may be the "DNA" of their lived experiences. In the case of the Children and ICT strategy paper, initial consultation with children was undertaken seven years ago, at the initiation of the strategy development, with no further consultation. Given the speed of change and development within the ICT sector, the challenges and opportunities are constantly changing for young people. Not only does this mean shifts in experiences and opinions, but the very language that makes policy relevant will arguably have fundamentally shifted. Before both the ICT Policy Green paper and the Children and ICT Strategy are finalized, further consultation with young people themselves should be integrated into the development process and included at each stage of the documents' development and finalization.

In its current trajectory, there is a very real possibility that the various policies framing young people's online experiences, behavior, and engagement will be finalized in a context of fear and intuitive responses to what is seen as both a moral and real threat. However, the opportunity to use empirical research and evidence to shape an enabling environment where young people's own resources and capacity is recognized is possible. Within this enabling, empowering environment, young people should be encouraged to successfully deal with online risks and develop resilience to online (and offline dangers) with support from parents, educators, and other adults, while at the same time minimizing the potential for harmful outcomes. Finally, such policies should adequately provide for the development of adequate support and response mechanisms for when harms to children and young people do occur.

\section{In Text}

1 For some notorious examples, see http://www.washingtonpost. com/national/why-we-should-fear-miamis-facebookmurderer/2013/08/09/2c331fec-0131-11e3-96a8-d3b921c0924a_ story.html and http://www.theguardian.com/uk/2010/mar/08/ peter-chapman-facebook-ashleigh-hall

2 It should be noted that these are not the only policy documents, or Acts, that impact on children and their use of ICTs and social media, but are the two that deal most directly with social media and ICT. Other pieces of legislation that have some relevance include the Film and Publications Act (1996) (Act No.65 of 1996 and the Amendment Act 2009), the Sexual Offences Amendment Act (2007) (Act No.32 of 2007), the Children's Act (Act No. No. 38 of 2005), the Protection From Harassment Act (2011) (Act No.17 of 2011), and the Child Justice Act (2008) (Act No.75 of 2008). A discussion of how some of these impact on children's use of social media, and specifically on their experiences of cyberbullying, is provided in Badenhorst (2011).

\section{References / Resources / Links}

Badenhorst, C. (2011). Legal Responses to Cyberbullying and Sexting in South Africa. CJCP Issue Paper no 10. Retrieved from http://www.cjcp.org.za/uploads/2/7/8/4/27845461/issue_ paper_10.pdf

Boyd, d. (2014). It's complicated: The social lives of networked teens. Yale University Press: New Haven.

CJCP. (2013). Connected Dot Com: Young People's Navigation of Online Risks. CJCP/UNICF.

Department of Communications (2013). Children and ICTs Strategy - Draft. Personal correspondence with Ms. Petronella Linders, Director, Department of Communication. South Africa.

Mitchel et al. (2014). Trends in Unwanted Online Experiences and Sexting, Crimes Against Children Research Center, University of New Hampshire. Retrieved from http://www.unh.edu/ccrc/pdf/ Full\%20Trends\%20Report\%20Feb\%202014\%20with\%20tables.pdf

World Wide Worx (2012). Internet Access in South Africa. Johannesburg, South Africa. Retrieved from http://www. worldwideworx.com/wp-content/uploads/2012/12/ExecSummary-Internet-Access-in-SA-2012.pdf 


\title{
Research and Generation of Public Policies: Future Challenges
}

\author{
Juan Cruz Gonzalez Allonca \\ Con Voz en la Web for Ministerio de Justicia y Derechos Humanos, Argentina
}

We have often read, or even quoted, that we cannot manage what we cannot measure. It seems quite obvious, but it is an irrefutable fact. Generations of managers have been influenced by Peter Drucker's unequivocal admonition:

\section{"If you can't measure it, you can't manage it."}

If you want to manage your organization-be it an automobile assembly plant, or a child welfare agency-argued Drucker, you have to be able to measure what you are doing. And why measure? Because such measures help managers do many tasks, from evaluating how well the organization has done in the past to learning how to improve it in the future.

Along similar lines, $\mathrm{H}$. James Harrington holds that "measurement is the first step leading to control and eventually to improvement. If you can' $\dagger$ measure something, you can't understand it. If you can't understand it, you can't control it. If you can't control it, you can't improve it." For the measurement to fulfill its purpose, it must be compared with a goal or purpose, with a moment (to achieve improvements), and with a referent.

It is also true that the direct implementation of exact sciences to human sciences within which we find ourselves has failed. The most radical case we can reference is the one of Thermo-economy that unsuccessfully attempted to apply physics and mathematics to economy. Since human beings were the objects under study, assessments and scales should have been subjective, personal, and under constant revision.

For that reason, as regulators we ask ourselves: Is it important to analyze, interpret, and implement policies on academic research? The answer is yes. With the help of evidence-based policies we can ascertain the scale and incidence of existing problems, identify priorities and policy needs, and reveal emerging issues. At the same time, such studies allow us to contextualize or interpret puzzles and problems, to enable the targeting of specific interventions, and evaluate the outcomes of interventions or policies.

However, decisions must be made not only based on statistical evidence, but after being in touch with the problem with actual presence in the field.

It is important to base our decisions on research, statistics, percentages, etc., following Peter Druker's concept. It is also very significant to listen to and evaluate the voices of children to both understand their motivations, perceptions, and experiences, and to contribute to the definition of certain strategies as an extra variable.

With this in mind, the Dirección Nacional de Protección de Datos Personales (Data Protection Agency of Argentina) through the national initiative Con Vos en la Web has developed activities on online risks and opportunities built around children as recipients, participators, and agents to guide research and policies. From our perspective, the opinions and perceptions of kids must be a relevant factor to define public politics. Essentially, we must listen to their voice.

We have many communication channels to listen to the voices of children. We must also listen to their voices in social networks. It is essential for our work that reflection and research accompany practice. The existence of one without the others is impossible since they both lose sense. Research would be worthless if the regulator is not questioned or examined in a given sphere of application about the mode, the time, or the purpose of his actions and his social role.

From the perspective of regulators, we gave ourselves the following challenges:

\section{Multi-Stakeholders Scopes}

In the international field we must think of globally effective links between researchers 
and educators, policymakers, and the public. Significant opportunities for the relationship between researchers and policymakers are given in multistakeholders' spaces. For example, during last April the NETmundial, the Global Multistakeholder Meeting on the Future of Internet Governance, was held in Brazil, with a focus on crafting Internet governance principles and proposing a roadmap for the further evolution of the Internet governance ecosystem. These meetings are excellent occasions to create links between researchers and policymakers to strengthen participation in areas related to scientific research in these scopes that seek to bring stakeholders together to participate in the dialogue about, decision-making of, and implementation of solutions to common problems or goals.

The multistakeholder process involves the full involvement of all stakeholders, consensusbased decision-making and operating in an open, transparent, and accountable manner. Multistakeholder processes could and should enhance democracy by increasing opportunities for the effective participation of those most directly impacted by decisions, particularly those at the grassroots who so often are voiceless in these processes. They should enhance democracy by ensuring that the decisions made are reflective of and responsive to local concerns and the broadest range of those who must bear the consequences. They should enhance democracy by making democratic processes more flexible and responsive, able to adjust to changing contexts, circumstances, technologies, and impacted populations.

\section{Inclusion of Researchers in the Participative Preparation of Regulations}

In Argentina, one of the opportunities we have as policymakers is to include areas related to research in the development of policies (Dispositions, Opinions, Rules and Regulations, etc.). The Participative Preparation of Regulations is a procedure in which by means of non-binding consultation, interested areas and general population participate in the preparation of administrative regulations and draft laws, whenever viability and opportunity allow it.

This is a mechanism by which an institutional space is created for the expression of opinions and proposals, regarding administrative regulations and draft laws. For example, nowadays we are working along with universities and research institutes on Information Sciences and Computing in a Disposition draft to determine a set of concrete obligations for data protection of users. These actions are intended both for application developers and suppliers, including advertising services providers.

\section{Strategies to Link Researchers and Social Needs / Social Policies}

We must think of a strategy in which I+D sectors select priorities and bear in mind those responding to the concrete needs of society set by social policies. We must also guarantee the transference and application of results by researchers. This implies the creation of networks with various stakeholders, articulation with users, implementation of new linking mechanisms, and promotion of social technologies and innovation.

To guide science and technology policies towards a convergence with social policies implies that we should think in terms of frontier scientific knowledge or advanced technology, given that both innovation and resolution of social issues in Latin American countries usually demand technologies with low or medium scientific content. In this case, the novelty of these programs lies in the capacity to duly identify the nature of the requirements, analyze the best solutions in dialogue with the involved parties, and present an analysis of the problems, pursuing the most socially adequate means of resolution.

Social sciences possess the necessary tools to help society think strategically, and they thus allow it to create an effective connection between the desired cohesion goals, the necessary means and actions towards such a purpose. These actions shall be developed in issues of interest such as works on digital inclusion, cyber security, and education, among others.

From the social sciences field it is possible to collaborate also in the elaboration of indicators to measure and monitor policies aiming to improve social cohesion. Indicators must not reflect only objective dimensions but perceptions and attitudes of involved parties, as cohesion implies considering the attitude of citizens towards the way in which public policies act. Actual application of knowledge can only be guaranteed by a close connection between policymakers and involved researchers. 


\section{E-Inclusion Is Social Inclusion}

\section{Ezequiel Passeron}

Con Vos en la Web

Over the last few years, we have witnessed an unprecedented social transformation related to the development of the new technologies and the ICTS (Information and Communication Technologies), which have introduced new behaviors and habits in users, especially kids and youth.

In Argentina, these changes were possible primarily because of increased access to both devices and connectivity. In order to explain the local scenario, we must emphasize the significant advances made with regard to public policies carried out by the state to strengthen digital access and e-inclusion. The National State has a global strategy for understanding the phenomenon of ICT penetration in our country.

One of the main public policies in Argentina is the Program "Conectar lgualdad", http://www. conectarigualdad.gob.ar/ through which over 3.5 million net-books have been delivered to students and teachers in public secondary schools all over the country. "Conectar lgualdad" works to decrease the digital divide, and also grants access to devices. The universal distribution of netbooks aims to equal rights of all populations. The computer (netbook in this case) creates an environment in which all children who receive one may, become informed, have fun, connect, and learn with technology.

The website, Educ.ar http://www.educ.ar/, part of the Ministry of Education, works to complement the delivery of netbooks with training and teaching incentives, and is dedicated to granting educational tools related to ICTs to teachers and families all across the country. The purpose of a website like Educ.ar is to foster innovation in using new technologies in the "Knowledge society". To achieve this, the website generates materials to stimulate active and innovative use of ICTs.
"Argentina Conectada" of the Ministry of Federal Planning is another public policy that intends to execute a comprehensive connectivity strategy to improve and democratize communication throughout the country. For this purpose, infrastructures and connectivity equipment have been developed, along with a federal fiber optic network, beginning with poorer areas, with the purpose of federalizing quality, prices, and contents.

On the other hand, to guarantee e-inclusion, the program implements various policies in order to develop skills and motorized tools so communities can evolve. For this reason, the "NAC"s (Access to knowledge Cores) and "PAD"s (Digital Access Points) http://www.argentinaconectada.gob.ar/ contenidos/nucleos_de_acceso_al_conocimiento. html have been created as new public spaces with free Internet to grant communities opportunities to connect, using computers, micro cinemas, and playing areas. In these spaces, children and youth can enjoy free Internet, play online games, learn with ebooks, watch educational movies, etc.

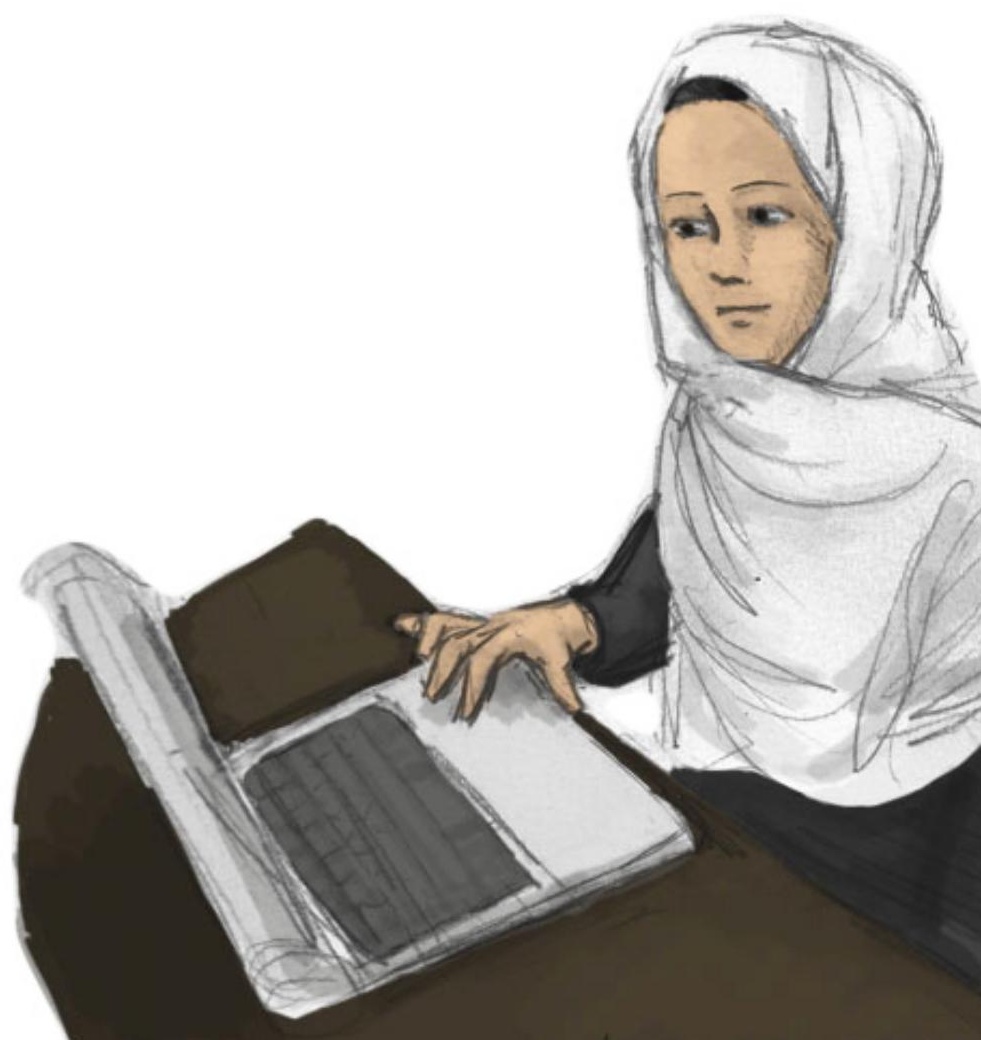


Such policies guarantee an increase in the number of ICT users. This means that people are immersing themselves in new worlds with new possibilities, but also with new risks.

In order to promote safe usage of the Internet, several state initiatives, such as "Internet Sano" (Healthy Internet) http://www.internetsano.gob. ar/paginas.dhtmlepagina=1, seek to promote social behaviors and values. These initiatives help children, young people, and adults (especially parents and teachers) use technology innovatively, comprehensively, and safely. Acknowledging that digital natives don't distinguish the offline world from the online world, we intend to help young people develop critical and reflective skills in order to maximize their abilities to identify and reduce harms.

Another program seeking consideration as a manual for responsible and safe use of ICTs is "Con vos en la web" http://www.convosenlaweb.gob.ar/, which hopes to make new technology users aware of the significance of taking care of personal information, mainly on the Internet and social networks. Personal data are the means of exchange by which we enter various Internet services such as social networks, emails, or different kinds of chats. The primary goal of this program is to highlight the importance of privacy and intimacy. These are two human rights at risk due to the web. Thus, for "Con vos en la web", it is crucial to give information, advice, recommendations,

tutorial videos, games, animations, and audiovisual content (videos) to show the opportunities offered by the 2.0 world, but also to illustrate the potential risks of its use. In that sense, several workshops, talks, and training sessions are conducted to prevent potential risks and handle them if necessary.

As we have seen, the Argentine State seeks to bridge the digital divide with different strategies: by delivering computers, providing connectivity, disseminating educational material, training teachers, and creating awareness about the best practices to avoid dangers on the web. In this way, we can have a country that values access to new technologies. At the same time, we will take care of the personal data and privacy of young people and adults. 


\section{It's a Youth Quake! Mobilising Youth Participation for Research, Policy and Practice}

Jane Burns

Young and Well Cooperative Research Centre

\section{Amanda Third}

Young and Well Cooperative Research Centre University of Western Sydney

It was with great excitement that we flew to the other side of the world to attend a two-day extravaganza of international thought leaders who shared our interest in using technologies for good. Co-hosted by UNICEF and the Berkman Center, we were delighted to have the opportunity to present at the symposium and reconnect with some of the leaders in our field, like Sonia Livingstone from UK Kids Online, and Amanda Lenhart and Mary Madden from the excellent Pew Internet American Life Project.

By way of background, the Young and Well CRC is an Australia-based, international research centre, bringing together practitioners, young people, policy makers and researchers from over 70 partner organizations to generate cutting-edge research that can inform policy, practice and products that can improve the lives of young people. We aim to empower young people to manage their own wellbeing and therefore invest heavily in app development, web-based interventions and digital campaigns. We also want to make sure young people are safe online, so we work closely with partners to educate young people about being cyber-savvy and contributive cyber citizens. Finally, we look to how technology can literally disrupt our mental health system by introducing new systems, new technologies and new approaches that aim to empower the new breed of consumer.

The Young and Well CRC looks to drive innovation in the mental health and wellbeing space through a simple process that begins with conceptual design using participatory design principles. This step ensures rapid prototyping with the inclusion of young people, sitting alongside scientists, practitioners and policy makers, to determine programs that best resonate with young people. Prototypes are developed for testing. This stage is one part of a crucial step that positions young people as the experts - experts in co-design, but also experts in co-research.

Co-research assumes that every research decision will be made with input from young people. For the Young and Well CRC, our process is pretty simple. Young people sit alongside our scientists, professionals and researchers. The Youth Brains Trust (YBT) is a branch of our organization we are incredibly proud of and one that truly sets us apart from other bodies in our sector and beyond. Our YBT is made up of young people aged 12 - 25 years, a diverse group that bring their own experiences and interests in mental health and wellbeing to the table. Each calendar year, the Young and Well CRC induct a new cohort, with more than 60 young people now comprising the YBT and extended alumni network. The experience of the YBT is best summarized in the words of one of our current members, Michael Fajardo:

"The vibes and energy surging through each YBT member that first time we met, it really was powerful! I really felt that as a group, in a concerted and coordinated effort, we really are changing the youth mental health landscape. We are making a difference."

The group interacts regularly, both face-to-face and via online platforms. The primary role of the YBT is to provide direction to the Young and Well CRC, and to determine if the proposed project would resonate with young people. In addition to this part of the process, our researchers are required to establish a youth advisory board, and/or have young people on their project board to inform the development of 
the project. This approach is clearly not a traditional academic one. It is fast paced and positions the young person as the equal partner rather than simply a research participant. This approach can, at times, make academics nervous.

It was, therefore, with great interest that we participated in conversations at the Berkman Center about young people and how our organization might collaborate to ensure better outcomes for young people. We believe we have an excellent model that is consistent with the Convention of the Rights of the Child, that empowers young people by giving them voice in all elements of decision making, and importantly that fast tracks research to ensure rapid prototyping.

Youth participation is central to the Young and Well CRC, placing young people at the centre of the development, trial and execution of policy and practices that will directly affect their lives. As an organization, we believe the strongest outcome is achieved via the genuine and active involvement of young people at each step of the process, translating to informed policy and practice. Meaningful participation is key to the success of our program, with respect for young people's views and experiences integral to generating inclusive outcomes.

The discussions at the symposium on Global Youth and Digital Media provided us, as researchers, with great motivation and excitement. Our sector is determined, and standing ready to help support young people via technology. Young people operate in the online space across every facet of their life, working, learning, socialising and playing via the Internet. It is a natural progression, then, for research examining how to best engage young people with mental health and wellbeing resources to factor the role of technology into this equation. This is a young person's domain, an arena where they feel comfortable, confident, and in control.

The opportunity to share our experiences with our international colleagues was invaluable, and we eagerly look forward to a collaborative future.

\section{References / Resources / Links}

Burns, J., Davenport, T., Durkin, L., Luscombe, G., \& Hickie, I. (2011). The Internet as a setting for mental health service utilisation by young people. Med J Aust, 192(11).

Burns, J., Davenport, T., Christensen, H., Luscombe, G., Mendoza, J., Bresnan, A., Blanchard, M., \& Hickie, I. (2013). Game on: Exploring the impact of technologies on young men's mental health and wellbeing Findings from the first Young and Well National Survey. Australia: The Young and Well Cooperative Research Centre.

Burns, J., Hickie, I., \& Christensen, H. (2014). Strategies for adopting and strengthening e-mental health. A review of the evidence. Australia: Awaiting publication in 2014 by SAX Institute.

Blanchard, M., Metcalf, A., Degney, J., Herrman, H., \& Burns, J. (2008). Rethinking the Digital Divide: Findings from a study of marginalised young people's ICT use. Youth Studies Australia, 27(4), 35-42.

Blanchard, M., Herrman, H., Frere, M., \& Burns, J. (2012). Attitudes informing the use of technologies by the youth health workforce to improve young people's wellbeing: Understanding the nature of the "digital disconnect". Youth Studies Australia, 31 (1), S1: S14-24.

Collin, P., Rahilly, K., Richardson, I., \& Third, A. (2011). The Benefits of socials networking services. Sydney: Cooperative Research Centre for Young People, Technology and Wellbeing.

Third, A., Kelly-Dalgety, E., \& Spry, D. (2013). Real livewires; A Research Report on the Role of Chat Hosts in the Livewire Online Community for Young People Living with a Chronic Illness or Disability. Melbourne: Young and Well CRC.

Third, A., Spry, D., \& Locke, K. (2013). Enhancing parents' knowledge and practice of online safety: A research report on an intergenerational 'Living Lab' experiment. Australia: Young and Well CRC and the University of Western Sydney. 


\section{Youth and Digital Media Research and Policy-Making Interface: Mapping Key Design Challenges}

Urs Gasser

Berkman Center for Internet \& Society

Harvard Law School

Evidence-based policy-making has become the "gold standard" not only when legislators and regulators are asked to address hard problems in the offline world, but also when considering policymaking for the digitally connected environment. At the same time, there is broad consensus in regulatory scholarship and practice that many other factors than "evidence" or "data" shape and, indeed, often decisively determine policy-making in both the offline and online space. Taking such a pragmatic perspective, and building upon the personal experiences of the author as well as reflecting on conversations at the Digitally Connected symposium, this essay highlights seven challenges (several others could be added) concerning the design of effective interfaces between research and public policymaking in the youth and digital media context.

\section{Synchronizing Time}

Research and policy-making typically move at starkly different speed levels. Consider the following example: Based on a series of disturbing news stories (a scenario we will revisit later in this essay), policy-makers might identify online privacy of young people as an issue to be addressed. In the US, for instance, policy-makers have recently responded very actively to perceived privacy threats faced by youth online and introduced several bills and proposals for changes in the regulatory system. In contrast, researchers only begin to gain a deeper understanding of privacy-relevant youth attitudes and online practices based on representative surveys and large-scale focus group interviews. The creation of a solid evidence-base for sound policymaking in the field of youth online privacy takes years of concerted research. The synchronization between research and policy cycles is a key challenge in the digital environment that is amplified in less-developed parts of the world, where typically much less data is available about youth online behavior, but where the pressure on policy-makers to address perceived risks and issues might be even greater than in the developed world.

The "different speed" problem is further complicated by the fact that researchers have difficulty catching up with the fast-paced development of digital technology that shapes (youth) behavior online. For instance, some of the best forthcoming research on youth privacy morality and ethics still relies - at least partially — on data collected at a time when MySpace was the most popular social networking site, while nowadays Facebook is the leading social media platform, with more recent trends towards platform diversification among youth. In order to be relevant to policy-makers, researchers must collectively find ways to reduce the time lag between the formulation of research questions and the publication of findings while still maintaining high levels of quality and reliability. Innovative approaches to research design and methods as well as new forms of academic publishing are important approaches to address at least some of these timing issues.

\section{Mind the (Semantic) Gap}

A second cross-cultural and cross-sectional problem related to the research and policy-making interface previously identified at the Digitally Connected symposium concerns the problem of semantic interoperability. It is challenging to establish an evidence base where relevant studies on youth online use not only different methodologies, but even diverging terminology. Research on cyberbullying is one powerful example in this respect. While there is no lack of research that could inform policy-makers, a low level of methodological and semantic interoperability among studies leaves decision-makers with widely varying prevalence rates and at times contradictory results. Against this 
backdrop, efforts to create harmonized or at least closely coordinated research strategies and methods (such as the EU Kids Online Project) are immensely important not only from a research, but also from a public policy-perspective. The promise and challenges of creating such coordinated research strategies at the global level was intensely debated at the Digitally Connected symposium.

The problem of semantic interoperability at the interface between research and policy-making is further complicated by the fact that policy-makers and researchers often use the same terms, but refer to very different things. Again, cyberbullying is illustrative in this respect, where legal definitions vary greatly from research-backed notions of bullying. Interop problems of this sort are further amplified where policy-makers face limited availability of relevant data from their own environment and have to build upon insights from research conducted in other jurisdictions. For instance, even if we assume comparability otherwise, U.S.-focused research on youth privacy cannot easily be translated into the European context given important cultural differences around the notion of privacy. There is no easy solution to this interoperability problem, but it highlights the importance of interface-creation between the worlds of research and policy-making, including the value of so-called "translational research" that considers different audiences and anticipates context shifts.

\section{Headlines Make Bad Law}

A third challenge at the interface between policymaking and research related to youth and digital media has to do with one prominent - and often problematic - mode by which the legal or regulatory system is activated: by news headlines about dramatic incidents involving young people and digital technologies. In both the developed and developing world, the list of examples in this category is long, including, for instance, extensive news coverage of "online addiction" in Indonesia or Vietnam, headlines about the allegedly fatal role of "ego-shooter games" in the context of a shooting in Switzerland, or mass-media coverage about the "stranger-danger" threat in the US. In a given political economy, such media coverage is often an effective trigger for policy-makers vis-à-vis (legitimate) concerns of important constituencies such as parents, teachers, etc. and their call for government intervention.

From a research perspective, the activation of the policy-making apparatus through headlines and mass-media news coverage often leads to unfortunate and at times counter-productive outcomes, as anecdotal evidence from around the world illustrates. A particularly rich case study in this area is the discussion of youth safety concerns in the US, where a series of shocking news stories about predators on social media sites led to strong reactions by federal and state regulators and arguably well-intended, but in the light of research evidence misguided interventions. In such politically charged situations, it is particularly challenging for researchers to communicate effectively with policymakers, especially where their findings don't support the perception of risk and corresponding narratives that triggered the (political) response. In the case of the US, the researchers tasked with evaluating options vis-à-vis the perceived, news-driven child safety risks were unduly attacked when they presented thoroughly-researched findings that didn't support the interventions proposed by the political decision-makers.

\section{Youth Agenda Hijacked}

Policy-makers around the globe face the challenge to create new or adjust existing frameworks to address risks that youth face online, ranging from safety concerns to problems of addiction, while at the same time supporting the promise of digital technologies for education, innovation, and participation. Even assuming the best intentions and an ideal-world policy-making environment, this is a very difficult task, given important knowledge gaps related to youth behavior online, the speed of technological development, evolving business models and practices, social adaptation and learning processes, and uncertainties around short versus long-term consequences, to name just a few complicating factors.

But not all policy-making in this space is necessarily always driven by the idea to advance youth's best interest. Anecdotal evidence - some of which was shared at the Digitally Connected symposium - 
demonstrates how governments have hijacked the youth protection agenda to pursue quite different goals. An extreme example in this category is the Green Dam saga, where the Chinese government required the installation of a specific filtering software product (called "Green Dam") on home PCs with the stated purpose to protect youth from harmful Internet content. However, a technical review of the software revealed that its functionality reached far beyond what was necessary for parents to protect their children from inappropriate material, and included filtering options to block political or religious content that was consistent with China's Great Firewall, adding a powerful new tool to the expanding national Internet filtering system. Due to internal political reasons, the Chinese government later dropped the plans to mandate the Green Dam software.

Less extreme examples concern situations in which industry players and lobbying organizations use youth protection language to shape policy outcomes in directions that are favorable to their business models. The above-mentioned US controversy around technical measures to increase child safety online is an example along these more subtle lines, where the intentions were not purely focused on youth wellbeing. Similarly, some observers argue that current lobbying efforts by leading US ed-tech providers using student privacy rhetoric serve the goal to shape the privacy framework in ways that favor their business models and gives them a competitive advantage.

\section{Unintended Consequences}

One hopes that, more often than not, policy-makers attempt to pursue sound objectives and seek to address legitimate concerns related to youth online risks and/or opportunities. The discussion at the Digitally Connected symposium suggests that even under such close-to-ideal circumstances, government interventions might lead to unintended consequences - a problem that is neither specific to Internet legislation nor youth-related policymaking. Illustrative in this respect is the Children's Online Privacy Protection Act (COPPA), a US federal statute that regulates the online collection, use, and disclosure of personal information from children under the age of 13 by operators of commercial websites and online services who are directed to children. In order to implement COPPA requirements and avoid collecting data about children under 13, many social websites require participants to be at least 13 years of age to join.

In the context of the latest COPPA reform, youth and media researchers submitted testimony demonstrating that most users were not only unaware of the privacy intentions that frame the COPPA age requirement, but that the regime was actually counter-productive or at least misleading. Focus group interviews revealed that many parents and youth believed that the age requirement they encountered when signing up to various websites were safety warnings, suggesting that the respective site is not suitable for children under the age of 13 . While this might be true in some cases, research demonstrates that the safety message conveyed by the age limitation obscured the lawmakers' intention to help users understand privacy issues and, ultimately, make informed choices about the collection of data by commercial actors.

\section{Corporate Dilemma}

Another challenge that surfaced at the Digitally Connected symposium when exploring the interplay between youth and digital media research and policy-making relates to the increasingly important role of private Internet companies. The challenge is at least twofold. First, it is often private companies that have most of the data about youth online that might inform policy-making. Consider the enormous body of data that platforms such as Facebook accumulate. Such data is not only the basis of incredible economic value and the driver behind contemporary business models of most Internet companies, but is also the holy grail of youth and digital media researchers. Currently, there is no (industry) best practice in sight that would regulate under what conditions and how such data can be accessed for research purposes. Instead, the relationship between external researchers and Internet companies remains complicated given the sensitive nature and commercial value of data.

Even where companies share data with researchers - as several US Internet companies do on an individual and ad hoc basis - a second challenge emerges: In big data environments, traditional 
methods of data anonymization don't adequately safeguard research subjects' privacy, and legal as well as technical solutions aimed at easing the tension between "privacy" and "utility" are still largely under development and have only selectively made their way into standard protocols backed-up by Institutional Review Boards. Both the access and privacy problem significantly limit what researchers can do empirically to learn about youth behavior online - insights that would be of great value when considering relevant policy options. If we don't want to leave youth-related big data research to the Internet companies, it is the shared responsibility of researchers, policy-makers, and the corporate sector to create safe environments for data sharing and analysis.

\section{Create Learning Systems}

Due to political pressures, policy-makers frequently respond to technical or societal phenomena without having all necessary data available that would meet the gold standard of evidence-based policy-making - neither in terms of problem description nor solution spaces. For the reasons outlined in the previous paragraphs, policy-makers who are charged to address a broad range of youth and digital media issues find themselves often under similar conditions of uncertainty when making complex decisions. Given the gaps in our current knowledge base, one of the most critical future design challenges is the creation of interfaces between research and policy-making that allow for continued learning and improvement as significant new knowledge about risks and opportunities becomes available.

In light of today's rapidly evolving technology environment and considering the fluidity of individual and social behavior, the existing institutional repertoire of learning mechanisms - including, for instance, periodic policy reviews and consultation processes or sunset clauses in legislation - needs to be expended in order to better incorporate new insights from research into existing youth and media policies. As with many of the challenges outlined in this essay, the creation of better interfaces between the research and policy sphere is a shared responsibility of all stakeholders, which requires innovative thinking as well as experimentation with new modes and tools of (online) participation.

\section{References / Resources / Links}

boyd, d., Gasser, U. \& Palfrey, J. (2010). How the COPPA, as implemented, is misinterpreted by the public: A research perspective. Retrieved from http://cyber.law.harvard.edu/ publications/2010/COPPA_Implemented_Is_Misinterpreted_by_ Public

Faris, R., Roberts, H., \& Wang, S. (2009). China's green dam: The implications of government control encroaching on the Home PC. Open Net Initiative. Retrieved from https://opennet.net/chinasgreen-dam-the-implications-government-control-encroachinghome-pc

Head, B. (2009). Evidence-based policy: Principles and requirements. Retrieved from http://www.pc.gov.au/_data/ assets/pdf_file/0007/96208/03-chapter2.pdf

James, C. (2014). Disconnected: Youth, new media, and the ethics gap. Cambridge: MIT Press.

Enhancing Child Safety \& Online Technologies: Final Report for the Internet Safety Taskforce (2008). Berkman Center for Internet \& Society at Harvard University.

Livingstone, S., \& Bulger, M. (2013). A Global Agenda for Children's Rights in the Digital Age: Recommendations for Developing UNICEF's Research Strategy. Retrieved from http://www.unicef-irc. org/publications/pdf/lse\%20olol\%20final3.pdf

Levy, N., Cortesi, S., Gasser, U., Crowley, E., Beaton, M., Casey, J. A., \& Nolan, C. (2012). Bullying in a Networked Era: A Literature Review. Berkman Center Research Publication No. 2012-17. Retrieved from http://ssrn.com/abstract=2146877

Madden, M., Lenhart, A., Cortesi, S., Gasser, U., Duggan, M., \& Smith, A. (2013). Teens, Social Media, and Privacy. Pew Internet \& American Life Project. Retrieved from http://pewinternet.org/ Reports/2013/Teens-Social-Media-And-Privacy.aspx

Noveck, B. (2009). Wiki government how technology can make government better, democracy stronger, and citizens more powerful. Washington, D.C.: Brookings Institution Press.

Palfrey, J., \& Gasser, U. (2008). Born digital: Understanding the first generation of digital natives. New York: Basic Books.

Palfrey, J., \& Gasser, U. (2012). Interop: The promise and perils of highly interconnected systems. New York: Basic Books. 
CHAPTER 9

Youth Submissions 


\section{A Q\&A with members of the UNICEF Youth Board (Netherlands)}

\section{What excites you most about the Internet?}

\section{Fleur, Age 15}

The thing that excites me the most about the Internet is the fact that you can talk, share pictures and videos, play games, etc. with people from around the world. I think it is a beautiful thing that I can send a message to someone at the other side of the world and I can receive a response in a matter of seconds. We could not imagine this happening without the Internet. I think the Internet has expanded our view of the world, because we can contact other people, and learn about their cultures and standards.

\section{Jitske, Age 17}

That you can have contact with people all over the world. You can build a community with people in China, the USA, or Namibia because you all share the same interests even though you never meet them in real life. Furthermore, you can look up things very easily.

\section{Koen, Age 16}

The most exciting part of the Internet is that you can keep in touch with people from all around the world. For example, I can maintain contact with my uncle in Australia, who lives a 24-hour flight away from me.

\section{Merel, Age 14}

When I think about the Internet, I think about all the possibilities it contains and all the advantages it grants. Because of the Internet, we can now communicate with people on the other side of the world; we don't have to write letters and wait a week for an answer. We can just send free messages to our friends and family. If I have a problem with my homework, l'll just look up an explanation on YouTube or Google.

\section{How has the Internet changed your life?}

Fleur, Age 15

Internet changed my life in various ways. For example, I have this Internet friend who lives in Brazil, and he tells me about his life in Rio de Janeiro. It is so cool to hear his stories, because I have never been to Brazil before, and his stories sound like heaven on earth. This has broadened my view of the world, and I have learned to accept other cultures. Also, it is really easy for me to search for information on the Internet. Without the Internet, I would have difficulties at school, and my common knowledge wouldn't be as sharp as it is now.

\section{Koen, Age 16}

Internet has changed my life so much. I can check the news 24 hours per day. I can stay in touch with people across the globe and even if I walk, for example, in Utrecht and I say to my mobile phone, "I want to go to Rotterdam", my phone will tell me how to get there. I don't even know what I have to do anymore without Internet

\section{Merel, Age 14}

I wouldn't say the Internet has changed my life, but it has had an enormous influence on how I live. The first thing I do when I have Wi-Fi is answer messages from people on Facebook or WhatsApp. When I'm on the train, I can check my e-mail and communicate with people from the other side of the country. I never expected the communication opportunities we have now and they have had a major influence on my life. 


\section{Rachna, Age 15}

In my opinion, the Internet has changed my life in two ways. First, I think the Internet is an educational resource. This is not only beneficial for my schoolwork, but also for my general knowledge. I can look for this information specifically, but I think I obtain it unconsciously. This is because most of us use social media. We are constantly reading things, which means we obtain information. Social media is the second reason why the Internet has changed my life. Besides the fact that it's an educational resource, it's also a method for staying connected with your friends, and actually the whole world.

\section{Yousra, Age 17}

It has made information more accessible, it has enhanced my life in that now instead of remember facts, I can look them up which increases my efficiency since I have access to an inexhaustible source of knowledge.

\section{What is the most influential online story/ storyteller you have come across?}

\section{Fleur, Age 15}

I have an account on Tumblr, and one time I read this story about a girl, who was always shy and not very outgoing but she learned to speak up for herself and she started to love herself more and gain confidence and one day she even did a big presentation in front of 800 people about her life story. This story had such a big influence on me because I always felt like the girl she was before, I never dared to speak up for myself, never had confidence, and because I read this story, I realized I can actually change this. This made me into the person I am today, I'm more confident about speaking in public and I'm just more confident about myself and a part of this change was this story.

\section{Koen, Age 16}

The most influence story I have heard was that a man was fired because he had posted on Facebook that he was at a party, but that day he had told his boss he was ill.

\section{Merel, Age 14}

I've been depressed for the last year, and my friends weren't there when I needed them, but the Internet was. I read a story written by a girl who had gone through the same experience. She unknowingly gave me life-changing advice. I never knew her name, but that didn't matter, because she was my friend and she didn't know this. Her story was about how people always let you down when you need them most and how you need to accept this. Because of her, I made new friends. Because of the Internet, I got back up on my feet.

\section{Who on the Internet has influenced you most?}

\section{Fleur, Age 15}

I often watch YouTube videos, but one time I came across a YouTube account called "watchbbbtv." This was a YouTube account set up by 2 brothers who won a trip around the world for 6 months by entering a competition. They made a video every week of every country they visited. They did this in such a fun way, and they showed so much beautiful footage every week! Every time I watched their videos, I felt like hopping on a plane and flying to an exotic destination. These videos made me want to travel the world, and maybe film it too.

\section{Merel, Age 14}

I met my best friend through the Internet. Via WhatsApp, we started talking and he has helped me through everything. He was there when I needed him and he still is. He has influenced my life most. It's hard to explain why, but he understands how I feel. I've only seen him three times in person, but he is still my best friend. I would not have met him without the Internet.

\section{DIGITALLY CONNECTED}


How does the Internet make you feel connected? Have you ever felt like a part of an Internet community? If so, what was that like?

\section{Fleur, Age 15}

The Internet makes me feel connected because I can talk to my friends and family all the time, no matter where they are or what time it is. I have never actually been a part of an Internet community, but it seems like it would be a lot of fun to be a part of one.

\section{Jitske, Age 17}

The Internet makes me feel connected because you can have contact with people from all over the world. You can see that there are many people feeling the way that you do; people that share passions, but also people that face the same problems. I've never been a part of an Internet community though. I tend to read a lot, but don' $t$ post much.

\section{Merel, Age 14}

I've never been part of an Internet community but I do feel connected through the Internet. I've been emailing an Australian guy. He's my age and really nice. He makes me feel connected because we are very much alike and he's from the other side of the world. I think it's pretty special to have an Australian friend.

\section{Rachna, Age 15}

It makes me feel connected because of the social media. With Facebook, Twitter, WhatsApp, and all other kinds of social media, you are able to share anything you want. If social media is an Internet community, I definitely feel like a part of an Internet community. For me, it creates solidarity. However, I'm sure that some people, who are not part of such communities, feel like outsiders if they are not on social media. I would almost say for some of us, it's an obligation to be part of an Internet community.

\section{What positive changes have you seen in your community and/or country because of the Internet?}

\author{
Jitske, Age 17 \\ I think the positive changes are that some pieces \\ of everyday life have become much easier. You \\ can browse for information within seconds and \\ share online content with family members that live \\ elsewhere in the world. Sharing information is very \\ easy nowadays.
}

\section{Koen, Age 16}

Our lives are more mobile nowadays. The possibilities of the Internet are enormous and therefore the world becomes smaller and more accessible for everyone.

\section{Rachna, Age 15}

I notice that more and more people are using the Internet. For example, the teachers at my school put our homework on the Internet now, and our P.E. teacher even created a special Facebook page for anything that takes place at our school. I think that it's a positive change, because almost everybody uses the Internet.

It's important to be open to these changes and experience the positive effects. 


\section{What role do web based mobile technologies play in your day-to-day life?}

\section{Fleur, Age 15}

For example, my mobile phone plays a big role in my day-to-day life. I can let my parents know where I am, talk to friends by using WhatsApp, check my email, etc . I think web based mobile technology is one of the most innovative things of our time.

\section{Jade, Age 16}

I, and many of my friends, use the smartphone app WhatsApp to communicate. Other popular smartphone apps include Snapchat, Instagram, Twitter and Facebook. There are obvious downsides to constant Internet connection of course, but it does enable everyone to stay in touch. Other than communication apps, there are other web-based mobile technologies such as navigation systems, or just Internet browsers to search for the supermarket's opening times, for instance. In short, web based mobile technologies makes day-to-day life more convenient. Although is has an effect on alienation too.

\section{Jitske, Age 17}

I think I use web based mobile technologies every day. I don't have a laptop, so I use my mobile phone a lot when I am not in my room. Internet sites adapt to your mobile phone and you can easily read online articles. I follow a blog and I read that everyday via the Internet on my mobile phone.

\section{Merel, Age 14}

I use the Internet mostly for school. For example, if I forget my diary, I just ask one of my classmates what the homework is through Facebook or WhatsApp. I notice that this is not only handy for me, but also for the rest of the students in our school. My mother is very busy with her work and she has to do a lot of things. I constantly hear her talking about the advantages of e-mail and Internet in the hospitals. It is easier to connect with someone from a different department and when she needs someone's file, she'll just search for it on her computer and in 5 seconds she'll know everything about that person's illness etc.

\section{What is missing from the Internet? What new tool/site/community would you create?}

\section{Fleur, Age 15}

l'd like to create a website where people can ask questions about anything. For example, you ask a question related to mathematics, culture, anything, and you receive an instant answer from another person anywhere on the planet.

\section{Jade, Age 16}

I sometimes worry about safety and privacy on the Internet and the increase of cyber-criminality. I think the Internet is a wonderful concept but the way it works is hard for the common citizen to understand. The average person has no idea how these new technologies work; they are too complex. But I think in a world where code rules everything around us, it is important to educate the masses in Internet/ computer technology.

\section{Jitske, Age 17}

This is a hard question because I can't really think of anything that I'm missing right now. Maybe some kind of community where kids from all over the world can talk with each other about things like their culture. Through this, you would learn about different cultures and hopefully respect them more. However, I'm not sure though if something like this would actually work out.

\section{Koen, Age 16}

I think that a special privacy zone in the Internet is missing: a place where no one can check your data. Privacy is important to many people and I think if you create a place on the Internet where people have guaranteed privacy, more people will use the Internet. 

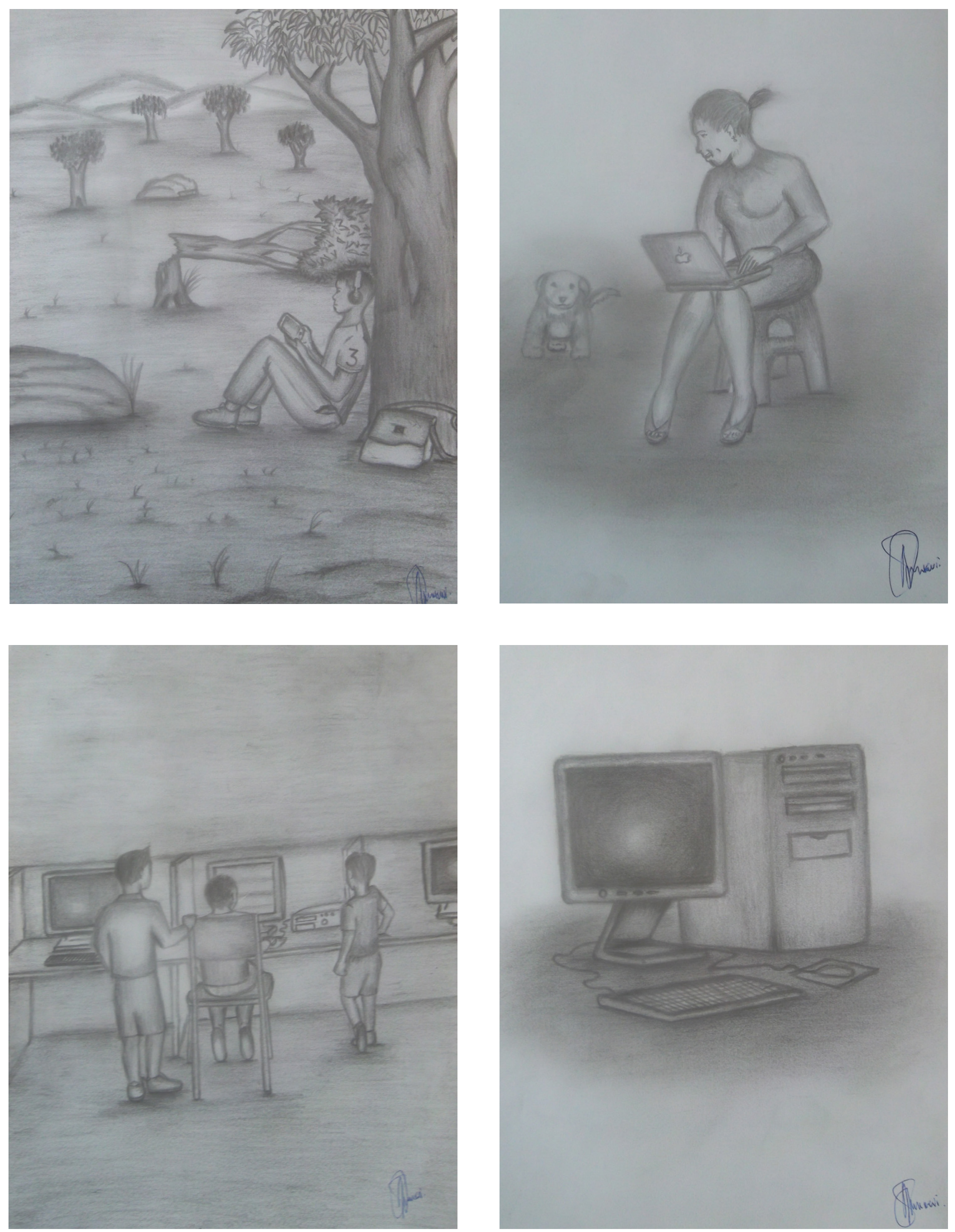

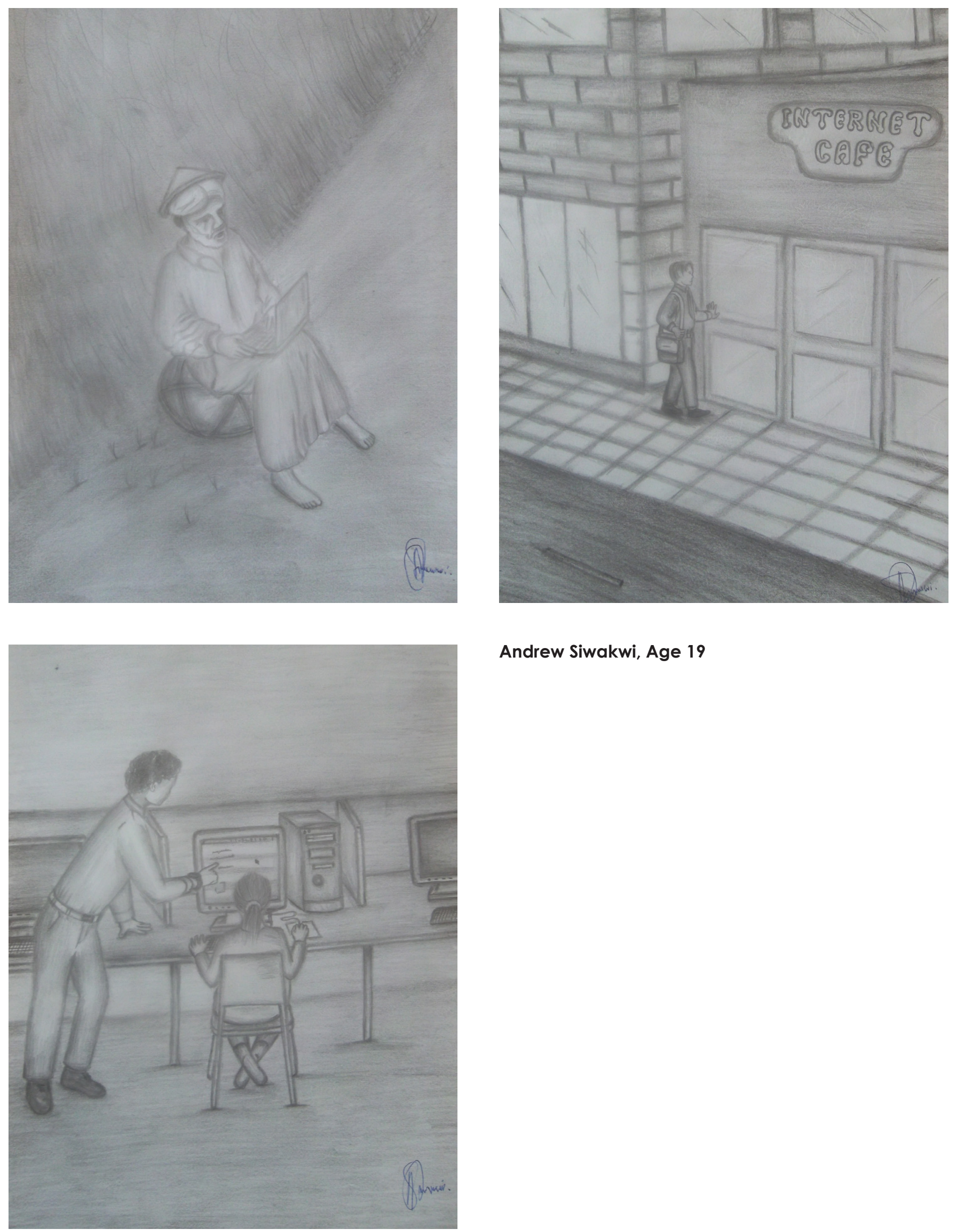

Andrew Siwakwi, Age 19 


\section{What We Think About the Internet}

\section{Submissions by Students from the Keta Senior High Technical School (Ghana) Facilitated by Eldad Nutakor}

\section{Submission \# 1}

Technically, the Internet is a global computer network that provides a variety of information and communication facilities. This big network consists of smaller interconnected networks, communicating with each other with standardized protocols (really technical). But I think the Internet is a very big shop that consists of both good and bad products.

The Internet has been beneficial in a variety of ways when it comes to social and economic life, including communication, research, long-distance education, etc. The Internet has made learning easier in some aspects of education. Information that cannot be found in books can be found on the Internet, and information that is not taught in school can also be discovered on the Internet. Social media has made communication with distant family and friends possible, using tools such as Facebook, Yahoo Messenger, Twitter, etc. There are many useful products that can be found in this shop (internet).

Bad products that can be found on the Internet include pornographic pictures and videos that influence youth in negative ways. Another product found on the Internet is fraud. Many people use the Internet to defraud others, which affects many people around the world and I think something can be done about this.

Overall, I think the Internet has been a great resource for many people and should be used in beneficial manners.

\section{Submission \#2}

I have been using the Internet for four years now. It has helped me immensely.

Social media sites such as Facebook, Twitter and others, have helped me keep in touch with family and friends. It's amazing how easily I can find friends that I have lost contact with on these social media. This affirms the saying, "the world is a global village."

The Internet has also assisted me academically because there is information I do not find in books but I can find on the Internet. Educational sites like Wikipedia, Encarta, etc. have helped me in my research.

The Internet is also like a restaurant — different types of dishes are served there. When a child goes on the Internet to search for something meant for children, it's like ordering a nice meal. However, should that same child search for information that is for adults, it's like ordering stale food. In conclusion, I think the Internet is such a fabulous resource for everyone. I hope sometime in the future places that do not have Internet access will gain it.

\section{Submission \#3}

Robert and Francis lived on the outskirts of a village called Oseikrom. If life were a science class, they'd be a perfect example of one of the laws of magnetism: "like poles repel and opposite poles attract." Robert was from an affluent home while Francis hailed from a poor family, but the two remained great friends anyway. One day, some tutors came to the village to educate people about computers and Internet use. During the first training session, the tutors noticed that digital literacy was greatly needed in the community so they decided to introduce it in schools so everyone could learn. This enabled Robert and Francis to learn more about this new technology, and they shared this knowledge with their families. 
Both of them begin to use the Internet to learn, but Robert, realizing the immense power of the Internet, decides there is another problem for which he needs the Internet. He needs to be making some money on the side. Even though he comes from a rich home, he feels his parents don't give him enough money because they don't want to spoil him. A lot of his time goes into moneymaking. It is not long before the obvious happens; his grades start tumbling. Francis uses the Internet for his studies and once in a while, a little entertainment. It isn't long before he moves to the top of his class. Robert, who decides to join a gang for their defrauding activities, becomes very disrespectful. Francis notices this change in Robert and tries to advise him but Robert ignores him. Consequently, Francis decides to part ways with his friend so he can concentrate on his studies. Francis does very well on his final exams and decides to learn about computer science due to his fascination with the Internet. He makes Bill Gates his inspiration and works very hard. Soon, he starts developing his own websites and software, off which he makes money.

Robert also keeps making dubious money and does not feel higher education is necessary until he and his fraudulent gang are arrested. Francis decides to go back to his community and contribute to its development by opening community centers where he advises youth not to end up like his friend. One day he decides to go and visit his friend and when Robert sees Francis, he is extremely amazed with how Francis had turned out. In a moment of regret, he said to his friend "the Internet is a good servant but a bad master, I guess it served you well."

\section{Submission \#4}

The Internet is making life easier in a variety ways. These days, you don't even have to go to Internet cafes to gain access. Although many people are excited about the Internet because it grants access to sports pages, chat rooms, movies, etc., what excites me most about the Internet is the educational sites and tools it provides for my research and studies. The Internet has changed my life in a positive way; the only negative aspect for me, I will say, can be Facebook. Facebook can become a problem when I spend too much time engaging in unproductive conversations. But on the positive side, it has helped me make new friends and keep me updated.
I can say that in my country, the Internet has become a useful tool for both the young and old. Most old people use it to communicate, research, and advertise their companies and products, while the younger generation primarily uses it for entertainment (listening to music, playing games, watching movies), chatting with friends, and meeting more people. The Internet has had positive effects on my country as well as some negative ones.

Web based mobile technologies are becoming the order of the day. They help a lot because they save money I might have spent browsing at Internet cafes. Now I don't have to go to the café, but I have Internet access on my phone sometimes at a cheaper rate than at the cafe.

If there is anything I wish did not exist on the Internet, it would be cyber fraud, which involves using false identities to steal from people online. People get rich through stealing. This is an immoral and terrible way to increase one's wealth because it puts others through pain and agony. Why should you work hard for something when someone else can get hold of it or take it from you if you let your guard down for even a few minutes? It is painful and I think cyber fraud should be stopped.

To summarize my thoughts, I think the Internet has excellent resources to offer, so let's get hold of them and leave the bad ones behind. I would like to tell people who think the Internet does not benefit society that it does, but just that certain individuals are the poison we can sometimes see emerging from it. The Internet is not the cause of all the negativity we see. Rather, it is the people misusing it.

Let's look at the greatest benefits of the Internet, the wonderful experiences, and fight to create more of those.

\section{Submission \#5}

Just as a coin has two sides, so too does the Internet. The question is "does the Internet have a more positive or negative impact on society?"

Negatively, we use the Internet for viewing adult materials under the pretense of learning. This can affect us negatively, because we tend to daydream during class. As a natural rule, everything has 
disadvantages and advantages. On the positive side, the Internet has made learning easier and faster. As students, we use the Internet for research on our projects. Speaking from experience, we better understand lectures when we get to see pictures or videos of the information being taught, especially in biology.

Also it makes communication easier and faster compared to previous times. We remember stories told by our grandparents about how they used to walk several miles to deliver a message or how they waited for years to receive letters. But in the 21 st century, within the blink of an eye, we can receive messages from loved ones several miles away anytime and anywhere.

\section{Submission \#6}

The Internet is a medium for interconnectivity that has advanced communication and information accessibility. This development has greatly aided the many individuals and countries.

What would the world be like without Internet? I guess it would be quite a pathetic scene. We would be living with many problems, to which solutions would be difficult to find. There would be no social media or easy access to information, using search engines like Google.

With the Internet, I can sit at home, develop any idea, and share it with people across the globe. It enables me to receive comments, feedback, and even learn from other people who are doing similar things worldwide. This is totally amazing!

Even though the Internet has very important uses, it can be a destructive tool if it is in the wrong hands. Some Internet users hijack others' accounts, access their information, and defraud them. Cyber bullying and identity theft are some common vices on the Internet. This sometimes makes it little confusing because you can't say for sure if the Internet is a good or bad tool. But l'll tell myself and all Internet users; "live with it but don't live by it"; take out the good stuff, leave the rest be.

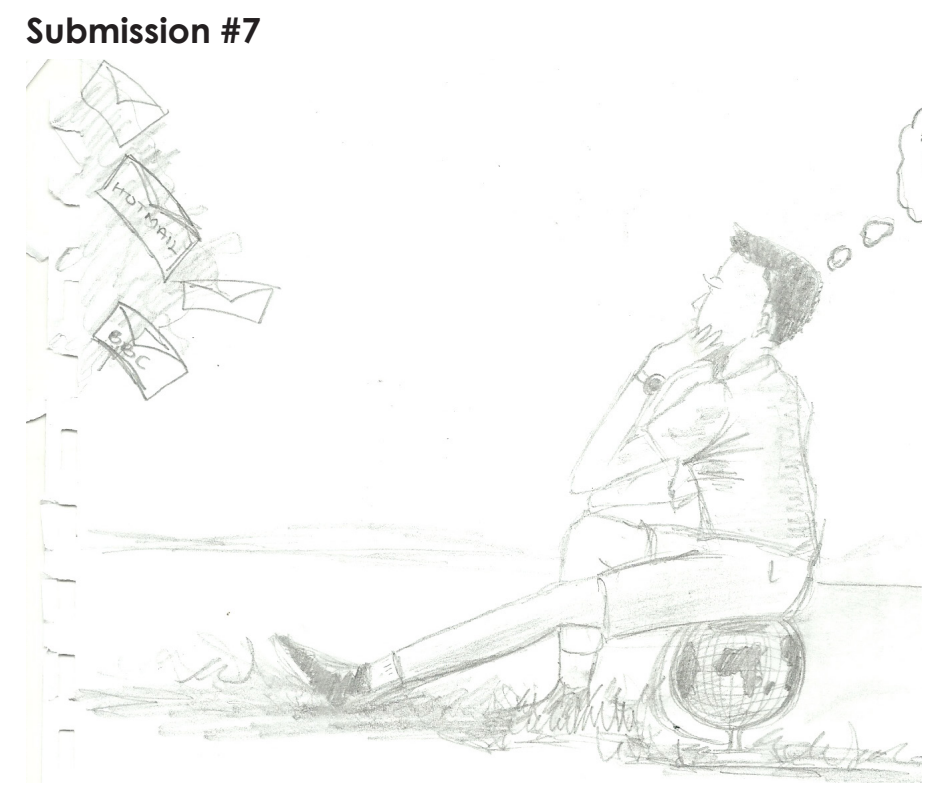

\section{Submission \#8}

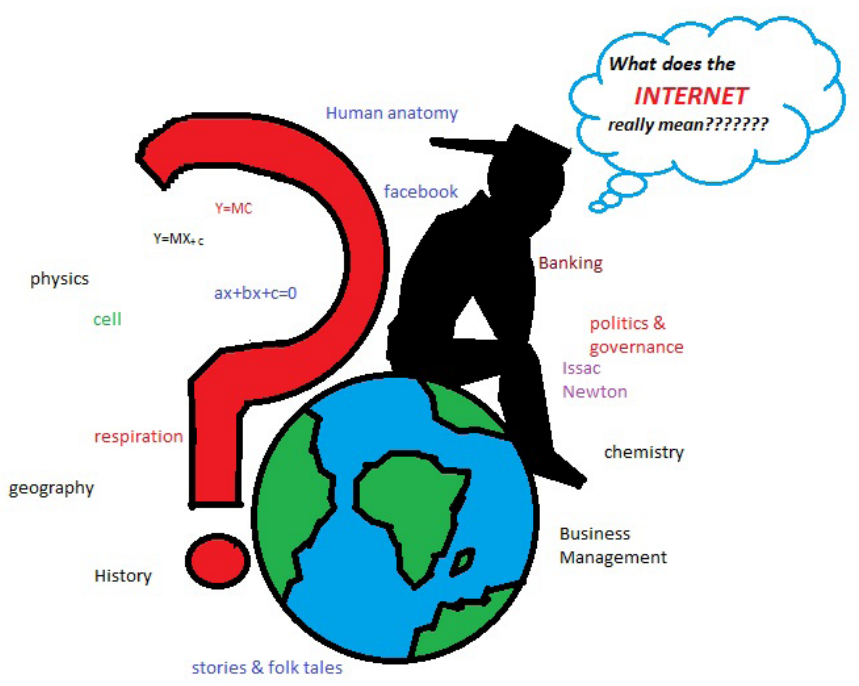




\section{Submission \#9}
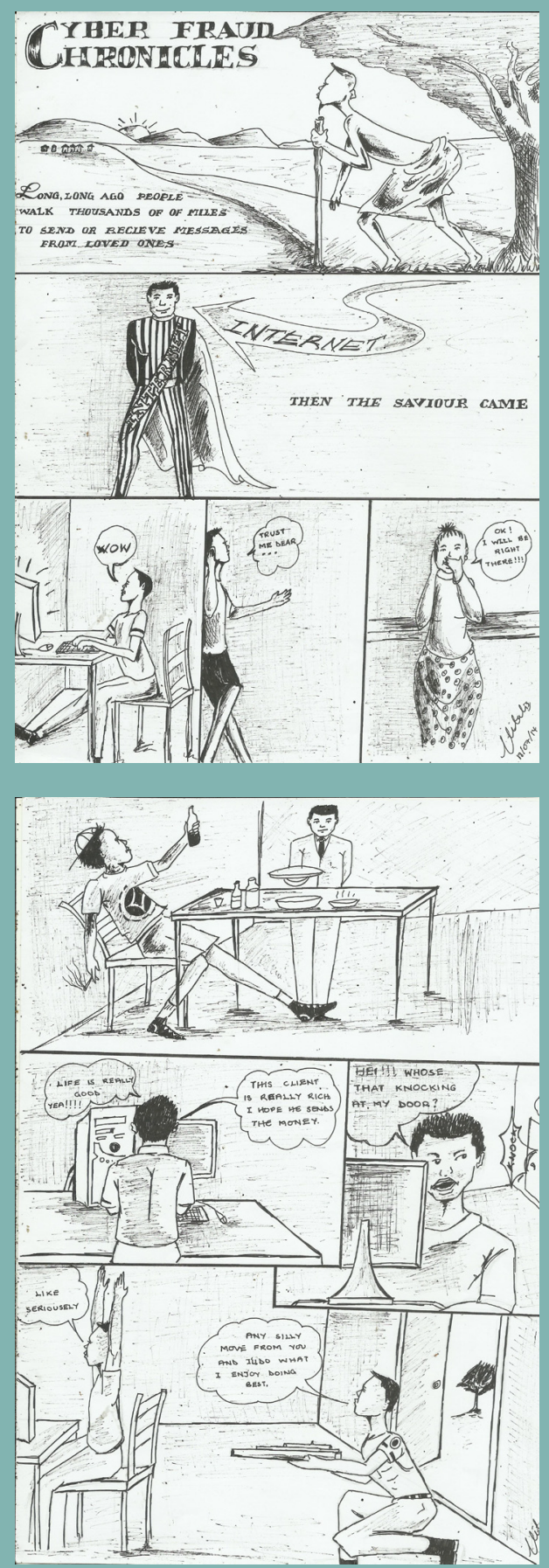
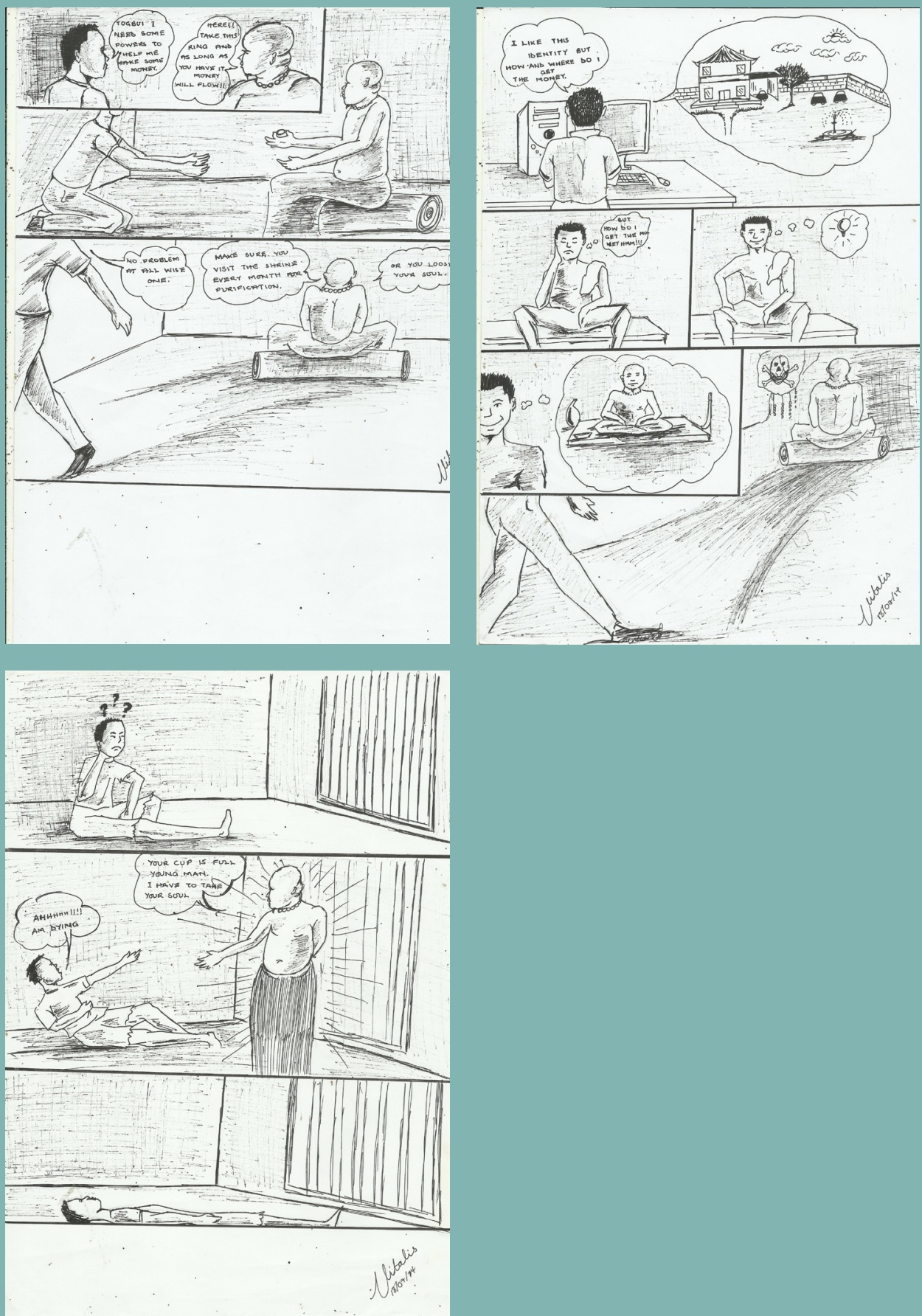


\section{Integrating the Internet into the Fabric of Our World}

\section{Grace Wang}

Age 16, Hong Kong

I was born in 1998 and I am unable to remember a time before the ubiquitous influence of the Internet. In fact, I struggle to imagine a life preceding the Internet's creation - when information was found in the depths of a library instead of Google, and when communication was limited to letters or phone calls instead of Skype video calls. Though this may portray me as a stereotypical teenager, whose phone is an extension of his or her arm, I unabashedly love the Internet. Even when older generations nostalgically long for the days of distraction-free meals and lament for smart phone-free conversations, I continue to be excited by the Internet. The Internet is limitless - so wide and vast, like the whole world compressed into a series of Os and 1s. It is incredible, with audiences from all over the world, all speaking different languages, united on the Internet. Through the Internet, we have limitless opportunities to explore, learn, and grow.

The Internet is exciting because of the manifold opportunities it affords its users. The Internet is truly one of a kind in its accessibility and diverse range of functions. It is completely inclusive - the world has never seen a more accessible and international platform. Anyone can post anything - from unique patent-free ideas to opinion blogs; the Internet is a forum for free exchange of ideas, innovation, and creativity. It breaks down international barriers and facilitates the spread of knowledge and information. The Internet promotes freedom of knowledge, expression, and of beliefs. With so much information, the Internet can truly be a force for good. It can help educate people, benefitting not only an individual, but also a community that can learn, explore, and grow from the freely available information on the Internet.
The Internet represents a new form of communication with usernames instead of real names, and avatars instead of personal faces. Communication - whether personal or professional - is easier than ever, and with just an Internet connection, one can connect with people from all over the globe. The fact that people with cultural, geographical, and religious barriers and differences can unite, discuss, and debate on this platform is incredibly exciting. The Internet has no doubt propelled globalisation even further. With so much information at their fingertips, people are able to experience (through photos, videos, and text) the world far beyond their country borders. Of course, the Internet can also provide us with limitless entertainment. In excess, this can be detrimental. However, it helps keep us up to date with our friends on social media, keeps us busy in times of boredom, and gives us relaxing entertainment in times of stress or harry.

The potential of the Internet is huge. With worldwide audiences, it is becoming a viable facilitator for discovering jobs, careers, and lives. Opportunities are easier to find with horizons rapidly expanding. Just take a look at any self-made Internet entrepreneur - Mark Zuckerberg, Eric Schmidt, Jeff Bezos - all immensely successful people making a living off the Internet and the opportunities it presents. It is becoming easier than ever to build up a worldwide audience on the Internet; websites such as YouTube and Vimeo are supporting the growth of creative filmmakers, video bloggers, and actors among others. The Internet is a truly extraordinary place, and its borders are expanding everyday to enhance creativity, innovation, and uniqueness. 


\section{Cynthia Massiel, Age NA}

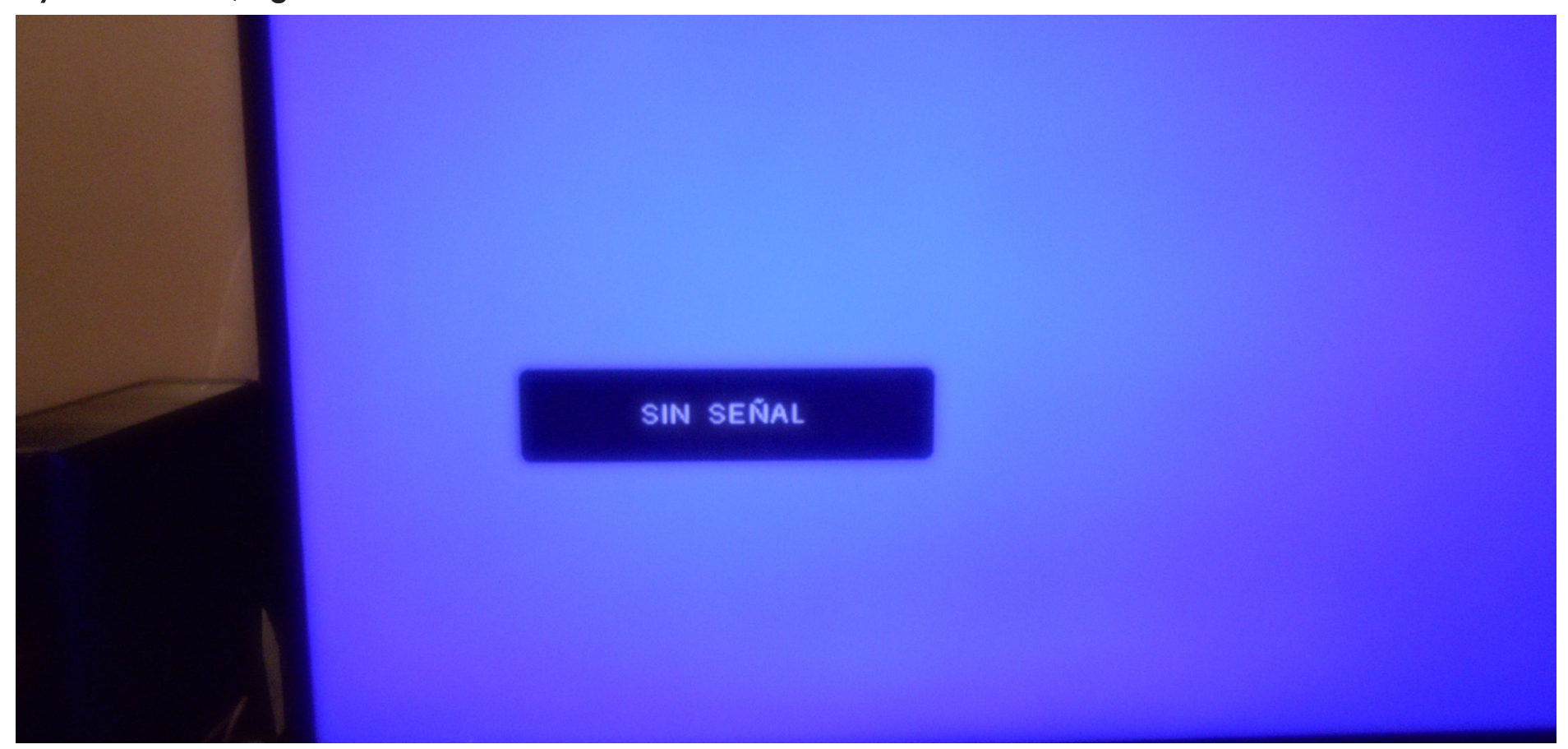

\section{Max Hertz, Age 17}

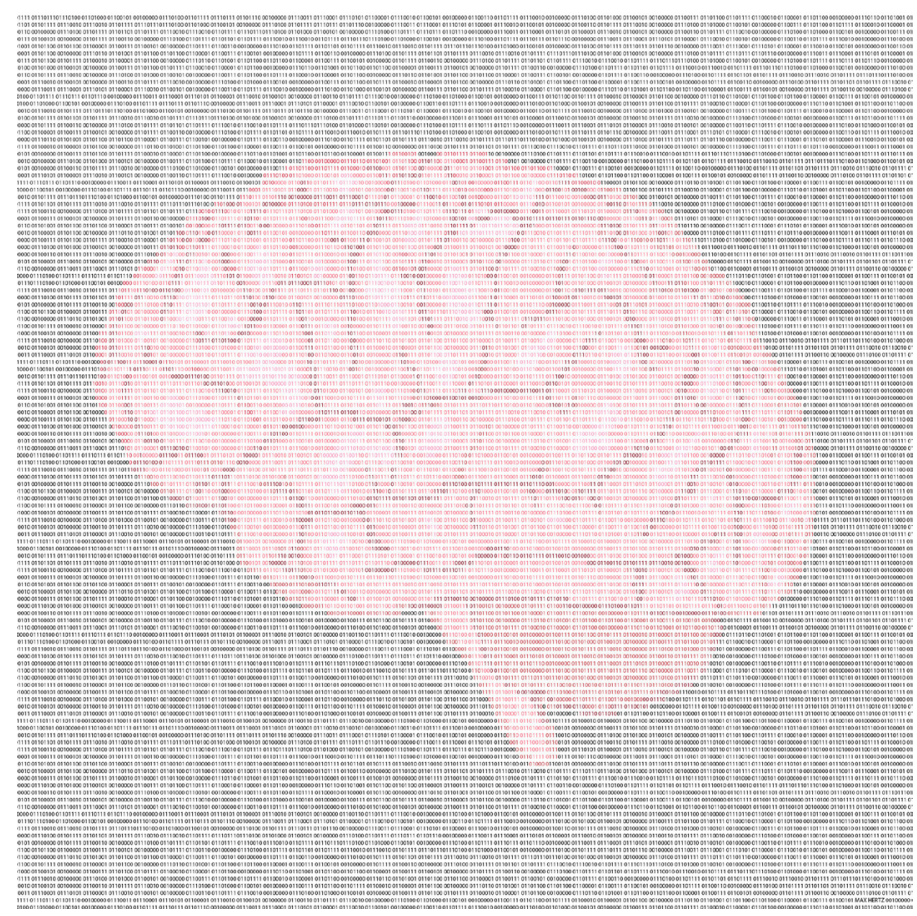

Yasir Khan, Age NA

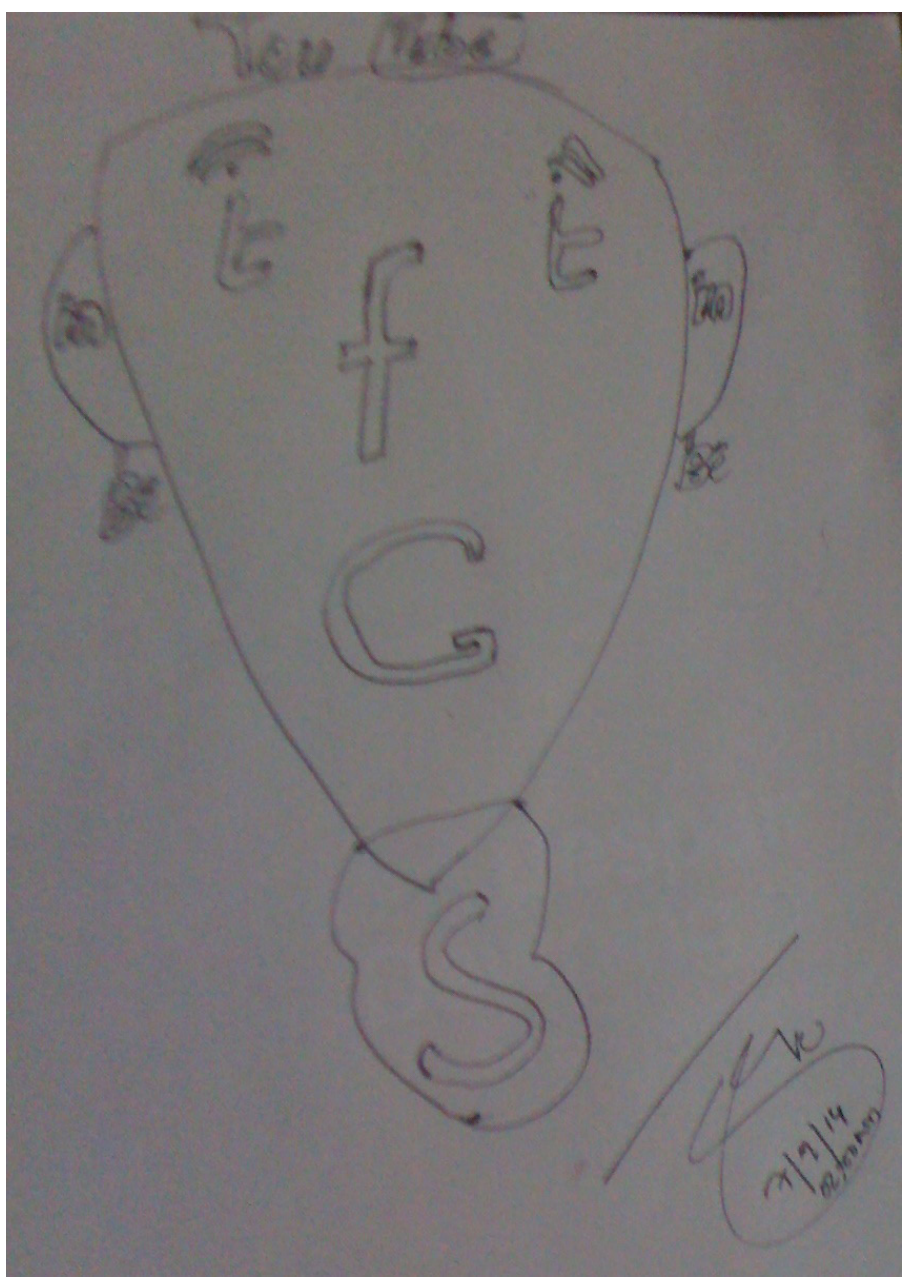


Heather Booth, Age 13, USA

"knowledge is of two kinds. We know a subject ourselves, or we know where we can find information on it."

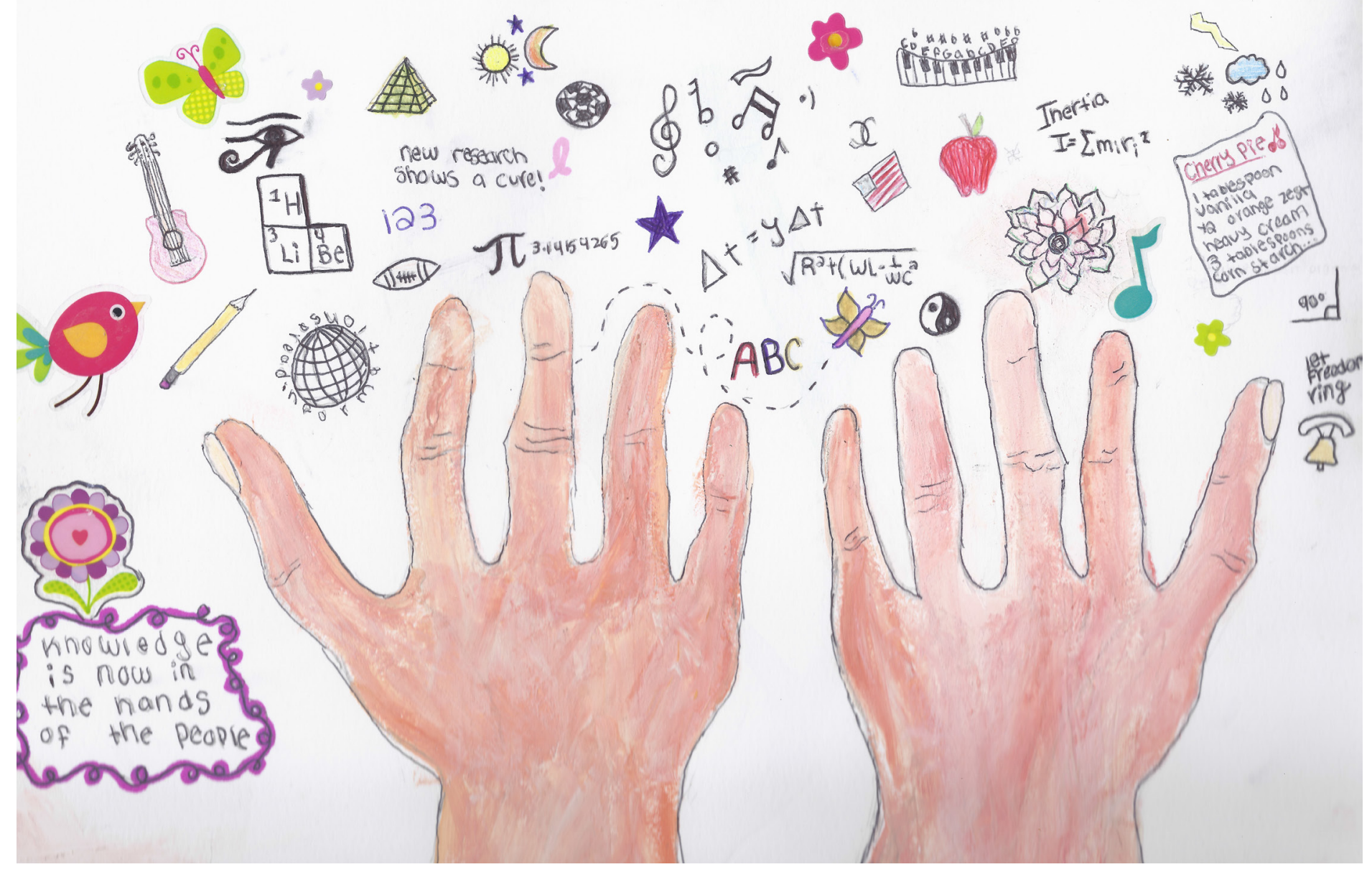

María Paula Latorre Guzmán, Age NA

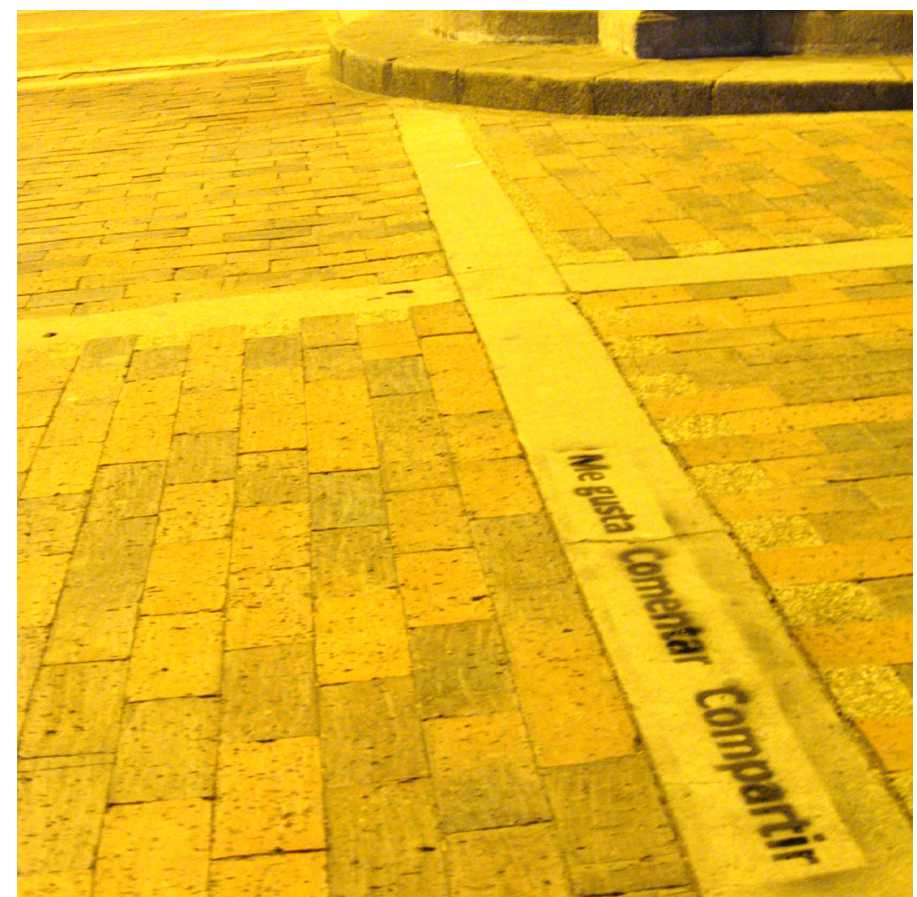




\section{The Internet as Home to Many Communities}

\section{Sarah Groustra}

Age 14, USA

When J.K. Rowling released an addition to the Harry Potter story, taking place at the Quidditch World Cup, I knew about it almost instantly. I got a notification from my Pottermore account, I saw a link on Facebook and Twitter, and I scrolled through dozens of posts about it on my Tumblr dashboard. It was exciting, for fans of the books, and we all wanted to talk about it.

Books are a huge part of my life, and it is really exciting to be part of the large online communities surrounding them. The Internet has spawned words like "fangirl", acronyms such as "OTP", and produced fan art, fan-fiction, gifsets, and videos for book fans to view at their leisure. It's not only books - TV shows, movies, and YouTubers alike have fan bases (or "fandoms") created through social media and Internet use.

One of the greatest things about the Internet is its power of connectivity. Authors now have the ability to bring their portraits on the book's dust jacket to life, bringing their presence, personality, and views into the homes and minds of their readers. A pair that has perfected this art is John and Hank Green. Their YouTube channel, Vlogbrothers, which gained popularity with John Green's rise to fame as an author, now has over 2 million subscribers (me being one of them). They often address their fan base as a whole, enforcing a sense of community between the viewers, and even go so far as to ask member's opinions on changes they might make. And while some people stare when I wear my "Pizza John" Vlogbrothers shirt, it always makes my day when someone recognizes it, because that means they are just as interested and enthusiastic about this community as I am.

There were skeptics, some who said that with the rise of the Internet, the era of books, in their original, old-fashioned, paper form, would be over. But I disagree. The Internet does not replace, but rather enhances the reading experience. Those who love books have a new, enormous forum to share their views and opinions about what they've read. I read commentary and articles about my favorite books, and reading others' perspectives can give me a new outlook or point out something new I hadn't noticed before. It gives a book a longer life span, its characters immortalized with every new photo edit and illustration. You can also read speculations about what happens next - stories about Tobias Eaton from Divergent living alone outside of the city, or alternate universe stories in which Harry Potter chooses Slytherin. It's a constant flow of information, full of creative genius and undiscovered talent.

There is a place on the Internet for people like me, who love writing and reading. There are book-themed blogs on Tumblr, Facebook pages dedicated to books, authors' Twitter feeds, book review vlogs, and so much more for us to explore. The Internet is a never-ending conversation, and I plan to be a part of it for as long as possible. 


\title{
The Internet and its Impact on Youth
}

\author{
Maximillion Colombo \\ Age 18, USA
}

Most young people can't survive a day without the Internet. Teens are constantly checking their Facebooks or Instagrams. Even little kids don't watch Elmo on TV anymore - they watch shows on tablets.

The Internet impacts this generation in so many ways. Social media platforms and video sharing websites all play a big part.

I can honestly say social media has played a major role with youth - not always in a good way. You hear it in the news. A local teen committed suicide from cyber bullying, a fight between two high school students was caught on video and criminal charges are being filed, or one can see pictures and videos of adolescents getting drunk and high. How can you explain to a parent that their child died because they were being bullied online? Or how about explaining to a teen that they aren't getting a job because of what they post on social media?

Another way the Internet can impact youth is through advertising. Advertisements are everywhere. And youth can't help themselves. Young people want the newest gadget from Apple or Google companies who make millions with their products. You may ask what they do to make millions.

Advertise. For example on YouTube, you can't watch three videos without getting hit by an ad. How does this relate to youth you may ask? Where do youth go to find new music or watch music videos? Where do recording agencies go to advertise a client's new CD? YouTube. Advertisements are everywhere including the Internet.
On the other hand, video sharing sites such as YouTube can be greatly beneficial and can lead to positive outcomes. Whenever you need to learn how to do something, you search for your question. If you need help doing your homework, there are videos to help you. If you want to see a review of a product, there is a video of a person's opinion. You can learn so much on YouTube. I learned about different equipment and tricks for photography by watching YouTube videos.

The Internet impacts youth in many ways on a daily basis. All in all, I feel that if you are using the Internet, you need to be responsible, but the Internet is a tool that you can use to achieve your wildest dreams. 


\section{Privacy: A Look Behind the Scenes}

\section{Christopher Onoka}

Age 20, Kenya

Let me start by saying that the Internet is literally the greatest thing mankind has ever invented. One might say that this is hyperbole, but I genuinely lack the words to describe the importance and brilliance of the Internet in this day and age. I am hard pressed to name something you can't do with the help of Internet. Being a university student, I can safely say that a lot of my life revolves around the Internet. I will use several tech companies as my main examples throughout the article because their websites are the ones I can associate with, and those that I personally use a lot.

Over the last year, questions around privacy have come to the forefront of the news in the wake of scandals such as the NSA Snowden affair and the resulting furore, which included tech companies coming together to "protect" their consumers. I have no doubt that their meeting was well-intentioned; I do however see irony in the convention, as many of these tech companies make their bread and butter from what they know about you. Many people are aware that Facebook, Google, etc. collect personal data, but this fact is simply acknowledged for a short moment and then forgotten or regarded as trivial.

For people who have no idea what I am talking about, let me oversimplify to jolt you into action. The reason that Facebook, Google, and most websites are free is because you are the product. "What? How can I be the product?", you ask. "How is money is being made off of me?" Let's think for a moment. You search for a new phone's specifications on Google and then suddenly while surfing Facebook, ads for mobile phones start appearing. While on YouTube, suggested videos and ads start appearing for phones as well. Coincidence? I think not. While this occurrence has now become so common place that most people have recognized search results' influence on advertisements, they aren't worried that every move funds big brother quests to effectively collect your data. Most people are unaware that Facebook even has an option to download all the data they have about you. It is surprising that without knowing you personally, Facebook can actually build a pretty accurate picture of you with all those "likes". Hmm, it can't be hard to find because they don't want you to go looking for this information, can it? There must be a reason why opting out of ads is one of the hardest things to do.

On the flipside, I have also seen several revamped privacy features and a general effort by the tech industry to disclose to its users that they collect data. The option to opt-out of ads or tracking is also a new feature that is being highlighted. One development I am watching is the "right to be forgotten" ruling, which in my opinion is definitely a step in the right direction regarding individual rights on the net.

This is not an effort to scare you from using the Internet; it is simply meant to raise awareness about what is going on behind the scenes. It's one thing if your government is spying on you, it's another if you hand them all the information on a silver platter. Then you are surprised when your details are uncovered by a simple Google search that links to your Facebook profile and displays all your pictures and likes in a matter of seconds. The younger demographic and perhaps many first time users sometimes do not seem to be concerned by the immense volume of information they upload about themselves and this needs to change.

In conclusion, I would like to unequivocally state that the Internet is the most valuable resource we have today. This essay simply seeks to open your eyes as to what is happening behind the scenes and to urge you to be conscious of what you share, "like", or even comment. I hope you keep the core statements of this essay in mind when you surf the Internet in future. Here's to a more educated and vigilant Internet user! 


\section{The World Made Global Thanks to the Internet}

\section{Zinelabidine Ghebouli}

Age 18, Algeria

"The Internet has made the world look like a small village". Whoever said that had the right idea in mind. I still remember when I connected to the Internet for the first time, it was something special. I felt as if l'd opened the gate of a whole new world! Being a part of the online community makes me realize that the world is so much bigger than just my city, country, or even continent. I know so many people, I read amazing essays, I participate in great debates, I exchange my ideas, and I'm grateful for the Internet. Without this useful platform, I wouldn't be able to do all of those amazing things and surely I wouldn't be able to access anything or anyone.

If someone asked me: "How do you describe your story and your life with the Internet?". It wouldn't be easy to answer that, because my life with this online world is like a love story that will never end. Today, we're able to speak freely and say what we want without being afraid. We can work with people from all over the world; we can easily denounce the negative happenings around the world. The Internet affords us with many opportunities. Today, you don't have to be in Paris, New York, or even London to know what's going on in those cities; you can simply surf the web and you'll find out whatever you are looking for. In this day and age, distance is no longer a problem, you can travel to Rome and see the Vatican and you don't even need to stand up from your desk chair. You can go to see the Egyptian pyramids with your laptop, and you can even visit the Niagara falls in Canada. You can do whatever you want, whenever you want, and wherever you want.

Since I live in North Africa, I have realized the Internet's importance in the governmental transition to democracy. Today, most nations believe they can effect a real change. For them, it's no longer a question of their capability or whether they can or they can't, but it's a question of how will they achieve what they want? I witnessed the Arab spring and I was truly impressed by the way the people were thinking. The Internet has became the savior for these people and their nations, and they finally have the chance to participate in the process of building their countries. They finally have the will and the desire to show the world what they can do. Through the Internet, they find ways to express themselves and to encourage, denounce, and voice ideas. It was difficult, but in the end, people realized the importance of the Internet in building countries and defending human rights.

Being a part of a global community is a pleasure for everyone. Personally, I'm glad I could discuss the real issues of my community with people who have a good vision and can give helpful solutions. Every morning, I feel excited to connect. I have my breakfast as I look at my social media profiles. I search the web to learn about the world I live in; sometimes, I find good news and sometimes I find the opposite... The important thing is that I'm capable of being in touch with anyone and I'm able to stay informed about everything that happens. It's a great feeling to know you have friends from all over the world, and it makes you excited to learn more about those friends, their countries, and their cultures. Thanks to the Internet, I can ask them whatever I want and get an answer in seconds even if I live very far from them. This is simply amazing.

I admit that the Internet has really made my life better. I've learned so much information and for that I'm absolutely grateful. I can't imagine how would my life be if there was no Internet. If only I could thank the man who invented the Internet, he surely has my blessings. I'm not ashamed to say the Internet is like a spiritual parent to me. It has been there during my hard times, helping and teaching me. Today, I'm able to effect changes in society. I believe in myself and I have so much to say to the Internet, social networks, forums and digital media. But no matter what I say, I can't thank them enough, so I think l'll say in a very simple way "Dear Internet, thank you!" 
Elsa Brown, Age 17, USA

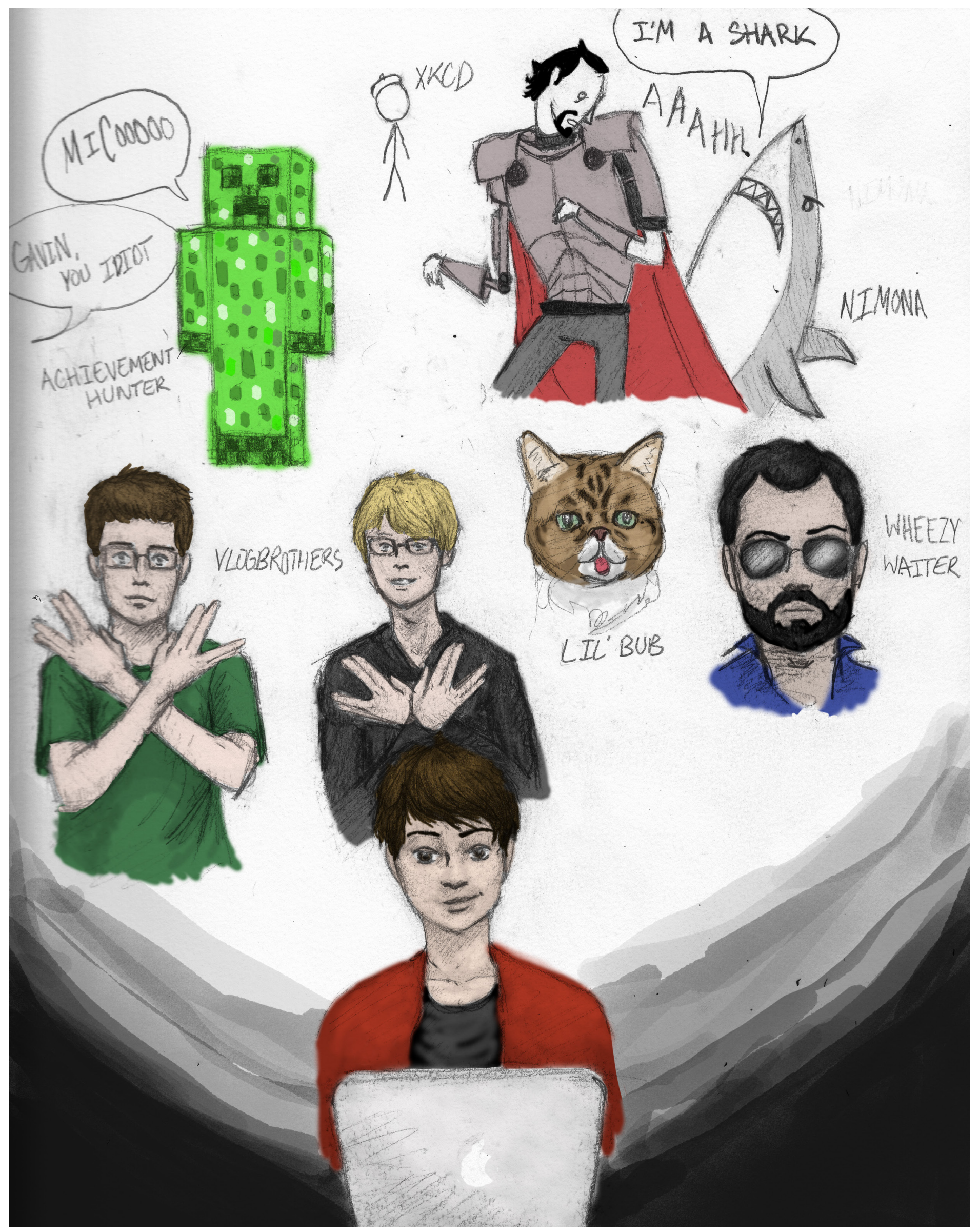


